\title{
Die Reichstürkenhilfe in der Zeit Karls V. ${ }^{1}$
}

Auf den deutschen Reichstagen der Reformationszeit war die Türkenhilfe der wichtigste Beratungsgegenstand neben den Religionsangelegenheiten. Trotzdem gibt es bis heute keine Gesamtdarstellung der Reichstürkenhilfe für die Zeit Karls V. oder gar für die ganze Epoche der Bedrohung des Abendlandes durch die Türken. Die spezifischen Probleme der Reichstürkenhilfe, ihre Finanzierung, Organisation, Funktionsweise und Fortentwicklung, wurden lediglich in zeitlich eng begrenzten Spezialstudien behandelt. Und auch das geschah meist nur beiläufig im Rahmen von Reichstagsmonographien, im Zusammenhang mit der Erörterung anderer Gegenstände der Reichsverfassungsgeschichte oder im Hinblick auf die Wechselwirkung zwischen Türkenkrieg und Fortgang der Reformation in Deutschland 2 . Eine Ausnahme bildet allenfalls die neunbändige materialreiche »Geschichte der Regierung Ferdinand des Ersten « von Franz Bernhard v. Bucholtz aus den Jahren $1831-1838^{3}$, in der die Türkenkriege und die Beschaffenheit der Türkenhilfe in mehreren gesonderten Abschnitten ${ }^{4}$ beschrieben werden. Die Darstellung von Bucholtz bezieht sich jedoch nicht nur auf die Hilfe des Reiches, sondern auch auf die anderen, vornehmlich von den habsburgischen Ländern aufgebrachten Türkenhilfen, soweit sie in den Türkenkriegen Ferdinands Verwendung fanden. Und in einer solchen Zusammenschau konnte die eigentümliche Entwidklung und Problematik der Reichstürkenhilfe nicht genügend berüdssichtigt werden. Denn die Reichstürkenhilfe ist ja nicht nur wegen ihres Beitrages zur Türkenabwehr bedeutsam gewesen, sondern sie verdient darüber hinaus Beachtung, weil sie viele politische und religiöse Entscheidungen beeinflußte und weil sie fast die einzige militärische Leistung des Reiches in der Zeit Karls V. darstellte, was zur Folge

1 Die Untersuchung ist ein Beitrag zur Auswertung des von mir bearbeiteten und 1970/71 in zwei Teilen veröffentlichten Bandes VIII der Deutschen Reichstagsakten/Jüngere Reihe. Sie bezieht sich allerdings nicht nur auf diesen Band, dessen 2. Teil die Akten zur Bereitstellung der Reichstürkenhilfe im Türkenkrieg 1529 enthält, sondern behandelt alle Türkenhilfen des Reiches in der Zeit Karls V. unter Verwertung gedrudkter und ungedrudkter Quellen. Folgende Abkürzungen werden im Anmerkungsteil für die häufiger erwähnten Quellenwerke und für die benutzten Archive verwendet: 1.) Deutsche Reichstagsakten/Jüngere Reihe, Bd I-IV (1893-1905, Neuauflage 1962/63), Bd VII, 1. u. 2. Halbband (1935, Neuauflage 1963), Bd VIII, 1. u. 2. Halbband $(1970 / 71)=$ RTA I, RTA II, RTA III, RTA IV, RTA VII-1, RTA VII-2, RTA VIII-1, RTA VIII-2. 2.) Neue und vollständigere Sammlung der ReichsAbschiede, bearb. v. J. J. Schmauß, Frankfurt a. M. 1747, 2. Teil = NS 2. 3.) Haus-, Hofund Staatsarchiv Wien $=$ HHStA/Wi. 4.) Bayer. Hauptstaatsarchiv, Abt. Geheimes Staatsarchiv, München = GStA/Mü.

- Zu nennen sind hier vor allem W. Friedensburg: Der Reichstag zu Speyer 1526 im Zusammenhang der politischen und kirchlichen Entwidklung Deutschlands im Reformationszeitalter (= Historische Studien, H. V, Berlin 1887) (zit. Friedensburg); J. Kühn: Die Geschichte des Speyerer Reichstags 1529 (= Schriften des Vereins für Reformationsgeschichte, Jg 47, H. 1 (Nr. 146), Leipzig 1929) (zit. Kühn); Ch. Turetschek: Die Türkenpolitik Ferdinands I. von 1529 bis 1532, Dissertationen der Universität Wien 10, Wien 1968 (zit. Turetschek); A. Westermann: Die Türkenhilfe und die politisch-kirchlidhen Parteien auf dem Reichstag zu Regensburg 1532 (= Heidelberger Abhandlungen zur mittleren und neueren Geschichte, H. 25, Heidelberg 1910) (zit. Westermann); A. Neukirch: Der niedersächsische Kreis und die Kreisverfassung bis 1542 (= Quellen und Darstellungen aus der Geschichte des Reformationsjahrhunderts, Bd X, Leipzig 1909) (zit. Neukirch); F. Hartung: Geschichte des fränkischen Kreises, Bd 1, Leipzig 1910; H. Traut: Kurfürst Joachim II. von Brandenburg und der Türkenfeldzug vom Jahre 1542, Gummersbach 1892 (zit. Traut). 
hatte, daß die Entwidklung der Reichsmilitärverfassung mit der Entwicklung der Reichstürkenhilfe weitgehend identisch war.

Die Zusammenhänge zwischen der Türkenabwehr und den großen religionspolitischen Entscheidungen während der Reformationszeit hat Stephen A. Fischer-Galati in seiner 1955 erschienenen Studie „Ottoman Imperialism and German Protestantism $1521-1555 \aleph^{5}$ untersucht. Fischer-Galati wollte in seinem Werk klären, inwieweit die Bedrohung des Abendlandes durch die Türken die Festigung, Ausbreitung und rechtliche Anerkennung der Reformation in Deutschland erleichtert hat. Dabei berüdksichtigte er durchaus, daß auch andere Faktoren diese Entwidklung gefördert haben. Aber er glaubte doch nachweisen zu können, daß der osmanische Imperialismus hierbei am wirksamsten gewesen sei ${ }^{\circ}$. Eine Studie, wie sie FischerGalati vorgelegt hat, kann natürlich ohne Hinweise auf die Größe, Art und Verwendung der versdiedenen Reidstürkenhilfen nicht auskommen; denn die Bewilligung der einzelnen Hilfen war ja der Ansatzpunkt für die religionspolitische Nutzung der Türkengefahr. In Fischer-Galatis Darstellung werden jedoch die Abwehrmaßnahmen der Reichsstände gegen die Türken nur unzulänglich und zum Teil unzutreffend geschildert. Verschiedene Zahlen, mit denen die Größe der Hilfen und das Ausmaß der Hilfswilligkeit der Reichsstände gekennzeichnet werden sollen, sind völlig falsch ${ }^{7}$. Mehrmals kommt Fischer-Galati wegen solcher falschen Zahlen zu abwegigen Folgerungen hinsichtlich des Verhältnisses von Religionspolitik und Türkenabwehr ${ }^{8}$.

Die Mängel in Fischer-Galatis Werk zeigen, wie notwendig eine spezifische Untersuchung der Reichstürkenhilfe während der Reformationszeit ist. Bei einer derartigen Untersuchung darf indessen nicht der gegenteilige Fehler gemacht und der jeweilige Zustand und die Entwidklung der Reichstürkenhilfe ohne Beziehung zur politischen Umwelt behandelt werden. Denn die allgemeinen politischen Verhältnisse wirkten wiederholt stark auf die Bewilligung und Handhabung der Reichstürkenhilfe ein. Vor allem haben drei wichtige politische Ereignisse nacheinander die Leistungsfähigkeit der Reichstürkenhilfe in der Zeit Karls V. beeinträchtigt, nämlich die innere Zerrüttung Ungarns während der Regierungszeit Ludwigs II., der Thronstreit in Ungarn seit der Sdhlacht bei Mohács und die Separation der evangelischen Reichsstände und Reichsstädte seit dem Speyerer Protestationsreichstag 1529. In der Entwidklung der Reichstürkenhilfe während der Regierungszeit Karls V. können im Hinblidk auf das Wirksamwerden dieser Ereignisse drei Epo-

- S. A. Fischer-Galati: Ottoman Imperialism and German Protestantism 1521-1555 (=Harvard Historical Monographs XLIII, Cambridge 1959) (zit. Fischer-Galati).

- Ebd., p. 117.

7 Auf folgende Fehler sei hier hingewiesen: Der dritte Nürnberger Reichstag Anfang 1524 bewilligte nicht eine eilende Hilfe von $\$ 12000$ foot soldiers and 4000 infantrymen* (p. 21), sondern erneuerte nur die Bewilligung des zweiten Nürnberger Reichstages von 4000 bis 6000 Fußknechten. Auf dem Speyerer Reichstag 1526 beschlossen die Reichsstände nicht die Entsendung von $\$ 24000$ men « zur Unterstützung der Ungarn (p. 26), sondern bewilligten lediglich zum 3. Mal die auf dem zweiten Nürnberger Reichstag zugesagte Hilfe der 4000 bis 6000 Fußknechte, die noch immer nicht zum Einsatz gekommen war.

- Fischer-Galati behauptet, die Reichsstände hätten durch ihre überraschend große Hilfswilligkeit im Jahre 1524, die ja in Wirklichkeit gar nicht vorhanden war (vgl. Anm. 7), Kaiser Karl veranlassen wollen, zur Beilegung des Glaubenszwiespaltes ein Generalkonzil zustande zu bringen (pp. 21-24). Die angeblich so große Bewilligung auf dem Speyerer Reichstag 1526, die gleichfalls gar nicht erfolgt ist (vgl. Anm. 7), wertet Fischer-Galati als Gegenleistung der Reichsstände für religionspolitische Konzessionen Ferdinands, und zwar u. a. für sein Versprechen, that a council would be convened within eighteen months « (p. 26). In Wirklichkeit wurde damals nur beschlossen, den Kaiser zu bitten, die Durchführung eines Konzils in dieser Frist zu ermöglichen! 
chen unterschieden werden, die durch Gliederung und Aufbau der nachfolgenden Untersuchung hervorgehoben werden.

Die Begriffe "Türkenhilfe" beziehungsweise "eilende Türkenhilfe" und "beharrliche Türkenhilfe« sind uns heute fremd und bedürfen einer Erläuterung. Das in diesen Begriffen enthaltene Wort "Hilfe« hatte in der Zeit Karls V. nicht nur wie im modernen Sprachgebrauch die Bedeutung "Unterstützung, Beistand ", sondern diente darüber hinaus als Bezeichnung für die zum Zwedke der Hilfeleistung bereitgestellte Kriegsmacht oder für die zur Unterhaltung dieser Kriegsmacht bewilligte Geldsumme. Die "Türkenhilfe" war demzufolge die zur Bekämpfung des Türken, das heißt des türkischen Sultans und seiner Heerscharen, verwendete Kriegsmacht oder Kriegssteuer. Charakteristisch für die »eilende Hilfe oder »eilende Türkenhilfe" war ihre rasche Bereitstellung, charakteristisch für die »beharrliche Hilfe" oder wbeharrliche Türkenhilfe« ihre größere Stärke und längere Dauer. Als lateinische Bezeichnungen dienten "auxilium «, »subsidium " und ssubventio « für "Hilfe«, "subventio celer et festina « für »eilende Hilfe «, "subventio tarda et duratura « für »beharrliche Hilfe«.

Die Reichstürkenhilfe vom Wormser Reichstag 1521 bis zur Schlacht bei Mohács 1526

Auf dem ersten Reichstag während der Regierungszeit Karls V., der vom 27. Januar bis 26. Mai 1521 in Worms stattfand, spielte die Türkenhilfe nur eine ganz unwesentliche Rolle. Eine ungarische Gesandtschaft, die ein Hilfegesuch an den Kaiser und die Reichsstände richtete, wurde hinhaltend beschieden. Zunächst erwiderte man ihr, daß Karl nach Beendigung der Reichsreform mit dem Papst und anderen christlichen Herrschern wegen des Türkenkriegs in Verbindung treten wolle. Als sich die Gesandtschaft mit dieser Antwort nicht zufriedengab, erklärte man ihr, der Kaiser hoffe, 1522 mit dem Reich und anderen christlichen Herrschern einen Feldzug zur Niederwerfung der Türken führen zu können, sei dies aber aus irgendwelchen Gründen nicht möglich, so wolle er bei einer Invasion Ungarns durch die Türken mit seinen eigenen Truppen und mit denen des Reiches Hilfe leisten. Für den Fall, daß sich die Ungarn nicht zutrauten, bis 1522 ihre Grenzen allein zu verteidigen, wurde ihnen der Abschluß eines einjährigen Waffenstillstandes mit den Türken empfohlen, sofern er ohne Schaden für den katholischen Glauben und die Christenheit möglich sei ${ }^{9}$.

Als die ungarischen Gesandten in Worms verhandelten, waren die Türken bereits im Anmarsch. 40 Jahre lang hatten sie nach Westen keine größeren Vorstöße unternommen. Jetzt, im Jahre 1521, begann unter dem wenige Monate vorher zur Herrschaft gelangten Sultan Suleiman II. eine neue Expansion gegen das Abendland. Ende Juni 1521 übersahen die Ungarn die heraufziehende schwere Gefahr. Ludwig II., der erst 15jährige König von Ungarn und Böhmen, richtete Hilfegesuche an den Papst, den Kaiser und die anderen christlichen Herrscher Europas ${ }^{10}$. Am 29. August 1521 fiel die Festung Griechisch-Weißenburg, das heutige Belgrad, in die Hände der Türken. Griechisch-Weißenburg galt neben Rhodos als unbezwingbares Bollwerk der Christenheit gegen den türkischen Glaubensfeind. An beiden Festungen hatte sich der Ansturm der Türken immer wieder gebrochen. Nach dem Verlust Griechisch-Weißenburgs mußte mit weiteren gofährlichen Kriegszügen des Sultans gegen Ungarn gerechnet werden.

- RTA II, S. 759.

10 I. A. Fessler: Geschichte von Ungarn, Bd 3, Leiptig, 2. Aufl. 1874, S. 328 f. (zit. Fessler). 
Sogleich im Sommer 1521 forderte Kaiser Karl die deutschen Fürsten und Städte unter dem Eindruck der bedrohlichen Nachrichten aus Ungarn zur Hilfeleistung mit Truppen oder Geld auf, hatte damit aber wenig Erfolg ${ }^{11}$. Karl befand sich damals bereits wieder in den Niederlanden. Er blieb dort bis Mitte 1522, reiste dann über England nach Spanien und kehrte erst 1530 über Italien nach Deutschland zurück. Neun Jahre lang konnte er infolgedessen nur aus der Ferne die Türkenhilfe der Reichsstände fördern. Oberste Instanzen im Reich während seiner Abwesenheit waren das 1521 eingesetzte Reichsregiment und Karls jüngerer Bruder Erzherzog Ferdinand als kaiserlicher Statthalter. Seit Dezember 1521 bemühte sich das Reichsregiment, eine Reichstürkenhilfe zustande zu bringen, die bei der Abwehr neuer türkischer Vorstöße, die zum Frühjahr 1522 erwartet wurden, Verwendung finden sollte. Um sie rasch bereitstellen zu können, machte das Reichsregiment dem Kaiser einen Vorschlag, durch dessen Annahme unbeabsichtigterweise die Frage der Türkenhilfe nicht nur für 1522, sondern bis zur Belagerung Wiens 1529 entschieden wurde. Das Reichsregiment trat nämlich dafür ein, die dem Kaiser auf dem Wormser Reichstag 1521 bewilligte Romzugshilfe als Türkenhilfe zu verwenden ${ }^{12}$. Karl erklärte sein Einverständnis ${ }^{19}$. Es schien, als würden hierdurch die Verhandlungen über die Türkenhilfe mit den Reichsständen erheblich erleichtert, denn es mußte von ihnen nun nicht mehr eine neue und zusätzliche Hilfe verlangt, sondern lediglich die andere Verwendung der bereits bewilligten Hilfe geregelt werden. Der tatsächliche Verlauf der Dinge entsprach freilich keineswegs diesen Erwartungen. Die Romzugshilfe wurde nämlich von den Reichsständen erst nach langwierigen Verhandlungen und nur in kleinen $\mathrm{Ra}$ ten für die Türkenhilfe neu bewilligt. Und von der bewilligten Türkenhilfe kam zunächst bloß ein kleiner Teil zum Einsatz. Der Hauptteil wurde erst im Türkenkrieg 1529 verbraucht. Die Reichsstände zehrten also bei der Türkenabwehr neun Jahre lang von der Romzugshilfe. Für die auffallend geringe Hilfeleistung der Reichsstände sind in der Epoche bis zur Schlacht bei Mohács am 29. August 1526 zwei Gründe bestimmend gewesen. Es erwies sich als sehr schwierig, die für den Romzug bewilligte und auf die Eigenart dieses Unternehmens abgestellte Hilfe im Türkenkrieg zu verwenden. Und es gelang nicht, mit den Ungarn, denen die Türkenhilfe gewährt werden sollte, die Bedingungen der Kooperation zu verabreden.

Die Romzugshilfe, auf der die Türkenhilfen des Reiches von 1522 bis 1529 beruhten, war eine notwendige Folge der Wahlkapitulation Karls V. vom 3. Juli 1519. Der Kaiser hatte sich in dieser Urkunde gegenüber den Kurfürsten verpflichtet, danach zu trachten, die kaiserliche Krone in Rom zu empfangen und die dem Reich entzogenen Fürstentümer und Herrschaften zurückzugewinnen ${ }^{14}$. Nach Karls Auffassung war es Aufgabe der Reichsstände, ihn bei der Erfüllung dieser Aufgaben zu unterstützen. Und so beantragte er auf dem Reichstag in Worms 1521 für den Romzug und für die Rekuperation der entzogenen Gebiete eine Hilfe der Reichsstände von mindestens 20000 Fußknechten und 4000 Reisigen für die Dauer eines Jahres. Er selbst erbot sich, zu dem Unternehmen 2000 Kürassiere, mehrere hundert geringere Pferde, 10000 Schweizer und 6000 Spanier auf eigene Kosten beizusteuern ${ }^{15}$. Wichtigstes Ziel der Rekuperationsbestrebungen war das

11 RTA III, S. 24-26.

12 RTA III, 27 f. Daß der Vorshlag, die Romzugshilfe als Türkenhilfe zu verwenden, vom Regiment gemacht wurde, ergibt sich aus RTA III, S. 51/Z. 8-24.

1s RTA III, S. 51/Z. 25 - S. 52/Z. 2 u. S. 60/Z. 11-19. Vgl. auch ebd., S. 29 f.

14 RTA I, S. 876 u. 869.

1s RTA II, S. 155, 390-393. 
Herzogtum Mailand ${ }^{16}$, das König Franz I. von Frankreich 1515 erobert hatte. Die Romzugshilfe sollte also in dem 1521 beginnenden langjährigen Krieg Karls mit Frankreich Verwendung finden und beim Angriff auf die heißumstrittene französische Schlüsselposition in Norditalien, nämlich auf Mailand, mitwirken. $\mathrm{Da}$ jedoch bereits im November 1521 ein kaiserlich-päpstliches Heer Mailand eroberte und Francesco II. Sforza das Herzogtum von Kaiser Karl V. als Reichslehen erhielt, entfiel die wohl wichtigste Aufgabe der Romzugshilfe. Wahrscheinlich ist es kein Zufall gewesen, daß bald nach dem Besitzwechsel Mailands die Korrespondenz zwischen dem Reichsregiment und dem Kaiser über die neue Verwendung der Romzugshilfe gegen die Türken in Gang kam. Offenbar bestand der Eindruck, daß die Romzugshilfe infolge der veränderten Lage in Italien für andere $\mathrm{Zwecke}$ verfügbar geworden sei.

Auf dem Wormser Reichstag 1521 hatten die Reichsstände die vom Kaiser beantragte Romzugshilfe nur mit Einschränkungen und unter bestimmten Vorbehalten bewilligt, die zumeist auch für die künftige Türkenhilfe Geltung behielten. Die Romzugshilfe sollte nur geleistet werden, wenn Friede und Recht im Reich bestanden. Sie wurde nicht, wie es der Kaiser gewünscht hatte, für ein volles Jahr bewilligt, sondern nur für die Dauer von sechs Monaten. Die Hilfe sollte mit Kriegsvolk und nicht mit Geld geleistet werden. Den Reichsständen wurde vorgeschrieben, die Truppen bis zum 1. August 1522 nach Trient zu schicken. Die bewilligten sechs Monate sollten zu diesem Termin angehen und der Wiederabzug der Truppen aus Italien bis Trient innerhalb jener sechs Monate erfolgen. Dem Kaiser blieb vorbehalten, den Zeitpunkt des Beginns der Hilfe zu ändern. Die Bewilligung der Reichsstände bezog sich lediglich auf den sechsmonatigen Unterhalt der 4000 Reisigen und 20000 Fußknechte ${ }^{17}$. Weder in den Verhandlungsakten noch im Abschied des Wormser Reichstages wurde vermerkt, wer das Führungspersonal, das Geschütz und das sonstige Kriegsmaterial aufbringen und unterhalten sollte, das den Einzelkontingenten der Reichsstände beigegeben werden mußte, um aus ihnen ein operationsfähiges Feldheer zu machen. Wahrscheinlich erschien eine ausdrückliche Vereinbarung hierüber überflüssig, da ohne weiteres vorausgesetzt werden konnte, daß der Kaiser als Empfänger der Hilfe das deutsche Kriegsvolk mit allem ausstatten würde, was es für den Einsatz im Felde benötigte. Bei den späteren Verhandlungen mit den Ungarn machten die Verordneten der Reichsstände folgerichtig geltend, die Romzugshilfe sei dem Kaiser unter der Voraussetzung bewilligt worden, daß er sie mit Übersolden (für besondere Funktionen), Hauptleuten und Artillerie versehe ${ }^{18}$. Ein anderer wichtiger Aspekt für die Leistung der Romzugshilfe, über den ebenfalls keine schriftliche Abmachung bestand, ergab sich aus dem Umstand, daß der Kaiser zu Beginn der Verhandlungen auf dem Wormser Reichstag den Reichsständen die Bereitstellung einer eigenen Truppenmacht zur Kooperation mit der Romzugshilfe zugesagt hatte $^{19}$. Es konnte auf Grund dieser kaiserlichen Zusage stets davon ausgegangen werden, daß die Hilfe der Reichsstände nicht als selbständiges Kriegsheer, sondern in Verbindung mit einer vom Empfänger der Hilfe zu stellenden Streitmacht zum Einsatz kommen würde. Gemäß dem Wormser Abschied sollten die Reichstruppen

10 RTA II, S. 393/Z. 29. Zum Kampf um Mailand 1515 u. 1521 vgl. E. Fueter: Geschichte des europäischen Staatensystems von 1492-1559, München, Berlin 1919, S. 280 u. 286.

17 RTA II, S. 394-403 (Verhandlungen über Romzugshilfe). Ebd., S. 737-740 (Bestimmungen des Reichsabschieds sowie des geheimen Beibriefs v. 26. 5. 1521 über die Romzugshilfe).

10 RTA III, S. 100/Z. 7-12, S. 308/Z. 22-23, S. 351/Z. 20-22, S. 348/Z. 18-19. Vgl. auch RTA II, S. 398/Z. 14-16, S. 399/Z. 38 - S. 400/Z. 5, S. 739/Z. 1-4.

10 Vgl. S. 10. 
auf den Kaiser oder auf den kaiserlichen Feldhauptmann vereidigt werden ${ }^{20}$. Auch hieraus ergab sich, daß ihre selbständige Verwendung unter eigener Oberleitung nicht vorgesehen war.

Kaiser und Reichsstände verpflichteten sich im Reichsabschied $1521 \mathrm{zu}$ einer gleichmäßigen Besoldung der Truppen. Ein Reisiger sollte monatlich 10 Gulden und ein Fußknecht monatlich 4 Gulden erhalten ${ }^{21}$. In Worms wurde eine Matrikel aufgestellt, in der die Anzahl der Reisigen und Fußknechte verzeichnet war, welche die einzelnen Reichsstände und Reichsstädte zum Romzug aufbringen mußten ${ }^{22}$. Derartige Matrikeln waren seit 1422 wiederholt für die Truppengestellungen zu den Reichskriegen vereinbart worden ${ }^{29}$. Die Wormser Matrikel von 1521 erlangte jedoch besondere Bedeutung, denn sie blieb über den aktuellen Anlaß ihrer Entstehung hinaus die Grundlage für die Kontingentierung der Reichstruppen bis zum Ende des alten Reiches ${ }^{24}$. Trotz dieser langdauernden Wirkung hatte die Wormser Matrikel in ihrer ursprünglichen Fassung von 1521 erhebliche Mängel. Sie führte Stände auf, die gar nicht existierten oder nicht reichsunmittelbar waren und infolgedessen auch zu den Reichshilfen nichts direkt beitrugen. Außerdem gab es "ungewisse" und "ungehorsame " Stände. Nach einer Berechnung von 1530 belief sich der voraussichtliche Fehlbetrag bei eilenden Reichshilfen etwa auf ein Sechstel der Reiter und Fußknechte ${ }^{25}$. Hinzu kam, daß sich viele Stände und Städte durch den Wormser Anschlag überfordert fühlten und nach und nach mannigfaltige Moderationen durchsetzten. Die Leistungen auf der Grundlage der Wormser Matrikel verringerten sich daher im Laufe der Zeit beträchtlich ${ }^{26}$. 1521 war diese Entwidklung noch nicht zu übersehen. Immerhin bestimmte aber der Wormser Reichsabschied vorsorglich, daß der Kaiser von den Ungehorsamen die Hilfe einbringen solle und daß der Anteil der Ungehorsamen an der Hilfe nicht auf die Gehorsamen geschlagen werden dürfe ${ }^{27}$.

Eine unsachgemäße Verwendung der Romzugshilfe brauchten die Reichsstände nicht zu befürchten, wenn der Kaiser der Empfänger der Hilfe war. Ganz anders lagen aber die Verhältnisse, wenn die Hilfe dem König von Ungarn geleistet werden sollte. Denn Ludwig II. besaß wenig Autorität in seinen Königreichen, und Ungarn war politisch zerrüttet durch den langjährigen Konflikt zwischen der eigennützigen Hofpartei der Prälaten und Magnaten unter Führung des Palatins Stephan Báthory und der Nationalpartei des Kleinadels unter Führung des Woiwoden von Siebenbürgen Johann Zápolya. Es mußte daher vor jeder Hilfeleistung Vorsorge getroffen werden, daß die deutschen Truppen durch diese Verhältnisse nicht in Mitleidenschaft gezogen wurden. Selbst wenn jedoch das ungarische Staatswesen in einer besseren Verfassung gewesen wäre, hätten die Reichsstände die Romzugshilfe nicht ohne weiteres König Ludwig zur Verfügung stellen können. Sie mußten vielmehr unter allen Umständen eine Vereinbarung über die Komplettierung dieser Hilfe und über die beiderseitige Kooperation treffen. Die

20 RTA II, S. 739/Z. 10-14.

21 RTA II, S. 739/Z. 5-9.

22 RTA II, Nr. 56, S. 424-443.

23 J. Sieber: Zur Geschichte des Reichsmatrikelwesens im ausgehenden Mittelalter (1422-1521) (= Leipziger Historische Abhandlungen, H. XXIV, Leipzig 1910).

$24 \mathrm{H}$. Weigel: Die Kriegsverfassung des alten Deutschen Reiches von der Wormser Matrikel bis zur Auflösung, Jur. Diss., Erlangen 1912, S. 10.

25 Staatsarchiv Weimar, Reg. E, Fol. 37a, Nr. 88b, fol. 51-53 (Kopie aus der Sammlung Herbert Grundmanns für die Reichstagsaktenedition).

20 Vgl. J. Müller: Das Steuer- und Finanzwesen des h. r. Reiches im XVI. Jahrhundert. (= Neue Jahrbücher für das Klassische Altertum, Geschichte und deutsche Literatur, 5. Jg. 1902), S. 659 f. (zit. Müller). 
Erwartung des Reichsregiments, daß die Aufbringung einer Türkenhilfe leichter sein würde, wenn es lediglich galt, die Romzugshilfe für den Einsatz im Türkenkrieg freizugeben, erwies sich daher als unzutreffend. Auf dem Reichstag in Nürnberg, der vom 27. März bis 30. April 1522 abgehalten wurde, gaben die versammelten Kurfürsten, Fürsten und Stände zwar ihre Zustimmung, daß die Romzugshilfe ganz oder zum Teil als eilende Hilfe zum Widerstand gegen die Türken verwendet werden sollte. Aber sie verlangten zugleich, daß die Hilfe in aller maß «, wie sie dem Kaiser 1521 zugesagt worden sei, geleistet würde ${ }^{28}$. Und diese Einschränkung, die im Grunde völlig berechtigt war, erschwerte und verzögerte dann jahrelang den Vollzug der Hilfe. Auf allen Reichstagen bis zum Sommer 1526 fanden langwierige Beratungen über die eilende Türkenhilfe statt, bei denen es weniger um einen Ausgleich unterschiedlicher Auffassungen der Reichsstände, sondern vornehmlich um die Herstellung einer Úbereinkunft mit den Ungarn über die Modalitäten der Hilfeleistung ging.

An dem Zustandekommen einer solchen Übereinkunft war besonders Erzherzog Ferdinand stark interessiert. Kaiser Karl hatte ihm in den Wormser und Brüsseler Teilungsverträgen vom April 1521 und vom Januar/Februar 1522 alle habsburgischen Länder in Deutschland östlich des Rheins zu erblichem Besitz und im Elsaß auf Lebenszeit überlassen ${ }^{29}$. Die Teilungsverträge wurden zwar nur, soweit sie sich auf die fünf niederösterreichischen Herzogtümer (Osterreich ob der Enns und unter der Enns, Steiermark, Kärnten und Krain) bezogen, sogleich veröffentlicht. Aber gerade mit diesen Ländern war Ferdinand auch die Hauptverantwortung für die habsburgische Südostpolitik zugefallen. Hinzu kam, daß Ferdinand 1521 König Ludwigs Schwester Anna heiratete und daß Anfang 1522 Karls und Ferdinands Schwester Maria mit dem Ungarnkönig vermählt wurde. Beide Eheverbindungen existierten formell bereits seit der Zeit Maximilians I. Sie waren in dem Wiener Vertrag von 1515 auf Grund früherer Heiratsabreden vereinbart und anschließend durch die Trauung der noch im Kindesalter stehenden Prinzen und Prinzessinnen rechtskräftig gemacht worden. Der gleiche Wiener Vertrag bestätigte die 1463 und 1491 erworbenen Ansprüche der Habsburger auf die Länder der Wenzels- und Stephanskrone für den Fall des Aussterbens der böhmischungarischen Linie der jagiellonischen Dynastie ${ }^{30}$. In Anbetracht der Erbfolgevereinbarung und der Familienverbindung mit den Jagiellonen waren Ferdinand und Karl darauf bedacht, die inneren Verhältnisse Ungarns zu stabilisieren und das Land gegen die Türken zu sichern. Ihre Gesandten in Ungarn betätigten sich neben dem päpstlichen Nuntius als Berater und Mentoren des jungen Königs und seiner Gemahlin ${ }^{31}$. Es kam besonders Ferdinand als Inhaber der östlichen Besitzungen des habsburgischen Hauses zu, die Beziehungen zu Ungarn und Böhmen zu entwidkeln und in der Frage der Türkenabwehr zwischen den Reichsständen und Ludwig II. zu vermitteln.

28 RTA III, S. 171/Z. 33 - S. 172/Z. 10. Vgl. zu der Formulierung win aller maß« ebd., S. 162/Z. 27-30 u. S. 165/Z. 29 - S. 166/Z. 5.

20 Text der Verträge W. Bauer: Die Anfänge Ferdinands I., Wien, Leipzig 1907, S. $241-253$. Erläuterungen hierzu ebd., S. 100-161.

so Fessler, S. 325 u. 333 . K. u. M. Uhlirz: Handbuch der Geschichte Osterreichs und seiner Nachbarländer Böhmen und Ungarn, Bd. 1, Graz, Wien, Leipzig 1927, S. 165, 169 u. 178 (zit. Uhlirz).

s1 Vgl. K. Stoegmann: Uber die Briefe des Andrea da Burgo, Gesandten König Ferdinands, an den Cardinal und Bischof von Trient Bernhard Cles, Sitzungsberichte der Kaiserlichen Akademie der Wissenschaften, Phil.-hist. Classe, Bd 24, Wien 1857, S. 159-239 (zit. Stoegmann). Hier werden S. 165 ff. Burgos Gesandtschaften nach Ungarn 1521-1524 und die damaligen Zustände in Ungarn charakterisiert. 
Wenn die deutschen Reichsstände mit den Ungarn verbindliche Abmachungen über die Türkenhilfe abschließen wollten, mußten sie bevollmächtigte ungarische Vertreter zu den Reichsversammlungen hinzuziehen. Bereits vor dem Reichstag vom Frühjahr 1522, als noch gar nicht zu übersehen war, welche Komplikationen die Umwandlung der Romzugshilfe in eine Türkenhilfe mit sich bringen würde, bat das Reichsregiment vorsorglich den Kaiser, er möge den Köng von Ungarn auffordern, Gesandte mit Vollmacht zur Beschlußfassung nach Nürnberg abzuordnen ${ }^{32}$. Die beiden ungarischen Gesandten, die auf dem Reichstag erschienen, genügten den Reichsständen jedoch nicht, weil sie nur von dem König und nicht von den ungarischen Ständen abgeordnet waren ${ }^{33}$. Außerdem konnten sie keine befriedigende Auskunft über die militärischen Machtmittel ihres Königs und speziell über die verfügbare ungarische Artillerie geben ${ }^{34}$. Die Reichsversammlung traf daher auch keine Entscheidung über den Vollzug der bewilligten Türkenhilfe, sondern forderte König Ludwig II. sowie die Stände Ungarns und Böhmens auf, kriegsverständige Verordnete mit genügender Vollmacht zu einem Tag nach Wien zu entsenden, um dort mit bevollmächtigten Vertretern der Reichsstände über die Größe und das Zusammenwirken der beiderseitigen Truppenkontingente und über die Unterhaltung des Geschützes endgültig zu beschließen ${ }^{35}$. Die Beteiligung ungarischer Ständevertreter erschien notwendig, weil man dem Wort eines Königs nicht vertrauen konnte, der nur geringe Autorität in seinem Lande besaß. Mit den Ständen der böhmischen Krone wollte man verhandeln, weil man das ungarische Militärwesen gering schätzte ${ }^{36}$ und daher die Entsendung eines böhmischen Truppenkontingents zur Kooperation mit der deutschen Hilfe wünschte. Das Königreich Böhmen war zwar auch in der Wormser Matrikel als gestellungspflichtig verzeichnet, gehörte aber zu den »ungehorsamen « Ständen.

Die beiden ungarischen Gesandten, die den Nürnberger Reichstag im Frühjahr 1522 besuchten, wurden dort nicht informiert, daß die Reichsstände die Romzugshilfe dem Kaiser 1521 unter bestimmten Bedingungen bewilligt hatten und die Erfüllung dieser Bedingungen nunmehr von den Ungarn und Böhmen verlangen wollten ${ }^{37}$. Auch auf dem Wiener Tag, der von König Ludwig auf den 20. Mai 1522 ausgeschrieben wurde ${ }^{98}$, kam diese Angelegenheit nicht zur Sprache. Denn es erschienen dort zwar bevollmächtigte Gesandte des Königs von Ungarn, aber keine Vertreter der ungarischen und böhmischen Stände. Die Verordneten des Reiches ließen sich infolgedessen nur auf unverbindliche Beratungen über allgemeine Fragen der Türkenabwehr ein. Nach längerer Wartezeit trafen schließlich Anfang Juli 1522 drei ungarische Bischöfe und mehrere andere ungarische Geistliche und Edelleute ein. $\mathrm{Da}$ aber auch sie keine Vollmachten der ungarischen Stände besaßen, verweigerten die Verordneten des Reiches den Ungarn jede Hilfe "s?.

Trotz des Scheiterns der deutsch-ungarischen Verhandlungen kam es im Jahre 1522 doch noch zum Vollzug einer kleinen Türkenhilfe. Nachdem nämlich die

- RTA III, S. 48/Z. 29 - S. 49/Z. 3. Das Reidısregiment bat König Ludwig auch noch direkt, kriegsverständige Räte zum 9. 3. 1522 nach Nürnberg zu entsenden. Vgl. dazu: Dès kursächsischen Rathes Hans von der Planitz Berichte aus dem Reichsregiment in Nürnberg, gesammelt von $E$. Wüldker, nebst ergänzenden Aktenstüdken bearb. von H. Virck, Leipzig 1899, S. 86 u. 114 ; RTA III, S. 30, Anm. 5.

as Vgl. hierzu RTA III, S. 200/Z. 9-12.

a4 Vil. RTA III, S. 80/Z. 22-33 u. S. 81/Z. 12-14.

"RTA III, Nr. 16/I-II, S. 88-92.

* Vgl. RTA III, S. 102/Z. 27 f.

97 Die Ungarn erfuhren hiervon erst am 18. 12. 1522. S. 18.

so RTA III, Nr. 19, S. 116 f.

so RTA III, Nr. 36, S. 197-210. 
beiden ungarischen Gesandten auf dem Nürnberger Reichstag jenen Bescheid erhalten hatten, der die Beschlußfassung über die deutsche Hilfe auf den Wiener Tag verschob, erreichten sie durch "vlissig anhalten «, daß die Reichsstände als Vorgriff auf die Leistung der gesamten Romzugshilfe wenigstens die sofortige Entsendung von 3000 Knechten nach Wien zugestanden. Über die Verwendung dieser Knechte sollte freilich erst auf dem Wiener Tag entschieden werden. Ihren Einsatz in Ungarn wollten die Reichsstände davon abhängig machen, daß König Ludwig ihnen eine gleidhe Anzahl böhmischer Knechte und das erforderliche Geschütz zuordnete ${ }^{40}$. Wegen des Ausbleibens der ungarischen und böhmischen Ständevertreter auf dem Wiener Tag wurde dieser Plan hinfällig. Statt dessen verabredeten die Verordneten des Reiches mit Erzherzog Ferdinand und seinen Räten die Verwendung der 3000 Knechte in einem Nebenland der ungarischen Krone, nämlich in Kroatien. Eine Hilfe erschien dort dringend notwendig, weil die Türken mehrere kroatische Orte erobert hatten, andere belagerten und von Kroatien nach Krain und Osterreich vordringen wollten. Uber den Einsatz der 3000 Knechte in Kroatien schlossen die Verordneten des Reiches mit den Räten Ferdinands am 16. Juni 1522 eine Vereinbarung ab, die in vollem Einklang mit den Vorschriften der Nürnberger Reichsversammlung stand. Die Osterreicher als Empfänger der Hilfe verpflichteten sich, die Reichstruppen mit Geschütz und Munition zu versehen, ihnen eine Streitmadht von etwa gleicher Stärke beizugeben und den Oberbefehlshaber für das vereinigte Heer zu stellen ${ }^{41}$.

Die Entsendung der 3000 Knechte nach Kroatien zeigt beispielhaft, unter welchen Modalitäten sich der Einsatz der gesamten Romzugshilfe in Ungarn eigentlich hätte vollziehen sollen. Davon abgesehen, ist der Vorgang wegen der eigentümlichen Aufbringung der 3000 Knechte bemerkenswert. Die Reichsversammlung in Nürnberg konnte nämlich die zugesagte sofortige Bereitstellung der 3000 Knechte nur bewerkstelligen, indem sie die Reichsstände nicht zur Gestellung ihres Anteils an Leuten aufforderte, sondern statt dessen die Zahlung der für diese Leute erforderlichen Soldkosten verlangte. Abweichend von den Bestimmungen des Wormser Reichsabschiedes wurde also ein Teil der Romzugshilfe in Geld umgewandelt erlegt. Das Verfahren fand seither häufig Anwendung. Es bildeten sich infolgedessen zwei Formen der Hilfeleistung auf der Basis der Wormser Matrikel heraus, nämlich die Truppengestellung und die Geldzahlung. Für die Besoldung der 3000 Knechte verlangte die Nürnberger Reichsversammlung das Geld für den Unterhalt von 1 $1 / 2$ Vierteln des Fußvolks der Romzugshilfe für die Dauer von drei Monaten. Diese Anforderung war ziemlich hoch. Sie bedeutete, daß man für den Einsatz von 3000 Knechten das Geld für 7500 Knechte erlegen ließ. Für den dreimonatigen Unterhalt der 3000 Knechte hielt man 40000 Gulden für erforderlich. Der Anschlag der 11/2 Viertel auf drei Monate hätte dagegen etwa 90000 Gulden erbringen müssen. Die überhöhte Forderung erschien notwendig, um die Einbußen durch säumige und ungewisse Stände auszugleichen und das Kriegsvolk mit Führungspersonal auszustatten. Die Gelder sollten innerhalb eines Monats an die Städte Frankfurt, Nürnberg oder Augsburg, die bereits früher als einnehmende oder Legestädte gedient hatten, abgeliefert werden ${ }^{42}$.

Neben der Absendung der 3000 Knechte nach Wien hat die Nürnberger Reichsversammlung vom Frühjahr 1522 auch Vorsorge für die rasche Aufbringung der restlichen Romzugshilfe getroffen. Im Reichsabschied wurden die deutschen Stände 
und Städte aufgefordert, ihre Kontingente entsprechend der Wormser Matrikel, jedoch abzüglich der für die 3000 Knechte aufgebrachten Leistungen, so weit bereit zu machen, daß sie noch im Sommer 1522 zur Verwendung kommen konnten. Zur Beschleunigung der Aufbringung wurde in Aussicht genommen, von den entfernter gelegenen Reichsständen keine Truppengestellungen, sondern Geldzahlungen zu verlangen ${ }^{43}$. Bei den Wiener Verhandlungen wollten die Reichsstände den Vollzug der großen Hilfe keineswegs durch ihre Bedingungen unnötig erschweren. Da sie nicht erwarteten, daß die Ungarn ausreichendes Geschütz zur Ausstattung des deutschen Heeres besaßen, wollten sie es ihnen darleihen. Und zwar dachten sie daran, die Geschütze, Kugeln und Büchsenmeister aus Österreich, aus dem Erzbistum Salzburg und von den Städten Straßburg, Augsburg, Nürnberg und Ulm zu beziehen und, soweit erforderlich, auf der Donau heranzuführen. Die Unterhaltung der Artillerie sollte jedoch den Ungarn obliegen. Außerdem sollten die Verordneten des Reiches in Wien verlangen, daß die Böhmen ein ebenso großes Heer wie die Deutschen ins Feld stellten und daß die Ungarn ihre ganze Kriegsmacht aufboten ${ }^{44}$.

Obgleich die Reichsstände grundsätzlich bereit waren, den Ungarn die restliche Romzugshilfe noch im Jahre 1522 zu gewähren, sofern eine Ubereinkunft über die deutschen Bedingungen erzielt wurde, setzte sich schon während der Nürnberger Beratungen im April 1522 die Auffassung durch, daß der Truppeneinsatz zu spät erfolgen würde und durch die kalte Jahreszeit behindert werden könnte ${ }^{45}$. Außerdem war man sich bewußt, daß mit der Romzugshilfe keine weitreichenden Erfolge errungen werden konnten. Nach Ansicht der ungarischen Vertreter auf dem Nürnberger Reichstag sollten die deutschen Hilfstruppen lediglich die befestigten Plätze in den Grenzgebieten Ungarns, Slawoniens, Bosniens und Kroatiens besetzen und sichern, um deren Wegnahme durch die Türken zu verhindern ${ }^{46}$. Die eilende Reichshilfe hätte hiernach allenfalls zur zeitweiligen Verteidigung der Grenzgebiete beitragen können. Die Rüdkeroberung der 1521 verlorengegangenen Schlösser und Städte Ungarns und die endgültige Eindämmung der türkischen Gefahr schien dagegen nur mit einer größeren und beständigeren Hilfe möglich zu sein, zu deren Aufbringung und Unterhaltung nicht nur die Reichsstände, sondern auch alle Untertanen des Reiches durch allgemeine Steuern herangezogen werden mußten. Um über eine solche beharrliche Hilfe zu beraten und zu beschließen, wurde am 30. April 1522 ein neuer Reichstag auf den 1 . September 1522 nach Nürnberg einberufen ${ }^{47}$. Außerdem baten die Reichsstände den Kaiser in einem Schreiben vom 13. April 1522, den Krieg mit Franz I. zu beenden, damit alle christlichen Herrscher zur "werenden hilf gegen die Türken beitragen könnten und diese schwere Last nicht allein von der deutschen Nation getragen werden müßte ${ }^{48}$.

Bis zum Beginn des neuen Nürnberger Reichstages änderte sich die Lage im Türkenkrieg erheblich. Suleiman II. unternahm 1522 keinen neuen Kriegszug gegen Ungarn, sondern führte mit der türkischen Flotte ein großes Heer nach Rhodos. Am 1. August 1522 begann unter seiner Leitung der Belagerungsangriff gegen die Johanniterfestung, am 21. Dezember 1522 kapitulierten die Ordensritter vor den

4 RTA III, S. 174/Z. 15 - S. 175/Z. 6, S. 105/Z. 26 - S. 106/Z. 5.

4 RTA IIL, S. $100 / Z .7$ - S. $101 / Z$. 18, Anm. c zu S. 97, S. 85/Z. 1-23, S. 88/Z. 24-26, S. $105 / Z$. $12-17$, S. $167 / Z$. 24-32.

45 RTA III, S. 98/Z. 1-23.

40 RTA III, S. 80/Z. 3-16.

47 RTA III, Nr. 34, S. 185-188. S. auch S. 191.

48 RTA III, S. 94. 
Türken ${ }^{49}$. Als der Nürnberger Reichstag verspätet am 17. November 1522 eröffnet wurde, war noch nicht abzusehen, wie das Ringen um Rhodos ausgehen würde. Die Ungarn wollten im kommenden Jahr zum Angriff übergehen und Belgrad belagern. Sie erwarteten, daß die Türken daraufhin von Rhodos ablassen würden, um den Belagerten in Belgrad zu helfen. Kam es zu einem türkischen Entsatzversuch, wollten die Ungarn einer Schlacht nicht ausweichen ${ }^{50}$. Das ungarische Vorhaben erforderte eigentlich beträchtliche militärische Mittel. Es hätte naheliegen müssen, hierfür die projektierte beharrliche Hilfe abzuwarten und in Anspruch zu nehmen. Aber die Ungarn erbaten in Nürnberg von den Reichsständen lediglich die Leistung der restlichen Romzugshilfe ${ }^{51}$. Und die Anträge des Kaisers, Erzherzog Ferdinands und des Reichsregiments waren ebenfalls in erster Linie darauf abgestellt, den Vollzug dieser Hilfe zu erreichen ${ }^{52}$. Die Frage der beharrlichen Hilfe wollte man offenbar nicht zum Hauptverhandlungsgegenstand werden lassen, weil die bei einer solchen Hilfe für notwendig gehaltene Mitwirkung der ganzen Christenheit vor einer Beendigung des Krieges zwischen Karl V. und Franz I. nicht möglich war ${ }^{53}$.

Die Reichsstände haben auf dem neuen Nürnberger Reichstag, der bis zum 9. Februar 1523 dauerte, im Einklang mit den an sie gerichteten Anträgen vornehmlich den Vollzug der restlichen Romzugshilfe erörtert. Die Aussichten für die Leistung dieser Hilfe hatten sich allerdings seit dem Frühjahr 1522 beträchtlich verschlechtert. Die wichtigste Voraussetzung hierfür, daß im Reich Friede und Recht gehalten würden, war nicht mehr gegeben, seitdem Franz von Sidkingen dem Erzbischof von Trier Ende August 1522 die Fehde angesagt und die Fürsten von Kurpfalz und Hessen gegen den Reichsritter Partei ergriffen hatten. Um nachteiligen Auswirkungen auf die Türkenabwehr vorzubeugen, unternahmen die Reichsstände während des zweiten Nürnberger Reichstages einen Ausgleichsversuch, der jedoch scheiterte. Der innere Krieg im Westen des Reiches fand erst Anfang Mai 1523 mit der Niederwerfung und dem Tod Sidkingens sein Ende ${ }^{54}$.

Ein weiteres Hindernis für die Leistung der restlichen Romzugshilfe war der ungenügende Geldeingang für den Zug der 3000 Knechte. Bis zum Oktober 1522 hatten die steuerpflichtigen Stände und Städte statt der 90000 Gulden erst 40000 Gulden erlegt. Die Zahlung weiterer 16000 Gulden konnte erwartet werden. Es blieb jedoch auch dann noch ein Fehlbetrag von 36000 Gulden ${ }^{65}$. Dieser Sachverhalt machte die schweren Mängel der Wormser Matrikel offenkundig. Da der Wormser Reichsabschied die Möglichkeit ausschloß, die Ausfälle durch Mehrleistungen der gehorsamen Stände auszugleichen, mußte bei allen künftigen Beratungen davon ausgegangen werden, daß die Romzugshilfe gar nicht in voller Höhe aufgebracht werden konnte.

Hinzu kam, daß seit Herbst 1522 die zeitliche Begrenzung der Romzugshilfe als schweres Hemmnis für ihre Verwendbarkeit im Türkenkrieg empfunden wurde.

10 J. v. Hammer-Purgstall: Geschichte des Osmanischen Reiches, Bd 3, Pest 1828 (Neudruds 1963), S. 18-31 (zit. Hammer-Purgstall).

RTA III, Nr. 55 u. 58, S. $323-328$ u. $333-335$.

51 RTA III, S. 324/Z. 25 - S. 325/Z. 3, S. 326/Z. 37 - S. 327/Z. 2, Anm. 1 zu S. 332, S. 294/ Z. 29-33.

52 Anm. 1 zu S. 256 (Weisung des Kaisers), S. 257/Z. 8-11 (Proposition von Statthalter und Reichsregiment), S. 331/Z. 17-22 (Vorschlag Ferdinands).

vs Vgl. RTA III, S. 331/Z. 15-17 (Stellungnahme Ferdinands zur Frage der beharrlichen Hilfe).

54 RTA III, S. 245/Z. 12-21, S. 288/Z. $25-$ S. 289/Z. 28, Anm. 1 zu S. 303. S. ferner ebd., S. 690 u. $726 \mathrm{f}$.

s5 RTA III, S. 263/Z. $30-$ S. 264/Z. 6. 
Die 3000 Knechte, die im Sommer 1522 nach Kroatien geschickt worden waren, mußten dort über die festgesetzte Zeit der drei Monate hinaus von Erzherzog Ferdinand weiter besoldet werden, weil ein termingerechter Abzug vor Abschluß der Kämpfe unerträglich gewesen wäre ${ }^{56}$. Die Romzugshilfe sollte nun freilich nicht nur drei Monate, sondern sechs Monate dauern. Aber auch das war für den türkischen Kriegsschauplatz zu kurz bemessen. Da für den An- und Abzug ein Monat abging, wären die Truppen nur fünf Monate im Kriegsgebiet verfügbar gewesen. Die Türken konnten sich während dieser Zeit zurüdkziehen und anschließend ihre Angriffe wieder aufnehmen. Sie hätten auf diese Weise die Reichshilfe ohne jeden eigenen militärischen Aufwand unwirksam machen können. Die Verordneten der Reichsstände, die auf dem zweiten Nürnberger Reichstag die Antwort an die ungarischen Gesandten vorbereiten sollten, hielten es mit Rüdksicht auf diese Sachlage für sehr beschwerlich und ungelegen, die Romzugshilfe ganz oder zum Teil in Ungarn zu verwenden. $\mathrm{Da}$ aber eine beharrliche Hilfe noch nicht in Aussicht stand und befürchtet wurde, daß die Ungarn und Kroaten bei Verweigerung jeder Unterstützung zum Paktieren mit den Türken veranlaßt werden könnten, rieten die Verordneten, den Ungarn im Sommer 15232 Viertel des Fußvolks der Romzugshilfe zur Türkenabwehr und zur Besetzung der Pässe und Festungen zur Verfügung zu stellen ${ }^{57}$.

Statthalter und Regiment stimmten dem Vorschlag der Verordneten zu, wollten jedoch den Ungarn noch Bemühungen um eine beharrliche Hilfe in Aussicht stellen und ihnen außerdem die Zusage geben, daß man beim Überhandnehmen der Türken mit Leib und Gut zuziehen und Hilfe bringen werde. Beide Ergänzungsvorschläge fanden Aufnahme in die Antwort, umstritten blieb aber, ob den Ungarn, wie Statthalter und Regiment das wünschten, auch die zahlenmäßige Stärke der für Sommer 1523 versprochenen Hilfstruppen bekanntgegeben werden sollte. Die Reichsstände hatten hiergegen Bedenken, weil völlig ungewiß war, wieviel Geld eingehen würde und wieviele Fußknechte von dem eingegangenen Geld abgefertigt werden konnten. Sie wollten daher den ungarischen Gesandten in ihrer Antwort lediglich »non aspernandas copias auxiliares» zur Sicherung der Festungen, Städte und Flußübergänge in den Grenzgebieten Ungarns oder Kroatiens versprechen. Die Antwort wurde den ungarischen Gesandten am 15. Dezember 1522 mit dieser Formulierung zugestellt. Die Gesandten begnügten sich damit nicht, sondern baten, unterstützt von dem päpstlichen Nuntius Chieregati, um Bekanntgabe der Summe der Hilfe. Nadh längeren Auseinandersetzungen mit Statthalter und Regiment fanden sich die Reichsstände hierzu schließlich bereit. Zur Ermittlung der Zahl ließen sie die Anschläge überprüfen und den voraussichtlichen Geldeingang schätzen ${ }^{58}$.

Während dies geschah, informierten die Verordneten der Reichsstände die ungarischen Gesandten am 18. Dezember 1522 zum ersten Mal darüber, daß die Romzugshilfe dem Kaiser unter bestimmten Bedingungen bewilligt worden sei, deren Erfüllung nunmehr den Ungarn obliegen sollte. Die ungarischen Gesandten erwiderten sofort, daß sie von diesen Bedingungen keine Kenntnis gehabt hätten und zur Übernahme entsprechender Verpflidhtungen nicht bevollmächtigt seien ${ }^{59}$. Eine

56 W. Bauer: Die Korrespondenz Ferdinands I., Bd 1: Familienkorrespondenz bis 1526 (= Veröffentlichungen der Kommission für neuere Geschichte Osterreichs, Bd 11), Wien 1912, S. 17 f. (zit. Bauer: Korrespondenz) (= Schreiben Ferdinands an Karl v. 2. 9. 1522); RTA III, S. 254/ Z. $21-32$.

57 RTA III, Nr. 59/I, S. 335-337.

68 RTA III, S. 300-309, 337-346.

50 RTA III, S. 309/Z. 9-21. 
endgültige Entscheidung über die deutsche Hilfeleistung konnte unter diesen Umständen auf dem zweiten Nürnberger Reichstag nicht mehr getroffen werden. Immerhin wurden aber die Bedingungen der Hilfeleistung jetzt schriftlich festgelegt. In dem gleichen Dokument, in dem das geschah, nannten die Reichsstände auch die Zahl der Fußknechte, die sie 1523 den Ungarn zusenden wollten. Die gestellten Bedingungen beruhten auf den Wormser Vereinbarungen des Kaisers und der Reichsstände über die Romzugshilfe oder betrafen die Behandlung der Reichstruppen während ihres Aufenthaltes in Ungarn. Uber das Dokument wurde vom 20. bis 22. Dezember 1522 mit den ungarischen Gesandten verhandelt. Dabei konnten die Ungarn noch verschiedene Änderungen durchsetzen. Der endgültige Text, der als Kooperationsvertrag dienen sollte, enthielt folgende Bestimmungen $^{60}$ : Statthalter, Kurfürsten und Stände des Reiches erklärten sich bereit, 4000 Fußknechte zum Schutze Ungarns und Kroatiens unter bestimmten Bedingungen zu entsenden. Die Truppen sollten am 25. Mai 1523 in Odenburg versammelt und sechs Monate unterhalten werden. Von diesen sechs Monaten ging ein Monat für den An- und Abzug ab. Die Ungarn sollten die 4000 deutschen Knechte mit Feldgeschütz ausstatten und ihnen 1000 Reiter für Wachdienste und zum Heranführen von Futter und Lebensmitteln beigeben. Die Führung der deutschen Fußknechte wurde dem deutschen Befehlshaber vorbehalten. Dieser sollte jedoch Befehle des ungarischen Königs, soweit sie notwendig erschienen oder im Einvernehmen mit ihm erteilt wurden, befolgen. Die Ungarn sollten dafür Sorge tragen, daß die deutschen Knechte in Ungarn zu einem angemessenen Preis Waffen und Proviant kaufen konnten. Sie sollten die zollfreie Zufuhr von Lebensmitteln zum deutschen Heer gewährleisten, den Durchzug und Abzug der deutschen Knechte nicht behindern, dem deutschen Befehlshaber ein bis zwei Dolmetscher zur Verfügung stellen und den Wert der ungarischen Münze, die nur die Hälfte des üblichen Feingehaltes besaß ${ }^{01}$, demjenigen des österreichischen Geldes angleichen. Die Böhmen sollten veranlaßt werden, Feindseligkeiten gegen die benachbarten deutschen Fürsten, die man damals befürchtete, zu unterlassen und die gleiche Zahl Soldaten wie die Reichsstände nach Ungarn zu entsenden. Die Annahme der gestellten Bedingungen wurde vom König von Ungarn und von den ungarischen Ständen bis zum 15. März 1523 verlangt. Sie sollte in einem gesiegelten und unterschriebenen Dokument erklärt werden.

In einem Zusatzbeschluß versprachen die Reichsstände auf Bitten der ungarischen Gesandten die Unterhaltung von 20 Büchsenmeistern und die Lieferung von 100 Zentnern Pulver für die 4000 Knechte. Außerdem stellten sie in Aussicht, bei genügendem Geldeingang weitere 1000 bis 2000 Knechte zu schicken. Ein großes Entgegenkommen bedeuteten diese Versprechungen freilich nicht. Denn die ungarischen Gesandten hatten die Reichsstände bei den Verhandlungen gebeten, über ihre ursprüngliche Zusage hinaus einige tausend Fußknechte und 500 bis 1000 Reisige zusätzlich zu bewilligen, die gesamte Ausstattung der Truppen mit Geschütz und Kriegsmaterial zu übernehmen, die Hilfe dem Befehl des ungarischen Königs zu unterstellen, für den An- und Abzug einen siebenten Monat zu gewähren und die Beteiligung der Böhmen am Feldzug nicht zur Voraussetzung für die Hilfeleistung zu machen ${ }^{62}$. Ganz offensichtlich hielten die ungarischen Gesandten die deutsche Hilfe für ungenügend und ihre Ausstattung mit Geschütz und ihre Verstärkung durch böhmische Truppen für schwer durchführbar.

so RTA III, Nr. 61, S. 346-352. S. auch den Verhandlungsbericht S. 309-311.

-1 Fessler, S. 338.

-2 Zusatzbeschluß der Reichsstände: RTA III, S. 351/Z. 3 - S. 352/Z. 33. Entgegnung der ungarischen Gesandten auf die ursprünglichen Zusagen; ebd., Nr. 62, S. 353 f. 
Die Erwähnung Kroatiens neben Ungarn als Einsatzort der Reichshilfe erfolgte, weil außer der ungarischen Gesandtschaft als Vertreter der kroatischen Stände Graf Bernardini Frangipani nach Nürnberg gekommen war und dort um sofortige Hilfe für Kroatien gebeten hatte. Den Vorrang bei der Hilfeleistung der Reichsstände hatten jedoch die Ungarn ${ }^{63}$.

Wie im Frühjahr 1522 ließen die Reichsstände die Hilfe auch jetzt wieder in Geld bezahlen. Das Verfahren der Truppengestellung war diesmal nicht anwendbar, da Geldmittel für Führungspersonal, Pulver und Büchsenmeister benötigt wurden. Die Zahlung der Beiträge sollte bis 16. März 1523 in den drei Legestädten erfolgen. Das Verfügungsrecht über das eingegangene Geld erhielten vier verordnete Einnehmer, die zugleich kaiserliche Regimentsräte waren. Die Legestädte sollten das Geld an die vier Einnehmer auszahlen, die es wiederum zur Unterhaltung der 4000 Knechte "mit haubtleuten und ubersolden ", zur Bezahlung der Büdhsenmeister und zum Kauf des Pulvers verwenden durften. Für den Fall, daß die 4000 Knechte im Sommer 1523 nicht nach Ungarn oder Kroatien geschickt oder vor Ablauf der sechs Monate wieder abgefordert wurden, waren die vier verordneten Einnehmer verpflichtet, das nicht ausgegebene Geld bis zum nächsten Reichstag bei sich zu behalten, wo es an die Reichsstände zurüdkerstattet werden sollte. Der Anschlag der 2 Viertel der Fußknechte der Romzugshilfe hätte 240000 Gulden erbringen müssen, aber hiermit war wegen der Mängel der Wormser Matrikel natürlich nicht zu rechnen ${ }^{64}$.

Nachdem die Reichsstände alle erforderlichen Maßnahmen zur Aufbringung der Hilfe getroffen hatten, war deren Vollzug allein vom Verhalten der Ungarn abhängig. Diese ließen den 15. März 1523 verstreichen, ohne die Ratifikation der gestellten Bedingungen vorzunehmen. Am 22. März 1523 schirieb König Ludwig dem Reichsregiment, daß die böhmischen Stände auf einem Landtag in Prag die deutschen Bedingungen, soweit sie sich auf Böhmen bezogen, angenommen hätten. Die ungarischen Stände berieten erst im Mai 1523 in Ofen (dem heurigen Buda!) über die Voraussetzungen der Reichshilfe. Sie beschlossen dort, die Reichsstände zu bitten, die in Aussicht gestellte Erhöhung der Zahl der Kriegsknechte von 4000 auf 6000 vorzunehmen, das geforderte Feldgeschütz den Ungarn leihweise und gegen Schadenersatz bei Verlust zur Verfügung zu stellen und als Versammlungsort der Hilfe und der 1000 ungarischen Reiter Wien statt Odenburg zu bestimmen. Die gewünschte Verbesserung der ungarischen Münze hielt König Ludwig nicht für ausführbar, er hoffte jedoch, die Reichstruppen vor finanzieller Schädigung bewahren zu können ${ }^{05}$. Die Abstriche der Ungarn an den gestellten Bedingungen waren nicht erheblich, denn der wichtigste Punkt, die leihweise Lieferung des Geschützes, war ja deutscherseits bereits auf dem ersten Nürnberger Reichstag erwogen worden. Voraussetzung hierfür sollte freilich sein, daß die Ungarn die Unterhaltungskosten für das Geschütz bezahlten.

Die Beschlüsse der ungarischen Stände wurden dem Reichsregiment zunächst nicht offiziell mitgeteilt. Offenbar verschoben die Ungarn ihre Stellungnahme, weil nicht abzusehen war, ob die Türken 1523 einen größeren Kriegszug gegen Ungarn beabsichtigten. Erst am 12. Juli 1523 erschien ein ungarischer Gesandter beim Reichsregiment in Nürnberg, bat um die Absendung der 4000 bis 6000 Knechte und teilte mit, daß er Befehl zur Beantwortung der gestellten Artikel und Voll-

23 RTA III, S. 292-294, 296-298, 302, 304, 306, 362-366.

a RTA III, S. 737-743 (Bestimmungen des Reichsabschieds v. 9. 2. 1523 über die Türkenhilfe); ebd., Nr. 64, S. 359 f. (Anschlag für die Türkenhilfe); ebd, Nr. 65, S. 360 f. (Mandat des Reidssregiments zur Zahlung des Anshlags für die Türkenhilfe v. 7. 1. 1523).

os RTA III, Anm. 1 zu S. 937; RTA IV, S. 3 f. 
macht zu weiteren Verhandlungen habe. Das Reichsregiment erwiderte am 22. Juli 1523, es könne in der Sache nichts mehr tun, da die Ungarn die gestellten Bedingungen weder zum festgesetzten Termin noch jetzt angenommen hätten, sondern erneut darüber verhandeln wollten. Dem Vorschlag des Reichsregiments, den nächsten Nürnberger Reichstag abzuwarten, der auf den 13. Juli 1523 ausgeschrieben worden war, aber wegen des langsamen Eintreffens der Ständevertreter noch nicht eröffnet werden konnte, leistete der Gesandte keine Folge. Er verließ Nürnberg voller Unwillen und mit der Behauptung, König Ludwig und die ungarischen Stände hätten den deutschen Forderungen Genüge getan ${ }^{60}$. Wie sich später zeigte, konnte der geplante neue Reichstag wegen des geringen Besuchs nicht abgehalten werden. Das Reichsregiment ließ sich jedoch von den anwesenden Gesandten der Reichsstände bestätigen, daß die Rückzahlung der eingegangenen Türkenhilfsgelder nunmehr gerechtfertigt sei. Noch im August 1523 wurde die Weisung hierzu an Nürnberg und wahrscheinlich auch an die beiden anderen Legestädte erteilt ${ }^{87}$. Die neue Türkenhilfe war damit gescheitert. Die Bedingungen und Grundsätze, die für ihre Durchführung seit Frühjahr 1522 erarbeitet worden waren, blieben indessen noch drei Jahre lang trotz verschiedener Anderungen und Einschränkungen für die Verhandlungen des Reiches mit den Ungarn über eine gemeinsame Türkenabwehr bestimmend.

Der Wegfall der Reidstürkenhilfe im Jahre 1523 hatte für die Ungarn keine nachteiligen Folgen. Denn der große türkische Angriff gegen das Königreich, der nach dem Verlust von Rhodos für dieses Jahr befürchtet worden war, blieb aus. Die Türken unternahmen nur Einfälle in die ungarischen Grenzgebiete, die mit schweren Rüdkschlägen endeten ${ }^{68}$. Trotzdem bestand die Türkengefahr unvermindert fort. Anfang 1524 erwarteten die Ungarn, daß der Sultan zu Frühjahrsbeginn mit seiner ganzen Macht zur Eroberung ihres Landes aufbrechen würde. Sie wandten sich daher wieder mit der Bitte um Hilfe an die Reichsstände ${ }^{\text {"日, }}$, die vom 14. Januar bis 18. April 1524 den dritten Reichstag in Nürnberg abhielten. Erzherzog Ferdinand befürwortete dort, unterstützt von dem kaiserlichen Kommissar Johann Hannart, die Leistung der ganzen restlichen Romzugshilfe als eilende Türkenhilfe ${ }^{70}$. Im Reichsabschied vom 18. April 1524 wurde jedoch lediglich die auf dem zweiten Nürnberger Reichstag 1522/23 zugesagte Hilfe neu bewilligt. Dabei blieben die damals aufgestellten Bedingungen der Hilfeleistung unerwähnt. Da aber die Neubewilligung unter Hinweis auf den Inhalt des letzten Reichsabschiedes vom 9. Februar 1523 erfolgte, in dem die Bedingungen Erwähnung fanden, kann angenommen werden, daß sie weiterhin gültig bleiben sollten ${ }^{71}$. Die Verhandlungsakten von 1524 stützen diese Auffassung, denn in ihnen wurde durchweg daran festgehalten, daß die neubewilligte Hilfe unter den gleichen Bedingungen wie 1523 gewährt werden sollte ${ }^{72}$.

66 H. v. d. Planitz: Berichte aus dem Reichsregiment, S. 488 f., 510 f.; RTA IV, S. 29/Z. 28-33.

or RTA IV, S. 5; RTA III, Anm. 2 zu S. 362.

os L. Kupelwieser: Die Kämpfe Ungarns mit den Osmanen bis zur Schlachr bei Mohács 1526, Wien, Leipzig, 2. Aufl., 1899, S. 210 (zit. Kupelwieser: Ungarn).

of Ebd., S. 210 f.; RTA IV, Nr. 88, S. 432 f.

70 Ferdinands Einfluß ist erkennbar in den Vorschlägen zur Türkenhilfe in Hannarts Proposition v. 4. 2.1524 (RTA IV, S. 299/Z. 15 - S. 295/Z. 6) und in dem Ratschlag des gemeinsamen Ausschusses des Statthalters, des Orators Hannart und der Stände v. 8. 4.1524 (RTA IV, Nr. 92, S. 442-451). In beiden Dokumenten wird die Leistung des ganzen Restes der Romzugshilfe befürwortet. S. hierzu RTA IV, S. 429 f.

71 RTA IV, S. 606.

72 RTA IV, S. 436/Z. 4-7, S. 457/Z. 25-26. Diejenigen, die die Bewilligung des ganzen Restes der Romzugshilfe befürworteten, wollten ebenfalls die Hilfeleistung nur unter bestimmten Bedingungen zugestehen. S. hierzu RTA IV, S. 439/Z. 16-22, S. 446/Z. 11-16. 
In einigen wichtigen Punkten unterschieden sich freilich die neuen Beschlüsse von denen des Vorjahres. Die Neubewilligung erfolgte den Ungarn "zu trost «, die Hilfe wurde jedoch nicht den Ungarn, sondern Erzherzog Ferdinand zugeordnet. Als Grund hierfür führte der Reichsabschied an, daß Erzherzog Ferdinand mit König Ludwig ein Zusammenwirken österreichischer und ungarischer Truppen für den kommenden Sommer vereinbart habe und die Reichshilfe den gemeinsamen Widerstand beider Fürsten gegen die Türken fördern solle ${ }^{73}$. Tatsächlich war aber ein solches Zusammenwirken gar nicht definitiv vereinbart worden. Bei einem $\mathrm{Zu}$ sammentreffen beider Fürsten im September 1523 in Wiener Neustadt hatte sich König Ludwig erboten, eine Truppe von 60000 Mann und 100 Geschütze aufzubringen, Erzherzog Ferdinand stellte 8000 Fußknechte, 1000 gerüstete Reiter, 1000 leichte Reiter und 30 Geschütze in Aussicht. Diese Zusagen blieben indessen unverbindlich, da König Ludwig den Erzherzog um eine größere Hilfe bat und Ferdinand sein Angebot an Bedingungen knüpfte, über deren Erfüllung zumeist kein Einverständnis erzielt werden konnte ${ }^{74}$. Den Reichsständen blieb diese Sachlage unbekannt. Ihnen ging es offenbar in erster Linie darum, dem Erzherzog mit der Zuordnung ihrer Hilfe auch die Verpflichtung aufzuladen, für die Erfüllung der Bedingungen sorgen zu müssen, unter denen die Reichshilfe geleistet werden sollte. Und an dieser Verpflichtung konnte ja die unzureichende Vereinbarung Ferdinands mit König Ludwig keineswegs etwas ändern.

Das Geld für die neubewilligte Hilfe sollte bis zum 25. Juli 1524 in den drei einnehmenden Städten erlegt werden. Das Verfügungsrecht über das Geld wurde diesmal aber nicht wie 1523 vier Regimentsräten zuerkannt, sondern dem Bischof Philipp von Augsburg und dem Herzog Wilhelm von Bayern. Dies war notwendig, weil das Reichsregiment während der Reichstagsverhandlungen gestürzt worden war und erst am 17. Mai 1524 in Eßlingen unter teilweise anderen Bedingungen und in neuer Besetzung wieder in Tätigkeit treten sollte. Den beiden verordneten Fürsten wurde aufgetragen, das Geld der neubewilligten Türkenhilfe erst auf Ansuchen Erzherzog Ferdinands von den einnehmenden Städten in Empfang zu nehmen und zur Bestellung von Hauptleuten und Knechten zu verwenden. Die Hilfe sollte nur geleistet werden, wenn die Türken im Sommer 1524 einen "gwaltigen zug" gegen Ungarn unternahmen. Unterblieb dieser, so sollte das Geld in den Legestädten aufbewahrt und auf der geplanten Nationalversammlung in Speyer zu Martini 1524 an die Stände zurüdkgezahlt werden ${ }^{75}$. Die Beschränkung auf defensive Aufgaben war an sich keine Eigentümlichkeit eilender Hilfen ${ }^{76}$. Wenn sie 1524 vorgeschrieben wurde, wollten die Stände offenbar verhindern, daß die Ungarn mit Unterstützung des Reiches Offensivaktionen begannen, durch welche die Türken in einer Zeit zu massiven Gegenschlägen herausgefordert werden konnten, wo über die beharrliche Türkenhilfe noch keine Entscheidung getroffen worden war.

Die Verhandlungen über die beharrliche Türkenhilfe scheiterten 1524 wieder an dem Fehlen jeder Aussicht auf eine Mitwirkung anderer christlicher Herrscher. Um Karl V. und Franz I. zu Friedensschluß oder Waffenstillstand zu bewegen, beschlossen die Reichsstände die Absendung einer Vermittlungsgesandtschaft nach

78 RTA IV, S. 606/Z. 12-28.

74 Quellen zur Vereinbarung zwischen König Ludwig und Erzherzog Ferdinand im Sept. 1523 in Wiener Neustadr: 1. Acta Tomiciana, Bd. VI, S. 327-337; 2. Bauer: Korrespondenz, S. 89; 3. RTA IV, S. 236/Z. 6-10; 4. Stoegmann, S. 168.

78 RTA IV, S. $606 \mathrm{f}$.

76 Bezeichnend hierfür ist die in RTA IV, S. 435/Z. 29-31 abgedrudkte Textstelle aus dem Gutachten der Verordneten der Stände über die beharrliche und die eilende Türkenhilfe von Ende März 1524. 
Spanien und Frankreich. Erzherzog Ferdinand versuchte dieses Vorhaben, mit dem sich die Reichsstände gleichsam zur neutralen Macht zwischen ihrem obersten Herrn und dem benachbarten König von Frankreich aufgeworfen hätten, unter allen Umständen zu verhindern und schreckte dabei sogar vor Drohungen nicht zurück. Die Reichsstände verzichteten schließlich auf die Aktion, legten aber wegen aller Nachteile und Schäden, die hierdurch für die Christenheit und das Reich entstehen konnten, Verwahrung ein ${ }^{77}$.

Der große Eroberungszug Suleimans II., mit dem die Ungarn für 1524 gerechnet hatten, verzögerte sich bis 1526. Wohl wegen dieser Sachlage wurde die 1524 bewilligte Reichshilfe nicht geleistet und das hierfür erlegte Geld zurüdkgezahlt ${ }^{78}$. Neue Beratungen der Reichsstände über die eilende oder beharrliche Türkenhilfe fanden bis 1526 nicht statt. Die geplante Nationalversammlung in Speyer zu Martini 1524, die sich mit der beharrlichen Türkenhilfe beschäftigen sollte, wurde vom Kaiser aus religionspolitischen Gründen untersagt. Im Jahre 1525 waren die Reichsstände mit den Bauernunruhen beschäftigt. Ein zum 29. September 1525 nach Augsburg ausgeschriebener Reichstag, dem der Kaiser die Erörterung der beharrlichen Türkenhilfe auftrug, tagte nur kurze Zeit um die Jahreswende 1525/26 und faßte wegen des geringen Besuchs keine Beschlüsse in der Türkensache ${ }^{7 \theta}$. Erst auf dem nächsten Reichstag, der vom 25. Juni bis 27. August 1526 in Speyer stattfand, wurde die Türkenhilfe wieder erörtert. Die kaiserliche Proposition verlangte von der Reichsversammlung Verhandlungen und Beschlußfassung über die beharrliche Türkenhilfe ${ }^{\mathbf{8 0}}$. Die große Not der Ungarn führte indessen dazu, daß sich die Reichsstände wieder vornehmlich mit der eilenden Türkenhilfe beschäftigten.

Am 23. April 1526 brach Sultan Suleiman II. mit mehr als 100000 Mann und 300 Geschützen von Konstantinopel zu seinem zweiten Kriegszug gegen Ungarn auf. Am 15. Juli erreichte er Belgrad, am 28. Juli fiel die ungarische Grenzfestung Peterwardein in türkische Hand. König Ludwig verließ am 20. Juli mit einer kleinen Streitmacht seine Residenz Ofen, rüdkte den Türken entgegen und versuchte gleichzeitig, Verstärkungen aus seinen Ländern heranzuziehen. Eine Feldschlacht stand bevor ${ }^{81}$. In dieser Situation begannen die Reichsstände Ende Juli in Speyer auf Drängen Erzherzog Ferdinands endlich mit der Beratung der Türkensache. Sie hatten sich zunächst wochenlang mit dem Glaubenszwiespalt beschäftigt, obgleich bereits am 30. Juni ein ungarischer Gesandter die Hilfe des Reiches erbeten hatte ${ }^{82}$. Die Beratung der Türkenhilfe endete ohne größere Zugeständnisse. Ein Vorschlag zur Leistung des ganzen Restes der Romzugshilfe stieß auf Ablehnung. Die Reichsstände fanden sich lediglich bereit, den Ungarn die 1523 bewilligten 2 Viertel des Fußvolks der Romzugshilfe erneut zuzusagen. Am 18. August 1526 wurde der ungarische Gesandte mit einer entsprechenden Mitteilung an König Ludwig abgefertigt ${ }^{33}$.

77 RTA IV, S. 435, 451, 458, 462-466, $607 \mathrm{f}$.

79 Quellen hierzu standen mir nicht zur Verfügung. Die Rüdzzahlung der Anschläge für die 2 Viertel des Fußvolks der Romzugshilfe muß jedoch erfolgt sein, da das gleiche Geld auf Grund des Speyerer Reichsabschiedes 1526 erneut erlegt wurde. S. hierzu S. 24.

70 Der Nürnberger Reichsabschied v. 18. 4. 1524 setzte fest, daß von der Nationalversammlung in Speyer zu Martini 1524 auch die beharrliche Türkenhilfe beraten werden sollte (RTA IV, S. 608). Drudk des ksl. Ausschreibens des Augsburger Reichstages 1525: W. Friedensburg: Zur Vorgeschichte des Gotha-Torgauischen Bündnisses der Evangelischen 1525-1526, Marburg 1884, S. 116-120. Drudk des Augsburger Reichsabschiedes v. 9. 1. 1526: NS 2, S. 269-272.

Bo Drudk der ksl. Reichstagsproposition v. 25. 6. 1526: Friedensburg, S. 523-534 (Passus über die beharrliche Türkenhilfe, ebd., S. 530 f.).

a1 Kupelwieser: Ungarn, S. $220 \mathrm{ff}$.

82 Friedensburg, S. 421-425.

es Ebd., S. 425-428. 
Der Speyerer Reichsabschied vom 27. August 1526 bestimmte, daß die Erlegung des Geldes für die neue Türkenhilfe jeweils zur Hälfte bis zum 29. September und 11. November 1526 in den einnehmenden Städten erfolgen sollte, zu denen jetzt als vierte Stadt Straßburg hinzukam. Zum Empfang des Geldes und zur Ausgabe desselben wurden diesmal wieder vier Regimentsräte bevollmächtigt. Musterung und Abfertigung der Knechte oblag Erzherzog Ferdinand als "Herrn des Krieges«. Kam es nicht zum Vollzug der Hilfe oder wurde das Kriegsvolk vor Ausgang der sechs Monate abgezogen, so sollte das nicht verbrauchte Geld auf dem nächsten Reichstag zurüdkgezahlt werden ${ }^{84}$. Voraussetzung für die Hilfeleistung war, daß sich der König von Ungarn und die ungarischen Stände zur Erfüllung der 1522/23 aufgestellten, jetzt aber wesentlich gemilderten Bedingungen verpflichteten. Anders als 1522/23 verlangten die Reichsstände nicht mehr, daß die Ungarn die deutschen Kriegsknechte mit Feldgeschüzz ausstatteten. Außerdem wurde die Zahl der ungarischen Reiter, die den deutschen Kriegsknechten für Wachdienste und für die Futter- und Lebensmittelbeschaffung beigegeben werden sollten, von 1000 auf 400 bis 500 herabgesetzt ${ }^{85}$. Mit dem nach Speyer gekommenen ungarischen Gesandten konnte über die Bedingungen der Hilfeleistung nidht verhandelt werden, da dieser hierfür keine Vollmachten besaß ${ }^{86}$. Um trotzdem den baldigen Abgang der Hilfe zu ermöglichen, schickten die Reichsstände eine eigene Gesandtschaft mit dem Auftrag nach Ungarn, dort eine Abmachung über die Bedingungen der Hilfeleistung zu treffen und zugleich Erkundigungen über die Offensive der Türken und über die Gegenmaßnahmen der Ungarn einzuziehen. Die Gesandtschaft sollte nach ihrer Rüdkkehr Erzherzog Ferdinand als Herm des Krieges und dem Erzbischof von Mainz als Erzkanzler Bericht erstatten ${ }^{87}$. Feldgeschütz und Proviant für das Reichskriegsvolk erbat die Reichsversammlung bei den Fürsten, die dem Kriegsschauplatz benachbart waren (Oberpfalz, Bayern, Bistum Passau, Pfalz-Neuburg) ${ }^{88}$. Für den Fall, daß Ungarn von den Türken erobert wurde oder daß die Ungarn mit den Türken einen Vertrag abshlossen, sollte die Hilfe für Osterreich oder andere anstoßende Fürstentümer Verwendung finden ${ }^{69}$.

Am 29. August 1526, zwei Tage nach der Ausfertigung des Speyerer Reichsabschiedes, kam es bei Mohács zur Schlacht zwischen den Ungarn und Türken. Die Ungarn wurden vernichtend geschlagen, König Ludwig fand auf der Flucht den Tod. Am 10. September 1526 zog der Sultan mit seinen Truppen in Ofen ein. Die Stadt wurde geplündert und niedergebrannt. Wegen des Proviantmangels und der bevorstehenden kalten Jahreszeit traten die Türken bereits am 25. September 1526 den Rüdkmarsch an. Sie räumten Ungarn, ließen aber in Peterwardein eine Besatzung zurück ${ }^{90}$. Die Reichsgesandten, welche mit König Ludwig die Bedingungen für die deutsche Hilfeleistung vereinbaren sollten, trafen bestimmungs-

s4 NS 2, S. 276. Uber Musterung und Abfertigung der Knechte enthält der Reichsabschied keine Bestimmung, Erzherzog Ferdinand wird jedoch in $\$ 14$ wals dieser Sachen verordneter Kriegsherr* bezeichnet (NS 2, S. 277). Nach dem "Anschlag und Bedenken der verordneten Räte die eilende Türkenhilfe belangend sollte es die Aufgabe Ferdinands als Herr des Krieges sein, an gelegener Mahlstatt die Knechte annehmen, mustern und hinwegfertigen zu lassen (GStA/Mü, Kasten blau 104/4 B, fol. 131 rv).

as Die Bedingungen werden im Reidhsabschied 1526 unter Hinweis auf den Nürnberger Reichstag 1522/23, aber ohne Angabe ihres Inhalts erwähnt (NS 2, S. 277, \14). Sie finden sich in vollem Wortlaut am Schluß der Instruktion für die Reichsgesandtschaft zu König Ludwig von Ungarn (GStA/Mü, Kasten schwarz 4197, fol. 129r-135r, Conditiones: fol. 133v-135r).

so Friedensburg, Anm. 6 zu S. 421.

87 Mitglieder der Gesandtschaft: Graf Georg von Wertheim, Ritter Philipp von Feilitzsch (Kursachsen), Veit Auerberger (Bayern). Vgl. NS 2, S. 277, \$14.

Bo Friedensburg, Anm. 4 zu S. 431.

Bo NS 2, S. $277, \$ 15$.

ot Kupelwieser: Ungarn, S. 235 ff. 
gemäß am 10. September 1526 in Regensburg ein und brachen von dort nach Ungarn auf. In Linz erfuhren sie von der Katastrophe bei Mohács. Auf Anraten Erzherzog Ferdinands setzten sie trotzdem ihre Fahrt fort, um die Ungarn in ihrer Bedrängnis nicht ohne Hilfe zu lassen. Sie trugen in Preßburg der Königinwitwe Maria ihre Werbung vor, erörterten mit den obersten Ratgebern Marias die Kriegslage und wurden am 25. September $1526 \mathrm{mit}$ der Antwort entlassen, es könne mit der bewilligten Reichshilfe gegen die große Macht der Türken in der Eile kein Widerstand geleistet werden, die Königinwitwe bitte daher die Reichsstände, eine nützlichere Hilfe in Erwägung zu ziehen ${ }^{91}$. Der Versuch, den Ungarn eine Reichshilfe zuzuführen, war damit zum vierten Mal gescheitert.

Seit 1522 hatten die Reichsstände wiederholt über eine Türkenhilfe zum Schutze Ungarns verhandelt. Es wurde aber in diesen vier Jahren nur den Kroaten eine kleine Reichshilfe gewährt. Die Ungarn gingen leer aus, weil sie die Bedingungen der Hilfeleistung nicht akzeptierten. Der Erzbischof von Mainz meinte am 30. Juli 1526 in Speyer im Hinblidk auf diesen Sachverhalt, man solle den Ungarn vorhalten, "was man hievor irenthalb gethan, und das der mangel an inen gewest «" ${ }^{92}$. Völlig berechtigt war dieser Vorwurf allerdings nicht. Denn die Reichsstände hatten es den Ungarn nicht eben leidht gemacht, den deutschen Bedingungen zuzustimmen. Lange Zeit erfuhren die Ungarn überhaupt nichts von den Vorbedingungen der Romzugshilfe, die von den Reichsständen dann zu Vorbedingungen für die Leistung der Reichstürkenhilfe gemacht wurden. Die Verhandlungen über die Hilfeleistung von 1522 bis 1526 zeigen, daß die ursprünglich gestellten Bedingungen durchaus in zwedkmäßiger Weise gemildert werden konnten. Seitdem im Frühjahr 1522 der Weg beschritten worden war, die Türkenhilfe in Geld erlegen zu lassen, besaßen die Reichsstände die Mögliḑkeit, die Ausstattung ihrer Truppen mit Führungspersonal, Geschütz und Pulver bei entsprechender Reduzierung der Mannschaftsstärke selbst zu finanzieren. Sie machten davon jedoch viel zu spät Gebrauch. Auffallend ist auch, daß immer nur Fußknechte, nie aber Reisige bewilligt wurden, deren Unterhaltung nicht den Städten, sondern den Fürsten, Grafen und Rittern oblag. Trotz dieser Kritik an dem Verhalten der Reichsstände muß freilich eingeräumt werden, daß eine Hilfeleistung in dem politisch zerrütteten Ungarn beträchtliche Gefahren einschloß. Die zerfahrene ungarische Gefechtsführung in der Schlacht bei Mohács macht deutlich, daß es für ein kleines Reichsheer nicht leicht gewesen wäre, mit den ungarischen Truppen im Türkenkrieg zusammenzuwirken. Vor allem aber muß berüdksichtigt werden, daß die Reichsstände in den Jahren 1522 bis 1526 den Ungarn lediglich kleine Hilfen als »Zusatz " zu den ungarischen Streitkräften bewilligten, weil sie eine nachhaltige Eindämmung der Türkengefahr allein mit der beharrlichen Hilfe und bei einem Zusammenwirken aller christlichen Herrscher für möglich hielten. Sie sträubten sich, ihre Mittel in dem zermürbenden Dauerkrieg zwischen Ungarn und Türken zu verbrauchen, ohne damit eine entscheidende Wendung der Dinge herbeiführen zu können. Die bewilligten Reichshilfen sollten die Ungarn nicht bloß materiell, sondern auch moralisch stärken und sie von einem Paktieren mit den Türken abhalten, bis der beharrliche Krieg unternommen werden konnte.

at Relation des Grafen Georg von Wertheim u. a., die zu König Ludwig gesandt waren, auf dem 18-Fürstentag in Eßlingen: HHStA/Wi, Mainzer Erzkanzlei, Reichstagsakten, Fasz. 4d, Bd 1, fol. $383 r-387 r$.

2 Kurmainzisches Protokoll des Reichstages zu Speyer 1526, Notiz zum 30. 7. 1526: HHStA Wi, Mainzer Erzkanzlei, Reichstagsakten, Fasz. 4d, Bd 1, fol. 50v. 
Die Reichstürkenhilfe vom Eßlinger 18-Fürstentag 1526 bis zur Belagerung Wiens 1529

Die Hauptschwierigkeit für die Leistung der Reichstürkenhilfe in den Jahren 1522 bis 1526 bestand darin, daß das Reichskriegsvolk einer auswärtigen Macht zur Verfügung gestellt und daß mit dieser Macht eine Vereinbarung über die Kooperation der beiderseitigen Truppen getroffen werden mußte. Nach dem kinderlosen Tod Ludwigs II. änderte sich diese Sachlage. Erzherzog Ferdinand erhob Anspruch auf die Nachfolge in den Ländern seines toten Schwagers. Mähren, Schlesien und die Lausitz fielen ihm auf Grund des Erbrechtes seiner Gemahlin zu, während in Böhmen und Ungarn die Stände durch Wahlen über die Nachfolge entschieden. Die böhmischen Stände wählten am 23. Oktober 1526 Ferdinand zu ihrem König. Aussichtsreichste Mitbewerber bei dieser Wahl waren die Herzöge Wilhelm und Ludwig von Bayern und König Sigismund I. von Polen ${ }^{93}$. In Ungarn wurde Johann Zápolya am 10. November 1526 auf einem Reidstag in Stuhlweißenburg zum König gewählt und am folgenden Tag gekrönt. Zápolya konnte sich auf den national gesinnten Kleinadel sowie auf die meisten Bischöfe und viele Magnaten stützen, die aus Opportunismus zu ihm gestoßen waren. Die wenigen Mitglieder der österreichischen Partei scharten sich um die Königinwitwe in Preßburg und wählten dort auf einem ordnungsgemäß durch den Palatin Stephan Báthory einberufenen Reichstag am 16. Dezember 1526 Ferdinand zum König von Ungarn ${ }^{94}$. Es gab nunmehr zwei Könige in Ungarn, einen fremden und einen einheimischen. Falls die Reichsstände eine künftige Reichstürkenhilfe Ferdinand zuordneten, entfiel die Notwendigkeit, die Kooperationsbedingungen mit einer auswärtigen Macht vereinbaren zu müssen. Zugleich bestand aber jetzt die Gefahr, daß die Reichstruppen in den ungarischen Thronstreit hereingezogen wurden.

Auf dem 18-Fürstentag in Eßlingen, der vom 10. bis 21. Dezember 1526 tagte, mußten sich die Reichsstände zum ersten Mal mit dieser Möglichkeit befassen. Die Einberufung eines 18-Fürstentages war dem Reichsregiment in der Wormser Regimentsordnung vom 26. Mai 1521 für den Fall vorgeschrieben worden, daß besondere Sachen vorfielen, die unverzügliche Beschlüsse erforderlich machten ${ }^{95}$. Zu den 18 Fürsten gehörten außer den sechs Kurfürsten je sechs geistliche und sechs weltliche Fürsten, die im Wormser Reichsabschied genannt waren ${ }^{86}$. Der Eßlinger 18-Fürstentag wurde vom Reichsregiment auf Betreiben Erzherzog Ferdinands am 25. September 1526 ausgeschrieben, um nach der Schlacht bei Mohács und nach dem Verlust Ofens eine größere Türkenhilfe als die in Speyer bewilligte zu beschließen ${ }^{87}$. Der Tag war gut besucht. Es erschienen drei Kurfürsten, sechs Bischöfe und zwei weltliche Fürsten in eigener Person ${ }^{88}$.

Erzherzog Ferdinand konnte wegen des gleichzeitig stattfindenden Preßburger Reichstages den Eßlinger Fürstentag nicht besuchen. Er informierte die Eßlinger Versammlung jedoch nicht von seiner bevorstehenden Wahl zum ungarischen Gegenkönig, sondern ließ ihr als Grund für sein Fernbleiben mitteilen, daß er in

9s Uhlirz, S. 190.

4 Fessler, S. 399-412.

os RTA II, S. 227, Abschn. 12.

20 RTA II, S. 731.

97 Ausschreiben des 18-Fürstentages zu Eßlingen v. 25. 9. 1526: HHStA/Wi, Mainzer Erzkanzlei, Reichstagsakten, Fasz. 4d, Bd 1, fol. 324r-325r. Daß das Ausschreiben auf Betreiben Ferdinands geschah, ergibt sich aus einem Shreiben Ferdinands an $\mathrm{Hg}$. Wilhelm von Bayern v. 4. 10. 1526: GStA/Mü, Kasten schwarz 4194, fol. 479rv.

o日 Verzeichnis der Anwesenden bei Eröffnung des 18-Fürstentages in Eßlingen: HHStA/Wi, Mainzer Erzkanzlei, Reichstagsakten, Fasz. 4d, Bd 1, fol, 334 rv. 
seinen Ländern die Türkenabwehr vorbereiten müsse ${ }^{99}$. In Wirklichkeit war es im Spätherbst 1526 durchaus ungewiß, ob die Türken im kommenden Jahr erneut in Ungarn einbrechen würden. Ferdinands wichtigstes Anliegen war es damals, die Besitzergreifung Ungarns vorzubereiten. Bei einer Zusammenkunft des Erzherzogs mit der Königinwitwe Maria vom 14. bis 18. Oktober 1526 in Hainburg bei Preßburg wurde in Aussicht genommen, im kommenden Frühjahr einen "gewaltigen Kriegszug gegen Ungarn zu unternehmen, falls Zápolya die Königswürde erhalten sollte. $\mathrm{Zu}$ den Maßnahmen, mit denen dieser $\mathrm{Zug}$ vorbereitet werden sollte, gehörte auch das Ersuchen an die Reichsstände um Bewilligung einer Türkenhilfe und die Verdächtigung Zápolyas als Parteigänger der Türken. Die Bekämpfung Zápolyas sollte als Beitrag zur Türkenabwehr und zum Schutze der Christenheit hingestellt werden ${ }^{100}$. Kurz nach der Hainburger Zusammenkunft schickte Ferdinand einen Gesandten zum Erzbischof von Mainz, zum Kurfürsten von der Pfalz, zu den Bischöfen von Straßburg und Speyer und zu Markgraf Philipp von Baden, um sich ihre Unterstützung auf dem Eßlinger Tag zu sichern. Er ließ die fünf Fürsten unterrichten, daß er in Eßlingen die Bewilligung einer stattlichen Reichshilfe anstreben werde, mit der er das Königreich Ungarn wieder in die Gewalt der Christenheit bringen wolle ${ }^{101}$.

Die drei Gesandten, die Ferdinand auf dem Fürstentag in Eßlingen vertraten, vermieden eine solche rüdkhaltlose Sprache. Obgleich sie von Ferdinand beauftragt worden waren, eine ansehnliche Reichshilfe zu dem Zweds zu erbitten, das der Christenheit abgerungene Land soweit möglich wiederzuerlangen, erklärten sie der Versammlung lediglich, die geforderte Reichshilfe solle zum Widerstand gegen die Türken und zum Schutz der Christenheit und des Reiches dienen ${ }^{102}$. Wie sie ihrem Herrn berichteten, wollten sie auf diese Weise dem Eindrudk vorbeugen, als ob Ferdinand die Reichshilfe zu seinem eigenen Nutzen für die Eroberung der Krone Ungarn beanspruche ${ }^{103}$. Gelungen ist ihnen das freilich nicht. Denn ihre weisungsgerechten langen Ausführungen ibber Zápolyas abwartendes Verhalten während des letzten Türkenkrieges und über seine angeblich im Vertrauen auf türkischen Beistand erfolgte Wahl und Krönung in Stuhlweißenburg ${ }^{104}$ machten die Eßlinger Versammlung offenbar stutzig. Bei den Kurfürsten und Fürsten wurde tagelang erwogen, eine Gesandtschaft zu Zápolya zu schidken, um in Erfahrung zu bringen, »was sich zu ime zu verlassen sey, auch welcher parthy er, cristisch oder durckig, sein wolle«. Falls sich ergab, daß er kein Anhänger der Türken war, wollten sich die Kurfürsten und Fürsten gegenüber Ferdinand und Zápolya so verhalten, daß der Ungar keine Ursache hatte, Anschluß bei den Türken zu suchen und diese gegen Ferdinand und die christlichen Lande zu führen. Die Gesandten Ferdinands sprachen sidh gegen die Fühlungnahme mit Zápolya

90 Mitteilung der Gesandten Ferdinands auf dem Eßlinger 18-Fürstentag am 10. 12. 1526: HHStA/Wi, Mainzer Erzkanzlei, Reichstagsakten, Fasz. 4d, Bd 1, fol. 344r-345v.

$100 \mathrm{Vgl}$. S. Smolka: Ferdinands des Ersten Bemühungen um die Krone von Ungarn, in: Archiv für österreichische Geschichte, Bd 57, 1879, S. 36-41, 74-77, 150-158 (zit. Smolka).

101 Instruktion Ferdinands für Kaspar Spät v. 21. 10. 1526: HHStA/Wi, Mainzer Erzkanzlei, Reichstagsakten, Fasz. 4d, Bd 1, fol. 330r-332v.

102 Instruktion Ferdinands für seine Gesandten zum 18-Fürstentag in Eßlingen Georg Truchseß von Waldburg, Frhr. Schweikhart von Gundelfingen und Dr. Beat Widmann v. 20. 11. 1526: HHStA/Wi, Urkundenreihe, 1526/November/20, fol. 1r-14r. - Schriftlicher Bericht der 3 Gesandten Ferdinands auf dem Eßlinger 18-Fürstentag (mit Abweichungen von der Instruktion): HHStA/Wi, Mainzer Erzkanzlei, Reichstagsakten, Fasz. 4d, Bd 1, fol. 340v-344r.

109 Bericht der Gesandten Truchseß, Gundelfingen u. Widmann an Ferdinand v. 11. 12. 1526: HHStA/Wi, Urkundenreihe, 1526/November/20, fol. 43r-467.

$104 \mathrm{Vgl}$. den in Anm. 102 nachgewiesenen schriftl. Beridit. 
aus, und die Kurfürsten und Fürsten verzichteten schließlich auf das Vorhaben ${ }^{\mathbf{1 0 5}}$. Aber sie verstanden es, ihre Intentionen in anderer Weise zur Geltung zu bringen. Sie schufen nämlich im Eßlinger Abschied eine Reichsdeputation als Kontrollinstanz für den Vollzug der eilenden Reichstürkenhilfe, die vor allem darüber wachen sollte, daß die Hilfe ausschließlich zum Widerstand gegen die Türken verwendet wurde. Zu Mitgliedern der neuen Reichsdeputation machte der Eßlinger Abschied Erzherzog Ferdinand, den Kurfürsten von Sachsen, den Kurfürsten von Brandenburg, Pfalzgraf Friedrich, Herzog Ludwig von Bayern und Bischof Philipp von Augsburg sowie die vier im Speyerer Reichsabschied 1526 zum Empfang und zur Ausgabe des Türkenhilfsgeldes bevollmächtigten Regimentsräte. Die Reichsdeputation sollte bei einem Angriff der Türken im künftigen Frühjahr gegen Polen von den Kurfürsten von Sachsen und Brandenburg nach Coburg oder bei einem Zug der Türken gegen Osterreich und Bayern von den vier anderen Fürsten nach Regensburg einberufen werden, um dort über den Vollzug der Hilfe zu beschließen und ihren Einsatzort zu bestimmen. Die Mitglieder der Deputation waren verpflichtet, die Hilfe im Sinne des Speyerer Reichsabschiedes 1526 an keinem anderen Ort »dann allein zu widerstand des Türcken« gebrauchen zu lassen, das heißt, die Hilfe durfte nicht gegen Zápolya und nïht offensiv verwendet werden ${ }^{106}$. Die in Eßlingen vertretenen Kurfürsten und Fürsten wollten ursprünglich Erzherzog Ferdinand nicht in die Reichsdeputation aufnehmen. Sie sahen hiervon erst auf Wunsch des Reichsregiments ab ${ }^{107}$. Hierdurch wurde vermieden, daß es allzu offenkundig wurde, gegen wen die neue Institution gerichtet war. An der Wirkung der Deputation konnte auch die Mitgliedschaft Ferdinands nichts ändern. Der Versuch des Erzherzogs, die Reichstürkenhilfe gegen Zápolya im Kampf um die Herrschaft in Ungarn zu verwenden, war gescheitert.

In Anbetracht der restriktiven Neuregelung des Vollzugs der Reichstürkenhilfe war es natürlich nur noch von sekundärer Bedeutung, daß in Eßlingen der Umfang dieser Hilfe wieder sehr knapp bemessen wurde. Ferdinands Gesandte beantragten eine stattliche und beharrliche Türkenhilfe, nannten dabei aber weisungsgemäß keine Zahlen, obgleich sie über die diesbezüglichen Wünsche und Erwartungen ihres Herm hinreichend informiert waren. Ferdinand hoffte, eine größere Hilfe als die restliche Romzugshilfe erlangen zu können, wollte sich aber auch mit dem Rest der Romzugshilfe zufriedengeben, wenn dieser über die sechs Monate hinaus als beharrliche Hilfe unterhalten wurde. Als Mindestforderung sollte die Leistung der restlichen Romzugshilfe gelten ${ }^{108}$. Die Kurfürsten und Fürsten waren indessen nur bereit, das Geld für die in Speyer bewilligte Türkenhilfe bei den vier einnehmenden Städten für den Fall eines neuen türkischen Angriffs gegen Ungarn im künftigen Frühjahr bereitzuhalten, um damit die deutschen Grenzfürsten unterstützen zu können. Zugleich wollten sie der Reichsdeputation, die über den Vollzug der Hilfe entscheiden sollte, die Vollmacht geben, die für sechs Monate bewilligte eilende Hilfe für drei Monate aufzustellen und die Zahl des Fußvolks zu verdoppeln ${ }^{100}$. Das Reichsregiment hielt die in Speyer beschlossene eilende Hilfe wegen der seither erfolgten Verwüstung Ungarns für unzureichend und trat dafür ein, zur Unterstützung der Grenzfürsten noch eine weitere und

105 Bericht der Gesandten Truchseß, Gundelfingen u. Widmann an Ferdinand v. 21. 12. 1526: HHStA/Wi, Urkundenreihe, 1526/November/20, fol. 16r-22r.

106 Abschied des Eßlinger 18-Fürstentages v. 21. 12. 1526: NS 2, S. 281-284 (s. bes. SS 9-13).

107 Bedenken der 6 Kurfürsten u. 12 Fürsten bzw. ihrer Botschafter: HHStA/Wi, Mainzer Erzkanzlei, Reichstagsakten, Fasz. 4d, Bd 1, fol. 377r-381r. Zweites Bedenken des Statthalteramtsverwesers und Regiments: ebd, fol. 389r-395v.

109 Bedenken der 6 Kurfürsten u. 12 Fürsten bzw. ihrer Botschafter: Nachweis in Anm. 107. 
stattlichere eilende Hilfe zu bewilligen ${ }^{110}$, konnte sich damit aber nicht durchsetzen. Ein anderer Vorschlag des Reichsregiments wurde nur mit großen Einschränkungen in den Eßlinger Abschied aufgenommen. Das Regiment empfahl, alle Reichsstände aufzufordern, bei einem türkischen Angriff den Grenzfürsten mit einer angemessenen Zahl von Reisigen und Fußknechten zuzuziehen. Diese allgemeine Hilfeleistung sollte zusätzlich zu der Hilfe des Reiches, die mit den Geldern der Romzugshilfe finanziert wurde, erfolgen ${ }^{111}$. Kurfürsten und Fürsten übernahmen den Vorschlag, machten aber die Einschränkung, daß lediglich die Grenzländer Osterreich, Sachsen, Brandenburg und Bayern aufgefordert werden sollten, einander im Falle der Not zuzuziehen ${ }^{112}$. Vergebens wandte das Regiment hiergegen ein, daß die Streitkräfte der Grenzländer zur Abwehr des großen türkischen Heeres nicht genügten ${ }^{113}$. Die Grenzfürsten blieben trotzdem weitgehend auf ihre eigenen Machtmittel angewiesen. Im Eßlinger Abschied wurden sie ermahnt, vorsorglich die Pässe oder festen Plätze gegen einen türkischen Einfall zu sichern und die Gegenwehr und wechselseitige Hilfe vorzubereiten ${ }^{114}$.

Eigentlich war es die Hauptaufgabe der Gesandten Erzherzog Ferdinands, in Eßlingen eine beharrliche Hilfe durchzusetzen. Zwischen dem Reichsregiment und den Kurfürsten und Fürsten bestand jedoch Übereinstimmung, daß die Eßlinger Versammlung eine derartig weitreichende Entscheidung nicht treffen konnte ${ }^{115}$. Infolgedessen wurde beschlossen, die Frage der beharrlichen Hilfe auf einem Reichstag in Regensburg beraten und entscheiden zu lassen, der am 1. April 1527 beginnen sollte. Um die Beschlußfähigkeit dieses Reichstages sicherzustellen, wurden die Stände aufgefordert, entweder persönlich zu erscheinen oder Gesandte mit ausreichenden Vollmachten abzuordnen ${ }^{116}$. Das Reichsregiment begnügte sich aber nicht mit der Ansetzung des neuen Reichstages, sondern wollte den Reichsständen zugleich eine Denkschrift über die beharrliche Türkenhilfe zusenden, damit diese mit ihren Untertanen das Vorhaben erörtern und in Regensburg ohne weitere Rüdkfragen über die Angelegenheit endgültig beschließen konnten 117. Das Reichsregiment verfaßte eine solche Denkschrift, die der Eßlinger Versammlung vorgelegt und mit dem Ausschreiben des Regensburger Reichstages vom 21. Dezember $1526^{118}$ als "Nottel oder verzaichnus einer beharrlichen hilf wider den Türcken " ${ }^{119}$ an die Reichsstände und Reichsstädte verschickt wurde.

Auf jedem der drei Nürnberger Reichstage in den Jahren 1522 bis 1524 war ein Entwurf für die beharrliche Türkenhilfe unter besonderer Berüdksichtigung der Finanzierungsweise hergestellt worden ${ }^{120}$. Diese drei Entwürfe riefen namentlich bei den Städten heftigen Widerspruch hervor. Auf dem Städtetag in Speyer im März 1523 entwarfen die Städtevertreter einen eigenen Plan für die Finanzierung

110 Zweites Bedenken des Statthalteramtsverwesers und Regiments: Nachweis in Anm. 107.

11 Erstes Bedenken des Statthalteramtsverwesers und Regiments: HHStA Wi, Mainzer Erzkanzlei, Reichstagsakten, Fasz. 4 d, Bd 1, fol. 356r-358v.

112 Bedenken der 6 Kurfürsten u. 12 Fürsten bzw. ihrer Botschafter: Nachweis in Anm. 107.

11a Zweites Bedenken des Statthalteramtsverwesers und Regiments: Nachweis in Anm. 107.

114 NS 2, S. 282, \$5 7-8.

$115 \mathrm{Vgl}$. Erstes Bedenken des Statthalteramtsverwesers und Regiments (Nachweis in Anm. 111) und Bedenken der 6 Kurfürsten u. 12 Fürsten bzw. ihrer Botschafter (Nachweis in Anm. 107).

116 NS 2, S. $281 \mathrm{f}$, $\$ \$ 1$-4.

117 Zweites Bedenken des Statthalteramtsverwesers und Regiments: Nachweis in Anm. 107.

116 Druck des Ausschreibens v. 21. 12. 1526: S. Stoy: Erste Bündnisbestrebungen evangelischer Stände (Separatdrudk aus der Zeitschrift für Thüringische Geschichte und Altertumskunde, Bd XIV), Jena 1888, S. 248-250 (zit. Stoy).

110 Druds Neukird, S. 197-214.

120 Vorschlag v. 30. 4. 1522: RTA III, Nr. 35, S. 188-197. Vorschlag von Ende Jan. 1523: RTA III, Nr. 72, S. 369-383. Vorschlag v. April 1524: RTA IV, Nr. 92, II. T., S. 445-451. 
der beharrlichen Hilfe ${ }^{121}$. Die Eßlinger Notel vom Dezember 1526 brachte die mehrjährigen Erörterungen zu einem gewissen Abschluß. Allerdings ließ sie noch manche Fragen offen. Sie vermied vor allem jede Angabe über die Größe und die Gesamtkosten einer beharrlichen Hilfe. Auch in den Akten der Nürnberger Reichstage wurden diese Punkte nur selten und unzureichend behandelt. Auf dem Wiener Tag im Sommer 1522 vertraten die ungarischen Gesandten die Ansicht, daß zur Wiedereroberung der von den Türken genommenen festen Plätze 300000 Mann erforderlich seien, da der Sultan 1521 mit 160000 bis 200000 Mann gegen Griechisch-Weißenburg vorgerückt sei und sein Heer in Zukunft auf 300000 Mann verstärken könne. Die ungarischen Gesandten schlugen vor, die erforderlichen 300000 Mann zu gleichen Teilen in Ungarn, Osterreich und Deutschland aufzubringen. Die deutschen Kriegsverständigen hielten dagegen insgesamt 100000 Mann zur Bezwingung der Türken bereits für ausreichend, da die Reichsstände nur geübtes Kriegsvolk zu schicken pflegten, welches den Türken überlegen sei ${ }^{122}$. In der Denkschrift des zweiten Nürnberger Reichstages wurde zu der Frage festgestellt, daß das Reich für eine beharrliche Hilfe 5000 gerüstete Reisige und 30000 Fußknechte mit Geschütz und Zubehör zwei bis drei Jahre lang unterhalten müsse ${ }^{123}$. Die Kosten dieser Streitmacht für die Dauer eines Jahres beliefen sich auf 3000000 Gulden, während die Romzugshilfe, sofern sie sechs Monate lang in ihrer Nominalstärke unterhalten wurde, 720000 Gulden erfordert hätte ${ }^{\mathbf{1 2 4}}$. Die beharrliche Türkenhilfe sollte offensiv und im Zusammenwirken mit anderen christlichen Gewalten geleistet werden ${ }^{125}$.

Alle Denkschriften der Jahre 1522 bis 1526 gingen davon aus, daß das Geld für die beharrliche Hilfe nicht durch Matrikularbeiträge der Reichsstände, sondern durch eine allgemeine Steuer aufzubringen sei. Uber Art und Höhe dieser Steuer gingen die Ansichten auseinander. Der Hauptstreitpunkt war die Behandlung der Kaufleute, Handwerker und Bauern. Sie sollten nach den ursprünglichen Absichten eine unverhältnismäßig hohe Vermögenssteuer zahlen, während die übrigen Personengruppen nur eine ziemlich niedrige Einkommensteuer zu entrichten gehabt hätten, die allerdings von den Geistlichen, soweit sie nicht Kurfürsten oder Fürsten waren, in doppelter Höhe zu leisten gewesen wäre. Später ermäßigte man die Anforderungen an die Kaufleute, Handwerker und Bauern und unterschied vor allem $\mathrm{zwischen} \mathrm{den} \mathrm{werbenden} \mathrm{Gütern,} \mathrm{mit} \mathrm{denen} \mathrm{die} \mathrm{Kaufleute} \mathrm{und} \mathrm{andere}$ Personen ihr Gewerbe trieben, und den sonstigen liegenden und fahrenden Gütern. Die werbenden Güter sollten doppelt so hoch besteuert werden wie die anderen Güter. Die Städte verwahrten sich gegen die starke Belastung der Gewerbetreibenden und machten auf dem Städtetag zu Speyer im März 1523 den Vorschlag, von allen Personen eine geringe Kopfsteuer in gleicher Höhe und eine progressive Vermögenssteuer zu verlangen ${ }^{126}$. Die Eßlinger Notel entschied diese schwierige Frage durch eine Regelung, die als Alternativvorschlag bereits in dem Entwurf des dritten Nürnberger Reichstages vom Jahre 1524 enthalten gewesen war, wenn

121 Der Vorschlag ist enthalten in dem Abschied des Speyerer Städtetages v. 22. 3. 1523: Stadtarchiv Ulm, Reichsstadt Ulm, 521.

122 RTA III, S. $203 \mathrm{f}$.

198 RTA III, S. 375 u. 382.

124 Für 20000 Fußknechte waren monatl. 80000 Gulden, für 4000 Reisige monatl. 40000 Gulden erforderlich. Das sind zusammen monatl. 120000 Gulden u. in 6 Monaten 720000 Gulden.

126 Später kam die Ansidht auf, daß eine allein durch die deutsche Nation aufgebrachte beharrliche Türkenhilfe defensiv, zum Schutze des Reiches und der anstoßenden Gebiete, verwendet werden könne. Vgl. V. v. Tetleben: Protokoll des Augsburger Reichstages 1530, hrsg. von H. Grundmann, Görtingen 1958, S. 177 (zit. Tetleben).

128 Nachweis des Vorschlages in Anm. 121. 
auch damals mit anderen Zahlen ${ }^{127}$. Und zwar sollten nach der Eßlinger Notel alle Personen sechs Jahre lang eine Vermögenssteuer zahlen, die jährlich für werbende Güter $0,2 \%$ und für die anderen Güter $0,1 \%$ betrug. Vergleicht man die Höhe der verschiedenen Steueranschläge in den Jahren 1522 bis 1526, so ergibt sich, daß diejenigen Personen, die nach den früheren Projekten Einkommensteuer zahlen sollten, durch die Vermögenssteuer der Eßlinger Notel ebenso hoch belastet wurden wie durch die Einkommensteuer der drei Nürnberger Entwürfe in Höhe von $2 \%$. Da nämlich die übliche Verzinsung $5 \%$ betrug, entsprach die Einkommensteuer von $2 \%$ einer Vermögenssteuer von $0,1 \%$. Ganz anders verhielt es sich jedoch bei den Kaufleuten. Diese sollten nach dem Entwurf des ersten Nürnberger Reichstages für werbende oder sonstige Güter 1 \% Vermögenssteuer abführen. Die Eßlinger Notel verlangte dagegen nur noch eine Vermögenssteuer von $0,2 \%$ für die werbenden und von $0,1 \%$ für die sonstigen Güter, das heißt, die ursprünglich vorgesehenen Anforderungen an die Kaufleute waren fünfmal beziehungsweise zehnmal so hoch wie diejenigen der Eßlinger Notel und wie die Belastung der nichtgewerbetreibenden und nichtgeistlichen Personen durch die Einkommensteuer, welche die Entwürfe der drei Nürnberger Reichstage empfohlen hatten. Für einige Personengruppen sah die Eßlinger Notel Sonderregelungen vor. Die Geistlichen mit Ausnahme der Kurfürsten und Fürsten sollten in Ubereinstimmung mit den Nürnberger Projekten mit einer Einkommensteuer von $4 \%$ belegt werden. Die Diener und Dienstboten sollten 0,5\% Einkommensteuer bezahlen. Von den Juden wollte man ein jährliches Kopfgeld von 1 Gulden und eine sehr hohe Vermögenssteuer von $1 \%$ verlangen. Alle Steuerpflichtigen sollten sich selbst veranlagen. Den Papst wollte man ersuchen, der deutschen Nation die Annaten zur Verwendung für die Türkenhilfe zu belassen. Die Vorschläge der Eßlinger Notel für die Steuer der beharrlichen Hilfe bedeuteten insofern einen Fortschritt gegenüber den Projekten der Nürnberger Reichstage, als sie die unterschiedliche Behandlung der gewerbetreibenden und nichtgewerbetreibenden Bevölkerungsgruppen wesentlich milderten, ohne sie freilich ganz zu beseitigen.

Mit der Einziehung und der Verwahrung der Steuergelder für die beharrliche Türkenhilfe sollten nach den Entwürfen der Nürnberger Reichstage die Reichsstände und Reichsstädte betraut werden. Die Eßlinger Notel wich hiervon ab, indem sie die Abführung der eingenommenen Gelder aus den Territorien und Städten an die Reichskreise vorschrieb. Auch die Aufbringung der Truppen sollte im Kreisverband erfolgen. Man wollte also die Kreise zu Reichsmilitärverwaltungsbezirken machen, wie es dann während der Türkenkriege von 1532 und 1542 zeitweise tatsächlich geschehen ist und wie es die Exekutionsordnung von 1555 für die Wahrung des Landfriedens im Innern des Reiches und die Reichsdefensionalordnung von 1681 für die Reichsverteidigungsmaßnahmen vorschrieben. Nach der Eßlinger Notel sollte die neue Ordnung zunächst nur für sechs der zehn Kreise gelten, das heißt, sie sollte sich nicht auf den Burgundischen, Osterreichischen, Kurrheinischen und Obersächsischen Kreis beziehen, in denen die Territorien der Habsburger und der Kurfürsten lagen. Zur Wahrnehmung ihrer militärischen Belange sollten die Stände der 6 Kreise jeweils 6 Kreiseinnehmer, 1 Kriegsrat, 1 Pfennigmeister und 1 Hauptmann bestellen. Die Eßlinger Notel enthielt detaillierte Vorschriften für die Tätigkeit dieser Funktionäre. Aufgabe der sechs Kreiseinnehmer war es hiernach, die Steuergelder an einem bestimmten Ort im Kreis in Empfang zu nehmen und zu verwahren. Der Kriegsrat und der Pfennigmeister sollten dem Obersten Kriegsherrn oder dem Obersten Hauptmann 
zugeordnet werden. Auf Anforderung des Obersten Kriegsherrn oder der ihm zugeordneten Kriegsräte mußte das Kriegsvolk von den Kreisen aufgebracht und mit einem Hauptmann versehen werden. Für die Musterung des Kriegsvolkes waren der Kriegsherr und die Kriegsräte zuständig. Die Kriegssteuereinnahmen des Kreises sollten von dem Pfennigmeister nach den Anweisungen des Kriegsherrn und der Kriegsräte ausgegeben werden.

Die Regelung der Besteuerung und die Nutzbarmachung der Kreise für die Organisation der beharrlichen Hilfe waren die Hauptanliegen der Eßlinger Notel. Die auf den früheren Reichstagen immer wieder betonte Notwendigkeit, die Mithilfe der anderen christlichen Herrscher für die beharrliche Hilfe zu erwirken, fand dagegen in der Notel nur andeutungsweise Erwähnung. Die Eßlinger Versammlung ridhtete jedoch an den Kaiser am 19. Dezember 1526 ein Schreiben, in dem die Vorbedingungen für die beharrliche Türkenhilfe genannt wurden. In diesem Schreiben verlangte die Versammlung die Beteiligung des Kaisers und der anderen christlichen Herrscher an der beharrlichen Türkenhilfe, sie erbot sich, eine Vermittlungsaktion durchzuführen, um eine Beendigung der Kriegshändel Karls V. zu ermöglichen, und sie forderte den Kaiser auf, im Reich Einigkeit und Frieden herzustellen und zu diesem Zwedk baldmöglichst nach Deutschland zu kommen ${ }^{128}$. Die Forderung der Wiederherstellung von Einigkeit und Frieden im Reich bezog sich auf den Glaubenszwiespalt. Sie bedeutete eine Neuerung. Der Nürnberger Reichsabschied vom 18. April 1524 hatte zwar schon einen "gemeinen Frieden im Reich" zur Vorbedingung für die beharrliche Türkenhilfe gemacht ${ }^{129}$. Die Eßlinger Formel war jedoch viel weitgehender. Um ihr Genüge zu tun, hätte der Kaiser Altgläubige und Evangelische zu einer einheitlichen Handhabung des Kirchenwesens veranlassen müssen. Die Reichsstände hatten bereits von sich aus versucht, eine solche Regelung auf der Speyerer Nationalversammlung zu Martini 1524 und auf dem Speyerer Reichstag 1526 zustande zu bringen, waren daran aber vom Kaiser gehindert worden, der ihnen die Befugnis zur eigenmächtigen Änderung des Kirchenwesens absprach. Auf dem Speyerer Reichstag 1526 beschlossen sie daraufhin, Karl V. durch eine Reichsgesandtschaft zu bitten, baldmöglichst ins Reich zu kommen und binnen einem oder anderthalb Jahren die Durchführung eines Generalkonzils oder einer Nationalversammlung in Deutschland zu ermöglichen, um wieder Einigkeit und Frieden im Reich herzustellen ${ }^{130}$. Die Reichsgesandtschaft sollte eigentlich von der Eßlinger Versammlung abgefertigt werden, hierzu ist es aber aus ungeklärten Gründen nicht gekommen ${ }^{131}$. Vielleicht befürchteten die altgläubigen Stände, von denen ja 16 in der Eßlinger Versammlung vertreten waren, daß der Kaiser den Evangelischen, da er seit Mai 1526 im Krieg mit dem Papst stand, zu weit entgegenkommen könnte. Ein gewisser Ausgleich für die Verhinderung der Reichsgesandt-

128 Undatierte Kopie im GStA/Mü, Kasten schwarz 4203, fol. 146r-149v. - Das Datum ist vermerkt in RTA VII-2, S. 1005/Z. 24.

120 Daß sich die Wendung "Einigkeit und Frieden im Reich» auf die Beilegung des Glaubenszwiespaltes bezog, ergibt sich aus anderen Textstellen, wo diese Wendung mit entsprechenden Erläuterungen gebraucht wird. Vgl. hierzu die Instruktion für die auf dem Speyerer Reidhstag 1526 beschlossene Reichsgesandtschaft zum Kaiser (Friedensburg, S. 563, letzte Zeile) und das Ständebedenken auf dem Regensburger Reichstag 1527 (RTA VII-2, S. 1001/Z. 29-30 u. 41-43). Zur Wendung rom "gemeinen Frieden im Reich» im Nürnberger Reichsabschied v. 18. 4. 1524, vgl. RTA IV, S. 608/Z. 3.

$130 \mathrm{Vgl}$. W. Steglic: Die Stellung der evangelischen Reichsstände und Reichsstädte zu Karl V. zwischen Protestation und Konfession 1529/30 - Ein Beitrag zur Vorgeschichte des Augsburgischen Glaubensbekenntnisses, in: Archiv für Reformationsgeschichte, Jg. 62, 1971, S. 163 f. (zit. Steglich). 
schaft war es nun, daß die Eßlinger Versammlung in ihrem Schreiben an den Kaiser die Notwendigkeit der Beilegung des Glaubenszwiespaltes betonte. Sie verzichtete dabei zwar auf die Konzilsforderung, aber sie gab dem Antrag durch die Verknüpfung mit dem Projekt der beharrlichen Türkenhilfe größeren Nachdruck. $\mathrm{Zu}$ befürchten war freilich, daß mit dieser Kombination eher die beharrliche Hilfe verhindert, als die Wiederherstellung von Einigkeit und Frieden im Reich gefördert werden würde.

Die Gesandren Erzherzog Ferdinands wurden über die Beschlüsse der Speyerer Versammlung erst informiert, als bereits einige Fürsten abgereist und andere im Aufbruch waren. Hierdurch wurde es ihnen unmöglich gemacht, eine nochmalige Erörterung der Türkenhilfe zu erzwingen. Sie konnten lediglich im Namen ihres Herrn und seiner Landstände wegen der gefaßten Beschlüsse Erschrecken, Beschwerung und Befremden äußern. Ein Versuch, wenigstens den sofortigen Vollzug der auf dem Speyerer Reichstag 1526 beschlossenen eilenden Türkenhilfe zu erwirken, fand Ablehnung ${ }^{132}$. Mit der Zurüdkweisung der Wünsche Ferdinands auf dem Eßlinger 18-Fürstentag begann eine neue Phase der Türkenhilfspolitik der Reichsstände. Während früher eine gewisse Hilfsbereitschaft gegenüber Ungarn immerhin bestand, wurde jetzt der Gesichtspunkt maßgebend, das Reich nicht durch die Gewährung einer Türkenhilfe für die Zwedke der habsburgischen Hausmachtpolitik in Südosteuropa in Anspruch nehmen zu lassen.

Ferdinand ließ sich durch die Eßlinger Beschlüsse in seinen Bemühungen um eine Hilfe aus dem Reich für den Ungarn- und Türkenkrieg nicht entmutigen. Er ging dabei allerdings jetzt neue Wege. Am 13. Januar 1527 schickte er an die Reichsstände und Reichsstädte 25 Gesandte aus, die bei ihnen direkt um eine Truppenoder Geldhilfe für seinen Zug nach Ungarn werben sollten. Die ${ }^{-}$Hilfe wurde als "Reiterdienst" bezeichnet und für sechs Monate erbeten. Die Gesandten sollten über den $Z$ weck des Zuges mitteilen, Ferdinand wolle Zápolya und seine Anhänger, sofern sie von ihrer Gegnerschaft und ihrer türkenfreundlichen $\mathrm{Hal}$ tung nicht abließen, strafen und dann mit den gehorsamen Ungarn den Türken entgegentreten. Begründet wurde das Verlangen eines *Reiterdienstes« gegen die Türken und Zápolya mit den Abgängen und Verzögerungen, welche bei der eilenden Hilfe infolge der Eßlinger Beschlüsse zu erwarten seien. Ferdinands Werbungen waren nicht besonders erfolgreich. Die Mehrheit der Stände verschob eine Stellungnahme bis zum Regensburger Reichstag, einige lehnten sofort $a b$, und nur neun Stände bewilligten eine Hilfe ${ }^{138}$. Immerhin war aber die Umgehung der zentralen Reichsinstanzen bei der Truppenaufbringung nicht ganz ohne Ergebnis geblieben, und zwei Jahre später sollte sich zeigen, daß dieses Verfahren in einer gefahrvollen Situation sogar sehr gute Wirkungen haben konnte. 1527 fehlte eben bei den meisten Reichsständen das Einverständnis mit den politischen Zielen Ferdinands.

Die schärfsten Widersacher der habsburgischen Südostpolitik waren die beiden Bayernherzöge Ludwig und Wilhelm. Sie hatten sich als Rivalen Ferdinands vergeblich um die böhmische Königskrone beworben und strebten in Konkurrenz zu Ferdinand danach, die Wahl eines römischen Königs, die damals wegen der langen Abwesenheit des Kaisers erwogen wurde, auf sich zu lenken. Eine Vergrößerung der habsburgischen Hausmacht durch den Erwerb Ungarns widersprach diesen Tendenzen. Um sie zu verhindern, traten die beiden Herzöge in Kontakt

132 Bericht der Gesandten Truchseß, Gundelfingen u. Widmann an Ferdinand v. 21. 12. 1526: Nachweis in Anm. 105.

139 RTA VII-1, S. 8-12. 
zu Zápolya, stellten ihm eine Reichshilfe gegen die Türken in Aussicht, schlugen ihm vor, seinen Streit mit Ferdinand durch einen Schiedsspruch der Kurfürsten zu beenden, und forderten ihn auf, den Regensburger Reichstag zu beschicken. Zápolya ging auf diese Empfehlungen ein und fertigte zwei Gesandte mit eingehenden Weisungen für eine Werbung um Türkenhilfe nach Regensburg ab. Die Mission scheiterte, da Ferdinand die Gesandten in Osterreich festhalten und zurüdkschicken ließ ${ }^{134}$. Einer Vermittlungsaktion der Kurfürsten kam Ferdinand zuvor, indem er Ende März 1527, einen Monat nach seiner Krönung zum König von Böhmen in Prag, Ausgleidhsverhandlungen mit Zápolya unter polnischem Vorsitz zugestand. Bis zu ihrer Durchführung im Juni 1527 in Olmütz herrschte Waffenruhe zwischen den beiden ungarischen Königen. Ferdinand war im Grunde zu einem Vergleich mit Zápolya gar nicht bereit, sondern ließ sich auf die Olmützer Verhandlungen nur ein, um Zeit für Kriegsrüstungen zu gewinnen und die Reichsfürsten von einer Einwirkung auf den Thronstreit abzuhalten ${ }^{135}$.

Während des Waffenstillstandes zwischen Ferdinand und Zápolya fand vom 27. April bis 18. Mai 1527 der Regensburger Reichstag statt. Er wurde schlecht und von seiten der Fürsten nur durch Botschafter besucht ${ }^{136}$. Auch König Ferdinand konnte an ihm nicht persönlich teilnehmen. Seine Gesandten stellten in der Reichsversammlung den Antrag, die in Speyer und Eßlingen bewilligte eilende Türkenhilfe ihrem Herrn zur Verfügung zu stellen. Sie sollte zusammen mit anderen Truppen aus den Ländern Ferdinands zur Rückeroberung der Schlösser und Pässe, welche die Türken 1526 eingenommen hatten, und zur Bekämpfung Zápolyas, falls dieser das Unternehmen zu verhindern suchte, Verwendung finden ${ }^{197}$. Die Reichsversammlung lehnte den Antrag der Gesandten mit der Begründung ab, $\mathrm{da} ß$ sie an den Bestimmungen der Abschiede von Speyer und Eßlingen über den Vollzug der eilenden Türkenhilfe nichts ändern könne. In diesen Bestimmungen sei geregelt, wie die Hilfe gebraucht und wie von den Bedürftigen um die Hilfe nachgesucht werden solle ${ }^{138}$. Die Reichsversammlung weigerte sich also, die Befugnisse der Reichsdeputation zum Vollzug der eilenden Türkenhilfe selbst wahr-

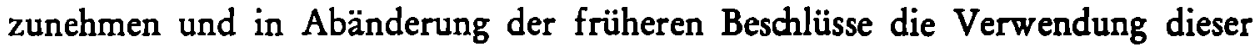
Hilfe auch gegen Zápolya zuzulassen.

Noch unergiebiger als die Beratungen über die eilende Hilfe war die Stellungnahme des Regensburger Reichstages zur beharrlichen Hilfe. Wegen des ungenügenden Besuches des Reichstages wurde über diesen Punkt überhaupt nicht verhandelt. Das Reichsregiment und die anwesenden Botschaften baten statt dessen den Kaiser in einem Schreiben vom 18. Mai 1527 um die Einberufung eines neuen Reichstages, auf dem erörtert werden sollte, wie die Türkengefahr abgewendet und die deutsche Nation und ihre Glieder "in fridlich einig wesen " gebracht werden könnten. Außerdem wurde der Kaiser erneut aufgefordert, einen allgemeinen Frieden in der Christenheit oder wenigstens einen "anstand" in den bestehenden Irrungen unter den christlichen Häuptern herbeizuführen ${ }^{139}$. Hätte sich die Regensburger Reichsversammlung mit der Eßlinger Notel befaßt, so wäre diese keineswegs unumstritten geblieben. Aus der Instruktion für den Kölner Reichstagsgesandten kann entnommen werden, daß man auf städtischer Seite

134 Smolka, S. 140 f.; RTA VII-1, S. 4 f., 26, 37, 71, 79 f.; RTA VII-2, Nr. 3 u. 21, S. 976-979 u. $996 \mathrm{f}$.

135 Smolka, S. 141-149.

180 Liste der Anwesenden am Schluß des Reichsabschiedes: RTA VII-2, S. 1003 f.

197 RTA VII-2, Nr. 22, S. $997-999$.

198 RTA VII-2, S. $1002 / \mathrm{Z}$. 20-24.

130 RTA VII-2, S. 1000-1002 u. Nr. 24, S. 1005 f. 
die Besteuerung des werbenden Gutes in doppelter Höhe und die bei dem vorgesehenen Besteuerungsverfahren notwendige Offenlegung des Vermögens der Bürgerschaften der Städte sehr beanstandete. Besorgnisse bestanden auch, daß die Besteuerung des gemeinen Mannes, der ohnehin stark mit Abgaben beladen war, nicht ohne einen weiteren Aufruhr abgehen würde ${ }^{140}$.

Für den neuen Reichstag, der über Türkenhilfe, Glaubenszwiespalt und Aufrichtung von Einigkeit und Frieden im Reich beraten sollte, empfahl der Kaiser am 1. August 1527 Regensburg als Tagungsstätte und den 11. November 1527 als Eröffnungstermin. Er überließ es jedoch Statthalter und Regiment, den Reichstag auszuschreiben ${ }^{141}$. Diese aber beriefen ihn erst zum 2. März 1528 nach Regensburg ein ${ }^{142}$. Bis zu diesem Zeitpunkt änderte sich die allgemeine Lage erheblich. Die Olmützer Ausgleichsverhandlungen scheiterten nach 14-tägiger Dauer Mitte Juni 1527. Ferdinand unternahm daraufhin unverzüglich den Feldzug zur Besitzergreifung Ungarns. Es standen ihm 8000 Fußknechte und 3000 Reisige zur Verfügung. Herzog Georg von Sachsen und Herzog Erich I. von BraunschweigCalenberg hatten deutsche Hilfstruppen entsandt. Zápolya verfügte zunächst nur über 3000 Mann. Er hatte in Erwartung eines friedlichen Ausgleiches die Kriegsvorbereitungen vernachlässigt. Ferdinand konnte am 20. August Ofen ohne Kampf einnehmen. Die sogleich dorthin beschriebenen ungarischen Stände bestätigten am 7. Oktober 1527 die Königswahl Ferdinands. Am 3. November 1527 wurde Ferdinand in Stuhlweißenburg mit der Stephanskrone gekrönt. Zápolya zog sich nach Siebenbürgen zurüdk und tat Ende 1527 jenen Schritt, den ihm Ferdinand bereits seit der Schlacht bei Mohács wiederholt unterstellt hatte. Er schickte den polnischen Magnaten Hieronymus Lasky als Unterhändler zur Pforte, um ein Hilfsbündnis mit dem Sultan zu vereinbaren. Am 29. Februar 1528 wurde ein Vertrag abgeschlossen, der Zápolya die Hilfe der Türken gegen das Haus Osterreich sicherte, ohne Ungarn tributpflichtig zu machen. Kurze Zeit nach dem Vertragsabschluß flüchtete Zápolya nach einer letzten militärischen Niederlage nach Polen ${ }^{143}$.

König Ferdinand hatte während des Streites um die ungarische Krone immer die Auffassung vertreten, daß Zápolya wegen seiner geringen Machtmittel einem künftigen Angriff der Türken gegen die Christenheit keinen Widerstand leisten könne und daß infolgedessen die Einbeziehung Ungarns in den habsburgischen Machtbereich im Interesse der Christenheit liege ${ }^{144}$. Der Bündnisabschluß zwischen Zápolya und Suleiman beschwor nun aber eine neue Gefahr für das christliche Abendland herauf. Aus dem Thronstreit zwischen Ferdinand und Zápolya entwickelte sich ein Konflikt zwischen Ferdinand und dem Sultan, das heißt, die habsburgische Expansion in Ungarn steigerte die Türkengefahr für die österreichischen Erblande und das Reich.

Im Jahre 1528 trat diese neue Komplikation noch nicht in Erscheinung. Trotzdem bemühte sich Ferdinand vorsorglich um eine Hilfe des Reiches für den Abwehrkampf gegen die Türken. Er beabsichtigte, zu diesem Zwedk den neuen Reichstag in Regensburg persönlich zu besuchen ${ }^{145}$. Kaiser Karl kündete den Reichstag jedoch im letzten Augenblidk ohne vorherige Unterrichtung seines Bru-

140 RTA VII-2, S. 982.

141 RTA VII-2, Nr. 26, S. 1009 f.

142 RTA VII-2, Nr. 27, S. 1010 f.

143 Fessler, S. 420-431; H. Kretschmayr: Ludovico Gritti, in: Archiv für österreichische Geschichte, Bd 83, 1897, S. 13-16.

144 RTA VII-2, S. 994/Z. 17-19, S. 998/Z. 38 - S. 999/Z. 4.

145 Kühn, S. 21. 
ders ab, weil er für seinen Krieg mit Frankreich und England direkt bei den einzelnen Reichsständen Truppenhilfe erbitten und diese Aktion nicht durch Verhandlungen einer Reichsversammlung über die Türkenhilfe beeinträchtigen lassen wollte ${ }^{146}$. Ferdinand blieb unter diesen Umständen nur übrig, den Zusammentritt der Reichsdeputation für den Vollzug der eilenden Türkenhilfe zu betreiben, um von ihr wenigstens die in Speyer und Eßlingen bewilligten Truppen zugeordnet zu bekommen. Der Deputationstag wurde mit Zustimmung der süddeutschen Mitkommissare Ferdinands auf den 1. Juli 1528 nach Regensburg einberufen und tagte unter dem Eindruck der sogenannten Packschen Händel. Die Deputation lehnte den Vollzug der Hilfe ab, weil das Bevorstehen eines türkischen Angriffes nicht erwiesen war. Eine gewisse Bedeutung erlangte der Deputationstag trotzdem, weil auf ihm die Frage erörtert wurde, ob die Bestimmungen des Eßlinger Abschiedes über den Vollzug der eilenden Türkenhilfe noch gültig seien und eine Verwendung der Hilfe in Ungarn zuließen. Wohl von bayerischer Seite wurde behauptet, der Eßlinger Abschied sei gefallen und die Reichsdeputation nicht mehr berechtigt, die in Speyer und Eßlingen 1526 bewilligte Hilfe zum Einsatz zu bringen, weil sich die damaligen Beschlüsse nur auf einen türkischen Angriff im Frühjahr und Sommer 1527 bezogen hätten. Osterreich, Kursachsen und Kurbrandenburg bestritten das und vertraten außerdem abweichend von den anderen Mitgliedern der Deputation die Auffassung, daß die Hilfe nicht nur den deutschen Grenzfürsten, sondern auch dem Königreich Ungarn geleistet werden dürfe ${ }^{147}$. Eine Entscheidung der Kontroverse brachte erst der nächste Reichstag, der vom 15. März bis 22. April 1529 in Speyer stattfand.

Der Speyerer Reichstag 1529 hat wegen der Religionsverhandlungen und der Protestation der Evangelischen gegen den Reichsabschied seine große historische Bedeutung erlangt, sollte aber nach dem Willen seines Initiators, des Königs Ferdinand, zuerst und vornehmlich über die Türkenhilfe beraten. Ferdinand gelang es nicht, die Reichsversammlung auf diese Reihenfolge festzulegen. Glaubenszwiespalt und Türkenhilfe wurden vielmehr gleichzeitig erörtert. Hinsichtlich der beharrlichen Hilfe kam die Reichsversammlung über die Stellungnahme der vorausgegangenen Reichstage nicht wesentlich hinaus. Bemerkenswert an der neuen Behandlung des Problems ist lediglich, daß neben der Beendigung der Kriegshändel in der Christenheit und neben der Teilnahme des Kaisers und anderer christlicher Herrscher an dem beharrlichen Kriegszug jetzt nicht mehr entsprechend dem Eßlinger Abschied die Wiederherstellung von Frieden und Einigkeit im Reich, sondern nur noch entsprechend dem dritten Nürnberger Abschied ein gesicherter allgemeiner Frieden im Reich zur Voraussetzung für die beharrliche Hilfe gemacht wurde ${ }^{148}$. Die Reichsstände verzichteten also darauf, die beharrliche Hilfe bis zur Beilegung des Glaubenszwiespaltes aufzuschieben. In einem Schreiben vom 20. April 1529 wurde dem Kaiser von den derartig modifizierten Vorbedingungen der beharrlichen Hilfe Kenntnis gegeben ${ }^{149}$.

Als eilende Türkenhilfe bewilligte die altgläubige Reichstagsmehrheit 1529 zusätzlich zu den seit 1526 nicht mehr zurüdkgezahlten Hilfsgeldern den ganzen Rest der Romzugshilfe, das heißt 1/2 Viertel der Fußknechte für sechs Monate, 11/2 Viertel der Fußknechte für drei Monate und alle Reisigen. Das Geld für diese Truppen sollte bis zum 25. Juli 1529 in Augsburg, Nürnberg oder Frank-

146 Ebd., S. 22, 29-31.

147 RTA VII-1, S. 313-319; RTA VII-2, S. 1052-1058.

148 RTA VII-2, S. 1303/Z. 11-21, S. 1151/Z. $29-$ S. 1152/Z. 21.

140 RTA VII-2, Nr. 142, S. $1269-1273$ (bes. S. 1272/Z. $9-$ S. 1273/Z. 2). 
furt erlegt und zusammen mit den früher gezahlten Beträgen nach Augsburg und Regensburg gebracht werden, weil beide Städte dem Kriegshandel "gelegen « seien. Sicher war es kein Zufall, daß gerade diejenigen Städte zur Abführung des eingenommenen Geldes nach Augsburg oder Regensburg veranlaßt wurden, welche der reformatorischen Bewegung anhingen ${ }^{150}$.

Die eilende Reichstürkenhilfe, welche auf Grund der Speyerer Beschlüsse von 1529 verfügbar wurde, war die größte seit 1521 . Anlaß für ihre Bewilligung waren Meldungen über einen bevorstehenden neuen großen Heereszug der Türken gegen Ungarn und die Christenheit. Für den Vollzug der Hilfe blieben die Bestimmungen des Eßlinger Abschiedes 1526 mit einigen Modifikationen gültig. Die Hilfe wurde Ungarn und den anstoßenden deutschen Fürstentümern zugesprochen, sollte aber nur zur Gegenwehr und zum Widerstand gegen die Türken bei einem "gewaltigen Heerzug « gegen jene Länder gebraucht werden. Den Fürsten der Reichsdeputation wurde aufgegeben, durch Kundschafter die Maßnahmen der Türken ständig zu überwachen und im Notfall das Türkenhilfsgeld in Empfang zu nehmen, um davon Hauptleute und Kriegsvolk zu Roß und Fuß zu bestellen und dem König von Ungarn zuzuschidken. Als Tagungsort der Reichsdeputation sollte nur noch Regensburg dienen. Von den Mitgliedern der Reichsdeputation wurde Pfalzgraf Friedrich, da er das Amt des Obersten Feldhauptmanns übernehmen sollte, durch den Erzbischof Matthäus von Salzburg ersetzrt $^{151}$. Neu an den Bestimmungen über den Vollzug der Reichshilfe war, daß jetzt der König von Ungarn ausdrücklich als Empfänger der Hilfe genannt und daß strenger als bisher die defensive Verwendung der Hilfe ausschließlich gegen die Türken vorgeschrieben wurde.

Im Verlauf des Reichstages beauftragten die Reichsstände die Reichsdeputation, mit König Ferdinand zu verhandeln, um den Beitrag seiner Länder zum Türkenkrieg und speziell seine Bestände an Artillerie und die Regelung der Proviantversorgung in Erfahrung $\mathrm{zu}$ bringen ${ }^{152}$. Die Verhandlungen fanden am 16. April 1529 statt und sollten wohl einen Ersatz für die früher angestrebte Kooperationsvereinbarung mit König Ludwig von Ungarn bilden. Ferdinand stellte beträchtliche Truppenhilfen und Geldmittel aus Böhmen, Mähren, Schlesien und den österreichischen Erblanden in Aussicht, obgleich er hierüber selbst noch gar keinen zuverlässigen Úberblick besaß ${ }^{159}$. Vor allem aber benutzte er die Verhandlungen mit der Reichsdeputation zu dem Versuch, die Beschlüsse der Reichsstände über die Verwendung der Reichshilfe zu modifizieren. Er schlug vor, auf die zeitraubenden Erkundungen der Reichsdeputation zu verzichten und auf Grund der bisher vorliegenden Meldungen die bewilligte Reichshilfe baldigst aufzustellen und nach Ungarn zu führen, um entweder den vorrüdkenden Türken eine Schlacht zu liefern oder beim Ausbleiben einer türkischen Offensive die verlorenen Befestigungen bis einschließlich Griechisch-Weißenburg zurückzuerobern. Außerdem forderte er die Reichsstände auf, die Hälfte der Kosten für 100 Geschütze auf Rädern zu übernehmen und die zahlenmäßige Stärke der Reichshilfe nicht von den eingehenden Geldern abhängig zu machen, sondern die als Türkenhilfe verwendete Romzugshilfe in ihrer Nominalstärke zu leisten ${ }^{154}$. Die Wünsche

1so RTA VII-2, S. 1301/Z. 18 - S. 1302/Z. 27, S. 1147/Z. 31 - S. 1149/Z. 13.

161 Die neue Besetzung ist erstmalig nachweisbar bei den Beratungen in Speyer am 27./28. 4. 1529 über die Bestallung Pfalzgraf Friedrichs als Oberster Feldhauptmann der eilenden Reichstürkenhilfe. Vgl. RTA VII-1, S. 861.

152 RTA VII-1, S. 756.

153 Vgl. RTA VIII-2, S. 835/Z. 14-18.

164 RTA VII-1, S. 757/Z. 2 - S. 758/Z. 3; RTA VII-2, Nr. 133, S. 1251-1254. 
Ferdinands wurden durchweg abgelehnt. Auf seine beiden Alternativvorschläge für den Feldzug im Jahre 1529 erwiderten die Deputierten, daß damit die deutsche Nation verfrüht in die beharrliche Hilfe gezogen werden würde und daß ein Fehlschlag der Unternehmungen eine demoralisierende Wirkung auf die deutsche Nation haben könne ${ }^{155}$.

Auch die Evangelischen beteiligten sich an den Verhandlungen über die Türkenhilfe. Sie versuchten vergeblich, ihren Einfluß auf die Reichsdeputation zum Vollzug der Hilfe zu verstärken, indem sie vorschlugen, den Markgrafen Georg von Brandenburg-Ansbach und die Reichsstadt Nürnberg zu Mitgliedern der Deputation zu machen ${ }^{156}$. Nach ihrer Protestation gegen die Beschlüsse der Reichstagsmehrheit in der Glaubensfrage vertraten die Evangelischen die Ansicht, daß sie an keinen Teil des neuen Reichsabschiedes mehr gebunden seien, das heißt, in dem Augenblidk, wo es zur Separation der Evangelischen wegen des Glaubenszwiespaltes gekommen war, wurde auch die bislang bestehende Ubereinstimmung der Reichsstände und Reichsstädte bei der Handhabung der Türkenabwehr in Frage gestellt. Allerdings erwies sich dann sehr schnell, daß die Protestierenden in den weltlichen Sachen zum Einlenken bereit waren. Sie bemühten sich nach ihrer Protestation, den Kaiser zur vorläufigen Tolerierung ihres Standpunktes in der Glaubensfrage bis zum geplanten Generalkonzil zu bewegen. Und im Rahmen dieser Aktion versprachen sie ihm die Leistung der Türkenhilfe. Die Ubermittlung der Zusage erfolgte durch eine Gesandtschaft, die das Verhalten der Protestierenden in Speyer rechtfertigen sollte und am 12. September 1529 im kaiserlichen Hoflager zu Piacenza Karl V. ihre Werbung vortrug und schriftlich übergab ${ }^{157}$. Schon vorher, Ende Juni 1529, hatte Kursachsen auf einer Tagung der Reichsdeputation in Regensburg die gleiche Erklärung zur Türkenhilfe, die dem Kaiser übermittelt wurde, bekanntgeben lassen ${ }^{158}$.

Der Zusammentritt der Reichsdeputation am 24. Juni 1529 in Regensburg war noch in Speyer zu dem Zwedke vereinbart worden, über die Bestallung Pfalzgraf Friedrichs und über andere Angelegenheiten der eilenden Hilfe zu beschließen. Ferdinand hatte seither Meldungen aus Konstantinopel erhalten, nach denen der Aufbruch des türkischen Heeres gegen Ungarn am 10. Mai 1529 erfolgt sein sollte ${ }^{159}$. Die Nachrichten waren zutreffend. Suleiman verließ mit einem Heer von 250000 bis 300000 Mann und mit 300 Geschützen am 10. Mai 1529 Konstantinopel, am 30. Juni erreichte er Nisch, am 14. Juli die Save bei GriechischWeißenburg, der Übergang über die Save konnte bis zum 3. August, der Übergang über die Drau bis zum 15. August beendet werden. Vom 10. bis 20. August lagerte das türkische Heer bei Mohács. Während dieser Zeit trafen Johannes Zápolya und Hieronymus Lasky beim Sultan ein. Suleiman empfing Zápolya als den von ihm anerkannten König von Ungarn, Zápolya huldigte dem Sultan, indem er ihm die Hand küßte. Am 8. September kapitulierte Ofen vor den Türken, Zápolya konnte sein Hoflager in der Königsburg zu Ofen aufschlagen. Am 14. September brach der Sultan mit seinem Heer von Ofen gegen Wien auf, am 26. September erreichten seine Truppen die Hauptstadt der österreichischen Erblande ${ }^{160}$.

166 RTA VII-1, S. 762/Z. 6-13, S. 772/Z. 28-32; RTA VII-2, Nr. 135, S. 1256-1258.

66 RTA VII-2, S. 1215/Z. 6-10.

157 S. Steglich, S. 166-173.

159 RTA VIII-2, S. 845.

150 RTA VII-1, S. 861 ; RTA VIII-2, S. 840 f.

100 L. Kupelwieser, Die Kämpfe Osterreichs mit den Osmanen vom Jahre 1526 bis 1537, Wien, Leipzig 1899, S. 17-21 (zit. Kupelwieser: Osterreich); Hammer-Purgstall, S. 81-84. 
Auf dem Regensburger Deputationstag Ende Juni 1529 war dieser zügige Verlauf des türkischen Vormarsches nicht vorauszusehen. Aus den vorgelegten Kundschaften ergab sich jedoch, daß der Sultan mit seiner ganzen Macht aufgebrochen war und auf Griechisch-Weißenburg zuzog. Ein Angriff gegen das Königreich Ungarn und gegen die anstoßenden deutschen Länder schien bevorzustehen. Ferdinand war auf dem Deputationstag persönlich anwesend, er schilderte weinend die bedrohliche Lage und versuchte mit höchstem Eifer, den Vollzug der Reichshilfe durchzusetzen. Aber er stieß bei ein oder zwei Deputationsmitgliedern auf Widerspruch ${ }^{101}$. Und es wurden infolgedessen lediglich vorbereitende Maßnahmen für einen eventuellen Vollzug der Hilfe angeordnet. Pfalzgraf Friedrich erhielt am 1. Juli 1529 seinen Bestallungsbrief als Oberster Feldhauptmann der eilenden Hilfe ${ }^{162}$. Mit den Hauptleuten über die Reisigen - Pfalzgraf Heinrich, Landgraf Georg zu Leuchtenberg und Freiherr Gangolf zu Hohengeroldseds wurden die Bestallungsurkunden vereinbart. Den Obersten und die Hauptleute über die Fußknechte sollte Pfalzgraf Friedrich bestellen. Den Hauptleuten wurde befohlen, ihre Leute schleunigst bereitzumachen und mit ihnen am 10. August 1529 an bestimmten Orten zur Musterung einzutreffen. Insgesamt sollten 1600 Reisige und 7000 Fußknechte aufgebracht werden. Im übrigen beschloß die Reichsdeputation, am 22. Juli 1529 erneut in Regensburg zusammenzutreten, um auf Grund der dann vorliegenden Kundschaften zu entscheiden, ob die Musterung stattfinden oder unterbleiben und ob im Falle der Absage der Musterung die bestellten Reisigen bis zum 24. August 1529 zu etwaiger Verwendung bereitgehalten werden sollten ${ }^{103}$.

Auf dem neuen Deputationstag Ende Juli 1529 wurde die Entscheidung über den Vollzug der Hilfe jedoch wiederum aufgeschoben. Da die vorliegenden Kundschaften ergaben, daß mit dem Anzug der Türken zu rechnen war, nannte man den Hauptleuten die Orte und Termine der Musterung, und zwar sollten die Reisigen am 23. und 28. August und am 1. September in Donauwörth, Neumarkt und Regensburg und die Fußknechte am 6. September in Höchstädt und Neumarkt gemustert werden. Die festgesetzten Musterungstermine lagen zwei bis vier Wochen später als der ursprünglich vorgesehene Termin. Die Deputationsmitglieder wollten am 18. August 1529, also vor Beginn der Musterungen, noch einmal in Regensburg zusammenkommen und in der Zwischenzeit über das Vorhaben der Türken durch zwei Kundschafter Ermittlungen anstellen. Durch die beiden Abgesandten sollte vor allem geklärt werden, ob sich der Sultan selbst bei dem anrückenden türkischen Heer befand, ob dieses die gemeldete Stärke hatte und ob ein Kriegszug gegen Ungarn und die anstoßenden deutschen Länder bevorstand. Als Kundschafter wurden der Regimentsrat Ritter Sebastian Schilling und der Stadtgraf von Braunau in Bayern, Konrad Pösnitzer, verwandt ${ }^{164}$.

Der Widerstand gegen den Vollzug der eilenden Türkenhilfe auf den beiden Deputationstagen im Juni und Juli 1529 ging von Bayern und Kursachsen aus. Herzog Ludwig von Bayern nahm an beiden Deputationstagen persönlich teil. Kurfürst Johann von Sachsen war durch Gesandte vertreten. Beide Fürsten wollten aus unterschiedlichen Gründen die Leistung der Reichshilfe nur zulassen, wenn Gewißheit bestand, daß der türkische Sultan mit großer Heeresmacht die im Speyerer Reichsabschied 1529 genannten Länder angriff. Der Bayernherzog sträubte sich gegen einen verfrühten Vollzug der Hilfe mit Rüdksicht auf Zápolya.

101 RTA VIII-2, S. 845, 848.

162 RTA VIII-2, S. $836-838$ 
Aufschlußreich hierfür ist ein Schreiben des bayerischen Sekretärs Johann Weißenfelder an Hieronymus Lasky vom 7. Juli 1529, in dem die Zurückweisung der Wünsche Ferdinands auf dem damals gerade beendeten ersten Regensburger Deputationstag und die Bemühungen um eine Beschränkung der militärischen Aúfgabe der Reichshilfe allein auf die Türkenabwehr rüdkhaltlos dargelegt wurden ${ }^{165}$. Das retardierende Verhalten der kursächsischen Vertreter in Regensburg ging auf Weisungen des Kurfürsten Johann zurüdk, der von Landgraf Philipp von Hessen ermahnt worden war, den Vollzug der Hilfe erst bei einem großen türkischen Angriff zu bewilligen, damit nicht etwa das Türkenhilfsgeld gegen die Protestierenden verwendet würde ${ }^{160}$. Auch in Regensburg scheinen derartige Besorgnisse geäußert worden zu sein. Denn die Reichsdeputation beschloß auf ihrer Tagung Ende Juli 1529 zur Beschwidhtigung der protestierenden Partei, neben Jakob v. Wernau als Obersten Hauptmann über die Fußknechte noch den kursächsischen Amtmann Kunz Gotzmann als Kriegsrat und Führer von 2000 Knechten zu bestellen ${ }^{107}$.

Als die Reichsdeputation ihre dritte Tagung am 18. August 1529 begann, konnte die aufkommende Kriegsgefahr nicht mehr in Zweifel gezogen werden. Nach dem Bericht Schillings und Pösnitzers, die bei der ungarischen Regierung in Ofen gewesen waren ${ }^{108}$, und nach neuen Kundschaften König Ferdinands hatte der Sultan mit einem gewaltigen Heer und viel Geschütz die Save bei Griechisch-Weißenburg überschritten und die Drau erreicht. Er sollte die Absicht haben, vor Wien zu überwintern. Unter diesen Umständen beschloß die Deputation am 20. August 1529 endlich die Ausführung der bewilligten Türkenhilfe. Gleichzeitig wurde bestimmt, daß sich Pfalzgraf Friedrich als Oberster Feldhauptmann und die Kriegsräte und Hauptleute der Reichshilfe durch Eid verpflichten sollten, das Kriegsvolk allein zur Gegenwehr gegen die Türken zu gebrauchen und es unter keinen Umständen an einem anderen Ort oder gegen irgendjemand anders zu verwenden ${ }^{168}$. Das Mißtrauen gegen die Absichten Ferdinands, das in dem Thronstreit mit Zápolya und in der Separation der Evangelischen in Speyer seinen Grund hatte, beherrschte also die Uberlegungen der Reichsdeputation auch noch in dem Moment, als über das Vorgehen der Türken Gewißheit erlangt worden war. Dabei erwarteten die Mitglieder der Deputation keineswegs, daß die Türken mit den Truppen Ferdinands und des Reiches zurückgetrieben werden konnten. Sie baten vielmehr das Reichsregiment, die 18 Fürsten zu beschreiben, damit diese weitere Vorsorge treffen konnten ${ }^{170}$.

Die eilende Reichshilfe, deren Vollzug am 20. August 1529 befohlen worden war, wurde nur für drei Monate bereitgestellt ${ }^{171}$. Sie kam zu spät, um noch zum Schutze Ungarns Verwendung finden zu können. Die Fußknechte, die auf der Donau herangeführt wurden, trafen jedoch am 21. und 25. September 1529, kurz

$10 s$ Daß Herzog Ludwig von Bayern und die kursächsische Botschaft den Vollzug der Hilfe auf dem zweiten Regensburger Deputationstag verhindert haben, ergibt sich aus dem Brief eines Unbekannten, von dem der Schweinfurter Stadtschreiber Haug am 18. 8. 1529 eine Kopie an den Amtmann zu Mainberg v. d. Kere sandte (RTA VIII-2, S. 860). - Nach den Mitteilungen Weißenfelders an Lasky v. 7.7. 1529 (RTA VIII-2, S. 847-849) ging der Widerstand gegen den Vollzug der Hilfe auf dem ersten Deputationstag von 1 oder 2 Deputationsmitgliedern aus. Weißenfelder nennt diese beiden Deputationsmitglieder nicht, ohne Zweifel meinte er aber Bayern und Kursachsen.

108 RTA VIII-2, S. 842 f.

167 RTA VIII-2, S. 860, 858, $861 \mathrm{f}$.

160 RTA VIII-2, S. 868-871.

160 RTA VIII-2, S. 871-873. 
vor Beginn der Belagerung, in Wien ein und übernahmen dort die Verteidigung des in der Anmarschrichtung der Türken gelegenen Abschnittes im Osten der Stadt. Gleidhzeitig mit den Fußknechten gelangten 100 Reisige der Reichshilfe nach Wien. Die übrigen Reisigen bezogen bei Krems Stellung, wo sich auch Pfalzgraf Friedrich befand. Jakob v. Wernau und Kunz Gotzmann kamen nicht mehr nach Wien herein und blieben in Krems. Den Befehl über die Reichstruppen in Wien übernahm Pfalzgraf Philipp, der Neffe des Pfalzgrafen Friedrich. Außer den Reichstruppen standen in Wien noch 12000 Fußknechte und Reisige, die König Ferdinand aufgebracht hatte. Die Reichstruppen bildeten also einen beträchtlichen Teil der Besatzung. Nach dem Urteil der niederösterreichischen Regierung wäre die Besatzung, die vor dem Eintreffen der Reichstruppen vorhanden war, zur Abwehr der Türken nicht ausreichend gewesen. Die Belagerung Wiens dauerte vom 26. September bis 14 . Oktober 1529. Proviantmangel und kalte Witterung veranlaßten die Türken, den ergebnislosen Kampf abzubrechen und den Rückzug anzutreten ${ }^{172}$.

Während der Belagerung blieben die Verteidiger weitgehend sich selbst überlassen. König Ferdinand war allerdings unablässig tätig, um den Entsatz der Stadt vorzubereiten. Er brachte in seinen eigenen Reichen und Ländern Hilfstruppen auf ${ }^{173}$ und wandte sich sogleich nach Eintreffen der Türken vor Wien unmittelbar an die einzelnen Reichsstände und Reichsstädte mit Hilfegesuchen ${ }^{174}$. Schon zu Beginn des Jahres 1529 und dann wieder während des Vorrückens der Türken im Sommer 1529 hatte er wiederholt ohne größeren Erfolg einzelne Reichsstände und Reichsstädte um eine Truppen- oder Geldhilfe beziehungsweise um die Lieferung von Pulver und Büchsenmeistern zur Türkenabwehr gebeten ${ }^{175}$. Seine Hilfegesuche vom 23. und 26. September $1529{ }^{176}$ bewogen dagegen die meisten Empfänger zu sofortiger und beträchtlicher Hilfeleistung. Mehrere führende evangelische Stände und Städte, allen voran Kursachsen, sahen in der Notlage Wiens eine willkommene Gelegenheit, die Gefahren des Glaubenszwiespaltes durch die Solidarität mit den altgläubigen Ständen bei der Türkenabwehr zu mildern und sowohl den Kaiser wie König Ferdinand günstig zu stimmen ${ }^{177}$. Kursachsen, das für die Romzugshilfe 60 Reisige und 277 Fußknechte beziehungsweise 10368 Gulden aufzubringen hatte ${ }^{178}$, stellte zum Entsatz von Wien 1000 Reisige und 1500 Fußknechte bereit, deren Unterhalt in sechs Monaten 125000 Gulden erfordert hätte. Eine gleiche Streitmacht wie Kursachsen wollten Kurbrandenburg und das Herzogtum Sachsen entsenden ${ }^{179}$. Gewiß war nicht überall die Hilfswilligkeit so groß. Einzelne Stände wie Hessen ${ }^{180}$ waren zu keiner Hilfe bereit. Immerhin wurden aber zur Rettung Wiens sehr viel mehr Reichstruppen aufgebracht als im Rahmen der Türkenhilfe, die aus der Romzugshilfe gewonnen worden war. Nach der Schätzung Kunz Gotzmanns befanden sich beim Abbruch der Belagerung Wiens

17ః F. Stöller: Soliman vor Wien (= Mitteilungen des Vereins für Geschichte der Stadt Wien, Bd IX/X, 1929-1930, S. 11-76 (zit. Stöller) (beste Darstellung der Belagerung Wiens unter Verwertung unveröffentlichter Akten mit Angaben über die Verwendung der Reichshilfe). Schreiben der niederösterr. Regierung an Ferdinand wegen der bevorstehenden Belagerung Wiens v. 20. 9. 1529: F. B. v. Bucholtz: Geschichte der Regierung Ferdinand I., Bd III, S. 619622 (zit. Bucholtz).

173 Vgl. ebd., Bd IV, S. 571-573 sowie die Hinweise in RTA VIII-2, S. 990 f.

174 RTA VIII-2, S. 898-907.

175 RTA VII-1, S. 478-481; RTA VIII-2, S. 885-897.

176 RTA VIII-2, S. 898-904.

177 Steglich, S. $176 \mathrm{f}$.

178 RTA II, S. 427.

178 RTA VIII-2, S. 919-952.

180 RTA VIII-2, S. $935 \mathrm{f}$. 
aus Böhmen, Mähren, Bayern und von anderen Fürsten und Städten des Reichs über 100000 Mann im Anmarsch ${ }^{181}$. Ferdinand ließ nach dem Abzug der Türken von Wien die aus dem Reich sowie aus Böhmen und Mähren anrüdzenden oder eingetroffenen Truppen heimkehren und schrieb den Reichsständen und Reichsstädten die Türkenhilfe ab. Er bedauerte, daß die Türken die Belagerung Wiens abgebrochen hatten, bevor die im Anzug befindlichen Hilfstruppen seiner Königreiche und Erblande und der Reichsstände eingetroffen waren, da nach seiner Meinung mit ihnen den Türken eine Schlacht hätte geliefert werden können, durch welche die Christenheit und die deutsche Nation von der Türkengefahr befreit worden wären ${ }^{182}$. Eine Verfolgung der Türken ist wohl vor allem deshalb unterblieben, weil bei dem Kriegsvolk in Wien und besonders bei den Reichstruppen nach der Aufhebung der Belagerung eine Meuterei ausbrach. Die Reidhskriegsknechte forderten drei zusätzliche Monatssolde als Sturmsolde und den Nachlaß der während der Belagerungszeit aufgelaufenen Proviantkosten, die sie nach damaligem Brauch selbst zu tragen hatten. Pfalzgraf Friedrich beauftragte Wernau und Gotzmann, mit den Knechten zu verhandeln. Beide wurden von diesen einen Tag lang im Ring mit gesenkten Spießen festgehalten. Um eine Plünderung Wiens zu vermeiden, hat man die Forderungen der Kriegsknechte schließlich bewilligt. Zum Glück traf damals der Reichspfennigmeister mit neuen Türkenhilfsgeldern in Krems ein, so daß die erforderlichen Beträge nicht durch Anleihen aufgebracht werden mußten. Man war froh, als man das Reichskriegsvolk nach viel Mühe und Arbeit endlich aus dem Land gebracht hatte. $\mathrm{Da}$ die Reichstruppen nur für drei Monate angenommen worden waren, hätten sie an einer längeren Verfolgung allerdings selbst dann nicht teilnehmen können, wenn keine Meuterei ausgebrochen wäre ${ }^{183}$. Unwahrscheinlich ist, daß der defensive Auftrag der Reichshilfe einer Verfolgung hinderlich gewesen wäre ${ }^{184}$. Denn die Reichshilfe war ja in Speyer auch zum Schutze Ungarns bewilligt worden, die Wiedereroberung Ungarns im Zuge der Verfolgung der Türken hätte daher eigentlich zulässig sein müssen. Kunz Gotzmann, der durch Eid verpflichtet war, die bestimmungsgemäße Verwendung der Reichstruppen zu überwachen, übte in seinen Briefen keine Kritik an solchen weitgespannten Zielen, beklagte ganz im Gegenteil die Verhinderung der Verfolgung durch die Meuterei und durch die zeitlich begrenzte Besoldung und meinte, es würde mein ewiger spot sein«, daß man »nit nachgeeylt«, denn nach Ausweis aller Kundschaften whet man dem Turken in der flucht ser wol abprechen mugen ${ }^{185}$.

Die Reichstürkenhilfe vom Speyerer 18-Fürstentag 1529 bis zum Schmalkaldischen Krieg 1546/47

Die auf dem Wormser Reichstag 1521 bewilligte Romzugshilfe wurde im Türkenkrieg 1529 so weit verbraucht, daß mit ihr nicht mehr eine weitere Reichshilfe finanziert werden konnte ${ }^{180}$. Neue Beschlüsse der Reichsstände waren erforderlich,

181 RTA VIII-2, S. 990/Z. 29-32.

182 RTA VIII-2, S. $988,990 \mathrm{f}$.

183 RTA VIII-2, S. 991. Die Ankunft des Pfennigmeisters erwähnt Kunz Gotzmann in seinem Schreiben an Christoph Kreß v. 30. 10. 1529 (Staatsarchiv Nürnberg, Ansbacher Kriegsakten 6, fol. $261 \mathrm{r}-263 \mathrm{v})$.

184 Dies behauptet Stöller, S. 66.

185 RTA VIII-2, S. 991.

186 Einiges Geld war noch zur Zeit des Augsburger Reidstages 1530 da und sollte zum Ersatz der Kosten verwendet werden, die bei der Gesandtschaft Pfalzgraf Friedrichs zum Kaiser nach Italien im März 1530 (vgl. RTA VIII-2, S. 1048-1054) entstanden waren (vgl. Tetleben, S. 86). 
um die Türkenabwehr für die Zukunft zu regeln. Die erste Reichsversammlung, die sich mit dieser Angelegenheit beschäftigte, war der 18-Fürstentag, den das Reichsregiment auf Vorschlag des dritten Regensburger Deputationstages auf Martini 1529 nach Speyer einberufen hatte ${ }^{187}$. Ursprünglich sollte dieser 18-Fürstentag dazu dienen, weitere Truppen zur Türkenabwehr im Herbst 1529 verfügbar zu machen, da die vom Reichstag im April bewilligteHilfe in Anbetracht des groBen türkischen Aufgebotes nicht ausreichend erschien. Der Abzug der Türken von Wien machte das überflüssig. Der Speyerer Tag, an dem keiner der 18 Fürsten persönlich teilnahm, beschäftigte sich infolgedessen mit Vorsorgemaßnahmen gegen einen neuen Einbruch der Türken im Frühjahr 1530. Die Gesandten König Ferdinands und das Reichsregiment befürworteten die Bewilligung einer beharrlichen Hilfe gemäß der Eßlinger Notel von 1526. Die anwesenden Fürstenvertreter hielten sich hierfür nicht für zuständig und beschlossen statt dessen, den Kaiser um die baldige Einberufung und den persönlichen Besuch eines neuen Reichstages zu bitten, der über die beharrliche Türkenhilfe entscheiden sollte. Für die Zeit bis zu dem künftigen Reichstag und bis zur Durchführung der beharrlichen Hilfe wurde den Grenzfürsten der Auftrag gegeben, sich in guter Rüstung zu halten, Kundschaften einzuziehen und bei einem türkischen Uberfall die anderen Stände um Hilfe zu ersuchen, die dann in möglichst großer Stärke zuziehen sollten ${ }^{188}$. Die Regelung untershied sich von der entsprechenden Bestimmung des Eßlinger Abschiedes ${ }^{18 \theta}$ dadurch, daß die Grenzfürsten im Falle der Gefahr jetzt nicht mehr auf die gegenseitige Hilfe angewiesen blieben, sondern alle Stände des Reichs zum Zuzug auffordern konnten. Welches Ausmaß ein solcher allgemeiner Zuzug annehmen konnte, hatte sich soeben während der Belagerung Wiens gezeigt, als Ferdinand unter Nichtachtung der noch immer gültigen und auf dem Speyerer Reichstag 1529 erneuerten Eßlinger Bestimmung ${ }^{190}$ Hilfegesuche an alle Reichsstände und Reichsstädte richtete. Wahrscheinlich wurde der Speyerer 18-Fürstentag durch das Fehlen anderer Hilfsmöglichkeiten veranlaßt, den Grenzfürsten die Erlaubnis zu geben, in künftigen Krisensituationen ebenso zu verfahren wie Ferdinand im September und Oktober 1529.

Unter den 18 Fürsten gab es zwei Protestationsverwandte, nämlich Kurfürst Johann von Sachsen und Markgraf Georg von Brandenburg-Ansbach. Die Gesandten dieser beiden Fürsten verlangten in Speyer auftragsgemäß als Voraussetzung für eine wirkungsvolle Türkenhilfe die Aufrichtung eines allgemeinen Friedens unter den Reichsständen und die Sicherstellung der Evangelischen vor einem Uberfall wegen ihres Glaubens ${ }^{101}$. Den Anstoß zu diesem Schritt gab das Scheitern der Appellationsgesandtschaft der Protestierenden zum Kaiser im Sommer und Herbst 1529 und die zeitweilige Arretierung der Gesandten in Piacenza ${ }^{192}$. Zieht man in Betracht, daß seit 1521 das Vorhandensein von Frieden und Recht im Reich als Voraussetzung für die Leistung der Romzugshilfe und der aus ihr abgeleiteten eilenden Türkenhilfe galt und daß 1524 und 1529 ein allgemeiner Frieden im Reich und 1526/27 die Wiederherstellung von Frieden und Einigkeit im Reich zur Voraussetzung für die beharrliche Türkenhilfe gemacht worden waren, so könnte es scheinen, als ob die Forderung Kursachsens und Bran-

187 RTA VIII-2, S. 882.

189 RTA VIII-2, S. 1020-1025, 1027-1035.

189 Vgl. S. 29.

100 Vgl. RTA VII-2, S. 1302/Z. 11-13.

191 Vgl. die kursächsische und die brandenburgische Instruktion: RTA VIII-2, S. 1000-1002 u. S. $1009 \mathrm{f}$.

102 Vgl. Steglich, S. 173-177. 
denburg-Ansbachs auf dem 18-Fürstentag im Herbst 1529 nichts wesentlich Neues beinhaltet habe. Und doch war dies der Fall; denn die Ankündigung einer nur bedingten Erfüllung der Kriegsdienst- und Steuerpflichten richtete sich jetzt gegen den Mehrheitsbeschluß auf dem letzten Speyerer Reichstag und sollte dazu dienen, die Tolerierung des durch Reichsgesetz verworfenen Standpunktes der Protestierenden zu erzwingen. Der Friedenszustand, den man als notwendige Voraussetzung für die Leistung der Türkenhilfe bezeichnete, sollte nicht Ausdruck der Einigkeit in den reichsrechtlichen und religiösen Fragen sein, sondern vielmehr den Verzicht auf die Herstellung einer solchen Einigkeit und die Duldung divergierender Auffassungen manifestieren.

Auf Grund der kursächsischen und brandenburgischen Anträge ersuchten das Reichsregiment und die Botschafter der 18 Fürsten den Kaiser, wegen der Besorgnisse vor Unfrieden und Überzug im Zusammenhang mit dem Glaubenszwiespalt allen Reichsständen für die Dauer einer Türkenhilfe gewaltsame Handlungen gegeneinander zu untersagen, damit die Hilfe um so bereitwilliger geleistet würde ${ }^{199}$. Obgleich das von der Speyerer Versammlung erbetene kaiserliche Friedensgebot nur zeitweilig, während der Aktionen zur Türkenabwehr, gelten sollte und daher den kursächsischen und brandenburgischen Wünschen keineswegs voll entsprach, kann doch in der damals anerkannten Wechselbeziehung zwischen Türkenhilfe und zeitweiliger Sicherstellung der Evangelischen vor gewaltsamen Maßnahmen wegen des Glaubens der Beginn jener Politik der Friedstände gesehen werden, welche für den Vollzug aller Türkenhilfen vom Augsburger Reichstag 1530 bis zur Katastrophe des Protestantismus im Schmalkaldischen Krieg 1547 charakteristisch gewesen ist.

Die Antwort, die der Kaiser auf die Anträge der Speyerer Versammlung erteilte, ist verlorengegangen ${ }^{104}$. Seine Stellungnahme zu den aufgeworfenen Fragen kann aber auch aus den Dokumenten erschlossen werden, mit denen er den Augsburger Reichstag 1530 einberief und eröffnete. Das Ausschreiben dieses Reichstages wurde am 21. Januar 1530 in Bologna ausgefertigt ${ }^{195}$, wo Karl V. fünf Wochen später die kaiserliche Krone aus den Händen Clemens' VII. empfing. Sowohl das Ausschreiben wie die kaiserliche Reichstagsproposition vom 20 . Juni $1530^{196}$ behandelten die beharrliche Türkenhilfe als ersten und wichtigsten Beratungsgegenstand. Der Kaiser stimmte also mit der Speyerer Versammlung der Fürstenbotschafter darin überein, daß der neue Reichstag ein Türkenreichstag werden sollte. Die allgemeine Lage schien damals die Aufstellung einer beharrlichen Türkenhilfe zu begünstigen. Denn der Kaiser hatte 1529 den Krieg in West- und Südeuropa beenden können ${ }^{197}$. Die immer wieder von den Reichsständen geforderte Beteiligung anderer christlicher Herrscher an der beharrlichen Türkenhilfe wurde daher jetzt für erreichbar gehalten ${ }^{198}$. Uber das Friedensgebot, das der Speyerer 18-Fürstentag befürwortet hatte, äußerte sich der Kaiser nicht. Im Reichstagsausschreiben kündigte Karl V. jedoch an, daß er in Augsburg den Glaubenszwiespalt durch einen gütlichen Vergleich der Meinungen überwinden wolle, das heißt, sein Ziel war die Wiederherstellung von Frieden und Einigkeit im Reich und nicht die Duldung der Separation der Evangelischen.

103 RTA VIII-2, S. 1041

104 RTA VIII-2, S. 1047.

105 Drudk: K. E. Förstemann: Urkundenbuch zu der Geschidhte des Reidhstages zu Augsburg im Jahre 1530, Bd 1, Halle 1833 (Neuaufl. Hildesheim 1966), Nr. 1, S. 1-9.

106 Drudk: ebd., Nr. 102, S. 295-309.

197 Friedensschlüsse zu Barcelona am 29. 6. 1529 u. zu Cambrai am 3. 8. 1529.

190 Vgl. zu diesen Erwartungen einen Passus im Abschied des Speyerer 18-Fürstentages v. 25.11. 1529: RTA VIII-2, S. 1032/Z. 6-11. 
Zu Beginn der Augsburger Reichstagsverhandlungen änderte sich die Rangfolge der Verhandlungsgegenstände. Die Glaubensfrage rüdkte sofort in den Vordergrund, und im Reichsabschied vom 19 . November $1530^{100}$ wurde der altgläubige Standpunkt noch unversöhnlicher als auf dem Speyerer Protestationsreichstag zur Geltung gebracht. Der Augsburger Reichsabschied enthielt zwar ein kaiserliches Gebot zur Wahrung des Landfriedens, aber die Bedrohung der Evangelischen mit Kammergerichtsprozessen wegen der Einziehung der Kirchengüter und der Verletzung der Jurisdiktion der Bischöfe verlagerte die Auseinandersetzung mit ihnen auf ein Aktionsfeld, auf dem ihnen der Schutz des Landfriedens versagt werden konnte. Die Evangelischen nahmen den neuen Reichsabschied wieder nicht an und schlossen sich im Schmalkaldischen Bund zusammen. Der fortdauernde Konflikt in der Glaubensfrage gefährdete natürlich die Ausführung der Reichstagsbeschlüsse über die Türkenhilfe.

Die altgläubige Mehrheit bewilligte in Augsburg eine beharrliche und eine eilende Türkenhilfe. Die beharrliche Hilfe sollte drei Jahre lang dem Kaiser geleistet werden und die Stärke der Romzugshilfe, das heißt 4000 Reisige und 20000 Fußknechte ${ }^{200}$, erhalten. Das Unternehmen wurde im Reichsabschied nur kurz behandelt. Der Kaiser verpflichtete sich, die Reichsstände über seinen eigenen Beitrag zur beharrlichen Türkenhilfe im voraus zu unterrichten und den Papst, Italien, Frankreich, Ungarn, England, Böhmen, Portugal, Polen, Dänemark und Schottland zur Mitwirkung an dem Vorhaben aufzufordern. Erst wenn von den anderen christlichen Mächten die Hilfszusagen vorlagen, sollte ein neuer Reichstag über den Vollzug der beharrlichen Hilfe beschließen. Auf dem Reichstag in Speyer 1542 ist das dann auch tatsächlich geschehen. Damals wurde die Aufbringung und Finanzierung der Reichstruppen für die beharrliche Hilfe bis in alle Einzelheiten geregelt, während der Reichsabschied von 1530 hierzu keinerlei Angaben machte.

Die in Augsburg bewilligte eilende Reichstürkenhilfe sollte in der Zeit bis zur Vornahme der beharrlichen Hilfe zur Abwehr eines ngewaltigen Heerzuges* der Türken gegen Ungarn, Mähren, Schlesien, Osterreich und andere Länder des Reides Verwendung finden. Bei den Beratungen waren die Fürsten dafür eingetreten, die eilende Hilfe erst bei einem türkischen Angriff gegen deutsches Gebiet leisten zu lassen, während sich die Kurfürsten dafür einsetzten, den Türken bereits auf fremdem Boden entgegenzutreten ${ }^{201}$. Der Reichsabschied folgte dem Vorschlag der Kurfürsten, indem er den Vollzug der eilenden Hilfe bereits bei einer türkischen Offensive gegen die vor der Südostgrenze des Reiches liegenden Länder vorschrieb. Die Größe der eilenden Hilfe wurde auf 40000 Fußknechte und 8000 Reisige festgesetzt. Sie sollte sechs Monate und im Bedarfsfalle acht Monate geleistet werden. Wie die Zahlen zeigen, ging die Augsburger Reichsversammlung sowohl bei der beharrlichen Hilfe wie bei der eilenden Hilfe von dem Grundmaß der Romzugshilfe aus. Die bewilligte beharrliche Hilfe hatte die Größe der Romzugshilfe, ihre dreijährige Dauer erforderte jedoch den sechsfachen Aufwand der Romzugshilfe. Die eilende Hilfe war doppelt so groß wie die Romzugshilfe. Das Festhalten am Grundmaß der Romzugshilfe sollte natürlich ermöglichen, die Reichshilfen auch weiterhin nach den Anschlägen der Wormser Matrikel aufzubringen. Eine Änderung trat allerdings insofern ein, als seit 1530 der Monatssold für einen Reisigen auf 12 Gulden statt bisher 10 Gulden festgesetzt wurde.

109 Drudk: NS 2, S. 306-332.

200 Die Zahlen über die Stärke der in Augsburg bewilligten beharrlichen und eilenden Hilfe sind in dem Drudk des Reichsabschiedes (vgl. Anm. 199) ausgelassen und werden hier nach dem Original des Reichsabschiedes (HHS $t \mathrm{~A} / \mathrm{Wi}$, Urkundenreihe, 1530/November/19) angegeben. 
Der Augsburger Reichsabschied stellte es den Kurfürsten, Fürsten und Ständen frei, die Mittel für den Unterhalt der bewilligten eilenden Hilfe durch Besteuerung ihrer Untertanen aufzubringen. Ein derartiges Zugeständnis war in den Reichsabschieden seit 1521 nicht gemacht worden, weil man damals eine allgemeine Besteuerung der Untertanen für die beharrliche Hilfe plante und dieses Vorhaben durch eine Inanspruchnahme der Untertanen für die Finanzierung der eilenden Hilfe nicht beeinträchtigen lassen wollte.

Die Deputation zum Vollzug der eilenden Türkenhilfe, die auf dem Eßlinger 18-Fürstentag 1526 eingesetzt worden war, blieb auch 1530 erhalten. Doch trat an die Stelle des Bischofs Christoph von Augsburg jetzt der evangelische Markgraf Georg von Brandenburg. Die Befugnisse der Deputation wurden stark eingeschränkt. Sie sollte zusammentreten, um eine vom Obersten Feldhauptmann vorgeschlagene Verlängerung der eilenden Hilfe von sechs auf acht Monate durch Mehrheitsbeschluß zu billigen oder zu verwerfen. Den Vollzug der Hilfe konnte der Oberste Feldhauptmann mit den ihm zugeordneten sechs Kriegsräten bereits anordnen, sobald ihm von den Mitgliedern der Deputation drei gleichlautende und zuverlässige Kundschaften zugekommen waren, aus denen sich ergab, daß die Türken mit einem "gewaltigen « Heer gegen Ungarn, Mähren, Schlesien, Österreich oder andere Länder des Reiches angezogen seien. Diese Bestimmung sollte offenbar verhindern helfen, daß die Reichsdeputation wieder wie 1529 den Vollzug der eilenden Hilfe übermäßig lange hinauszögerte.

Der Augsburger Reichsabschied schrieb vor, daß die eilende Hilfe nicht in Geld, sondern mit Leuten zu leisten sei. Diese Bestimmung sollte einer Zweckentfremdung der Türkenhilfe vorbeugen. Ihr Nachteil war die Verlangsamung der Truppenbereitstellung. Denn es waren mindestens drei Wochen erforderlich, um die Kontingente aus Nordwestdeutschland an die Ostgrenze des Reiches zu führen. Die Kontingente der Reichsstände sollten nicht einzeln zum Versammlungsort der Reichshilfe marschieren, sondern zunächst innerhalb der zehn Reichskreise zu Kreiskontingenten zusammengefaßt werden. Durch dieses neuartige Verfahren wurde die aus dem Jahre 1512 stammende Kreiseinteilung des Reiches im Sinne der Eßlinger Notel von 1526 zur Grundlage für die Gliederung und Aufbringung des Reichskriegsheeres. Die Kreisstände mußten einen Kreishauptmann wählen, dem die Anforderung der Einzelkontingente, ihre Musterung am Kreismusterplatz und die Führung des Kreiskontingentes im Krieg oblag.

Die Vereidigung der Kreistruppen und Kreishauptleute sollte auf den Obersten Feldhauptmann erfolgen. Dieser aber mußte sich zusammen mit den Kriegsräten, die ihm die Augsburger Reichsversammlung zuordnete, durch Eid verpflichten, die Hilfe nur gegen die Türken und ihre Anhänger und Helfer und erst bei einem "gewaltigen " Heerzug gegen die im Reichsabschied genannten Länder zu gebrauchen. Die Bestimmung, daß die Verwendung der Reichshilfe auch gegen die Anhänger und Helfer der Türken zulässig sei, war in den Reichsabschieden vor 1530 nicht enthalten gewesen und sollte offenbar den Einsatz des Reichskriegsvolkes gegen Zápolya ermöglichen, falls dieser die Türken unterstützte. Abweichend von der früheren Regelung wurde in Augsburg die Befugnis, andere Reichsstände bei Gefahr zur Hilfeleistung aufzufordern, allein dem Obersten Feldhauptmann zuerkannt. Er sollte von dieser Befugnis Gebrauch machen, wenn die Türken über Polen gegen die anstoßenden Reichsgebiete oder wenn sie gegen Ungarn und Kroatien vorrüdkten. Die Aufforderung zum Zuzug durfte jedoch nur an die Grenzfürsten gerichtet werden, das heißt, die Aufbringung einer allgemeinen Türkenhilfe blieb den Reichsversammlungen vorbehalten. Ein Ausschuß der Reichsstände wählte in Augsburg wieder Pfalzgraf Friedrich zum Obersten Feldhaupt- 
mann. Unter den sechs Kriegsräten, die ihm beigegeben wurden, gab es zwei Evangelische, nämlich Ritter Siegmund v. Heßberg und Kunz Gotzmann.

Ebenso wie bei den früheren Türkenhilfen sollte der voraussichtliche Empfänger der neuen eilenden Türkenhilfe zu deren Ausrüstung einen eigenen Beitrag leisten. König Ferdinand verpflichtete sich in Augsburg, den Obersten Feldhauptmann und die Kriegsräte der eilenden Türkenhilfe zu besolden, 100 Geschütze mit Büchsenmeistern und Schanzknechten bereitzustellen und eine Flottille auf der Donau zu unterhalten ${ }^{202}$. Die Zusagen Ferdinands wurden nicht in den Augsburger Abschied aufgenommen. Auf dem Regensburger Reichstag 1532 wurden sie erneut erörtert, weil umstritten war, ob Ferdinand auch für die Unterhaltung des Personals des Obersten Feldhauptmanns aufkommen müsse ${ }^{203}$.

Die Einbeziehung Ungarns in den Kreis der Länder, deren Überzug die Reichsverteidigungsmaßnahmen auslösen sollte, war keineswegs erfolgt, weil die Reichsstände ihre Einstellung zu dem ungarischen Thronstreit geändert hatten. Kaiser Karl war der Ansicht, daß Ferdinands Expansion in Ungarn die Türkengefahr heraufbeschworen oder zumindest verschlimmert habe. Ebenso wie die Reichsstände verlangte er daher von seinem Bruder im Interesse der Christenheit die Anbahnung eines Friedens oder Waffenstillstandes mit Zápolya. Allerdings mutete er ihm nicht zu, hierbei sein Recht auf Ungarn aufzugeben. Im Gegensatz zu Karl war Ferdinand der Meinung, daß seine Nachfolge im Königreich Ungarn für die Christenheit nicht nachteilig sei, weil nur so verhindert werden könne, daß das Land ein türkisches Einfallstor gegen die Christenheit würde. $\mathrm{Da}$ er aber mit seinen geringen militärischen Mitteln nur die nordwestlichen Gebiete Ungarns zurückzuerobern vermochte, bemühte er sich seit Anfang 1530 dann doch auf verschiedenen Wegen, mit Zápolya und mit den Türken Waffenstillstand oder Frieden zu schließen. Ein Friedensschluß erwies sich jedoch als unmöglich. Der türkische Sultan betrachtete Ungarn nach seinen zwei Eroberungszügen in den Jahren 1526 und 1529 als sein Eigentum, auf das er nicht mehr verzichten wollte und das er seinem Diener Zápolya lediglich zur Verwaltung überlassen hatte. Ferdinands Angebot, durch jährliche Geldzahlungen für die in seiner Hand befindlichen Gebiete Nordwestungarns die Pforte zum Friedensschluß zu bewegen, wurde zurüdkgewiesen. Eine direkte Verständigung mit Zápolya ohne Rücksicht auf die Ansichten des Sultans erschien unzwedkmäßig. Infolgedessen konnte lediglich am 21. Januar 1531 ein dreimonatiger Waffenstillstand mit Zápolya auf der Basis des status quo abgeschlossen werden, der dann mit Genehmigung des Sultans um ein Jahr verlängert wurde. Als 1532 dieser Waffenstillstand ablief, unternahm Suleiman seinen vierten großen Kriegszug gegen die südöstlichen Gebiete des Abendlandes ${ }^{204}$.

Während das türkische Heer von Konstantinopel bis Griechisch-Weißenburg vorrüdste, verhandelte Karl V. vom 17. April bis 27. Juli 1532 auf dem Reichstag in Regensburg über den Vollzug der in Augsburg bewilligten eilenden Türkenhilfe. Es gelang ihm nicht, eine Steigerung der Hilfe um ein Fünftel und ihre Leistung in Geld durch die entfernter gelegenen Reichsstände durchzusetzen. Vor allem aber stieß er auf den hartnädkigen Widerstand der altgläubigen Mehrheit, als er

202 Bucholtz, Bd IV, S. 566. Nach Bucholtz (ebd.) soll sich Ferdinand noch verpflichtet haben, „das auf das Haus Osterreich fallende Contingent zu stellen ${ }^{*}$. Nach den Akten des Regensburger Reichstages 1532 wurde jedoch Ferdinand auf dem Augsburger Reichstag 1530 wegen seiner Leistungen für die Artillerie, Schiffahrt u. a. die Aufbringung der Kontingente Böhmens, Osterreichs und Württembergs erlassen (s. Westermann, S. 201).

203 Vgl. Westermann, S. 111 f. u. 229-231.

$204 \mathrm{Vgl}$. Turetschek, S. 130-260. 
die Türkenhilfe der augsburgischen Konfessionsverwandten, die ein Viertel der Reichshilfe ausmachte, durch Zugeständnisse in der Glaubensfrage ermöglichen wollte ${ }^{205}$. Bereits am 4. April 1531 hatten die protestierenden Stände und Städte dem Kaiser in einem Schreiben aus Schmalkalden mitgeteilt, daß sie zur Leistung der Türkenhilfe vor Einstellung der Religionsprozesse am Kammergericht nicht imstande seien, weil sie keine großen Geldmittel für die Entsendung von Truppen gegen die Türken aufbringen könnten, während sie mit Reichsacht und Reichsexekution bedroht würden ${ }^{206}$. Ferdinand, der im Januar 1531 zum römischen König gewählt und gekrönt worden war und seither in Abwesenheit seines Bruders die Reichsregierung ausübte, setzte sich bei Karl V. wegen der Türkengefahr dringend für einen Kompromiß ein ${ }^{207}$. Vermittlungsversuche, die seit Sommer 1531 unternommen wurden, blieben zunächst erfolglos. Erst die Verhandlungen, die zur Zeit des Regensburger Reichstages in Schweinfurt und Nürnberg stattfanden, führten zu einer Verständigung. Der am 23. Juli 1532 abgeschlossene Nürnberger Religionsfriede wurde jedoch nicht von den altgläubigen Ständen anerkannt, sondern durch ein kaiserliches Mandat für sie verbindlich gemadht. In diesem Mandat gebot Karl V. allen Ständen des Reiches, bis zum künftigen Konzil oder bis zum nächsten Reichstag einander wegen des Glaubens, der Religion oder anderer Sachen nicht zu bekriegen. In einem Geheimdokument gab er den Evangelischen außerdem die Zusicherung, daß alle Kammergerichtsprozesse in Sachen des Glaubens bis zum Konzil eingestellt würden ${ }^{208}$. $\mathrm{Da}$ der Nürnberger Religionsfrieden künftige Anhänger der neuen Lehre nicht sicherstellte und zeitlich befristet war, konnte er nur vorübergehend beruhigend wirken. Schon nach wenigen Jahren verlangten die Evangelischen seine Erweiterung und den Wegfall der Befristung ${ }^{200}$.

Auf dem Regensburger Reichstag wurde beschlossen, die eilende Reichstïrkenhilfe, die gemäß den Bestimmungen des Augsburger Abschiedes in Kreiskontingenten anrücken sollte, bis zum 15 . August 1532 bei Wien zu versammeln ${ }^{210}$. Wegen der Mängel der Wormser Matrikel und wegen des Wegfalls der Kontingente aus den habsburgischen Ländern Böhmen, Osterreich und Württemberg erreichte sie nur eine Stärke von 6000 Reisigen und 30000 Fußknechten ${ }^{211}$. Das Reichskriegsvolk sollte nicht für sich allein operieren, sondern mit umfangreichen Streitkräften Karls und Ferdinands vereinigt werden. Karl V. stellte 5000 Reisige und 25000 deutsche, spanische und italienische Fußknechte zur Verfügung. Ferdinand konnte aus Böhmen, Mähren und Schlesien 5000 Reisige und 30000 Fußknechte und aus den österreichischen Erblanden 3000 Reisige und 12000 Fußknechte aufbringen. Alle diese Truppen, insgesamt etwa 24000 Reisige und 97000 Fußknechte,

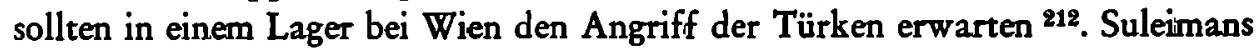

20s Westermann, S. 180, 185, 187-197, 199-200, 210 f. (Steigerung der Hilfe), S. 207, 214, 217, 234 (Leistung der Hilfe in Geld), S. 106 (Anteil der Protestierenden an der Hilfe), S. 117 ff. (Einstellung der altgläubigen Reichstagsmehrheit zu Konzessionen an die Protestierenden in der Glaubensfrage).

206 Bucholtz, Bd IX (Urkundenband), S. 19 f.

207 Fischer-Galati, pp. 47-48.

200 A. Engelhardt: Der Nürnberger Religionsfriede von 1532 (= Mitteilungen des Vereins für Geschichte der Stadt Nürnberg, Bd 31, 1933, S. 17-123). Politische Correspondenz der Stadt Straßburg im Zeitalter der Reformation, Bd 2: 1531-1539, bearb. v. O. Windkelmann, Straßburg 1887 , S. $166-169$.

209 Fischer-Galati, Pp. 62-69.

210 Westermann, S. 108-110.

211 Ebd., S. 93 u. 201 f. Vgl. auch Anm. 202.

212 Oberblid über das Kriegsvolk des Kaisers, König Ferdinands und der deutschen Reichsstände v. 16. 8. 1532: Turetschek, S. 364-366. Zum Lager bei Wien vgl. ebd., S. 315. 
neuer Feldzug richtete sich gegen Karl V. und das Reich. Das türkische Heer führte wenig Belagerungsgeschütz mit sich, der Sultan wollte offenbar Karl, dessen Kaisertum er als eine Beeinträchtigung seines eigenen Kaisertums und seines Weltherrschaftsanspruches empfand, in einer Feldschlacht engegentreten. Das türkische Heer rückte nicht wie 1529 entlang der Donau gegen Wien vor, sondern zog durch Westungarn und näherte sich von Süden der Hauptstadt der österreichischen Erblande. Im August belagerte es drei Wochen vergeblich die kleine Stadt Güns, die nur von 700 Leuten verteidigt wurde. Die fortgeschrittene Jahreszeit, Lebensmittelmangel und die starke Position des christlichen Heeres im Lager bei Wien scheinen Suleiman bewogen zu haben, von Güns über Graz den Rüdkmarsch anzutreten ${ }^{213}$. Das Reichskriegsvolk gelangte lediglich einmal zum Kampfeinsatz, als es am 19. September 1532 bei Leobersdorf südöstlich von Wien eine türkische Streifschar von 8500 Rennern und Brennern vernichtete, die mordend, sengend und plündernd nach Niederösterreich eingedrungen war ${ }^{214}$. Im übrigen blieb es ebenso wie die Truppen Karls und Ferdinands im Lager bei Wien. Als dort Anfang Oktober die Pest ausbrach, wurde die große Menschenansammlung aufgelöst, ohne daß ein Versuch zur Rückeroberung Ungarns unternommen worden wäre ${ }^{215}$.

Der Fehlschlag seines Kriegszuges im Jahre 1532 und neue Verwidklungen mit Persien veranlaßten den Sultan im Jahre 1533, mit Ferdinand einen wewigen Frieden « auf der Basis des status quo abzuschließen. Bereits 1536 begannen freilich die türkischen Einfälle in die Grenzgebiete von neuem, 1538/39 erwartete Ferdinand zeitweise eine neue große Offensive der Türken, akut wurde jedoch die Türkengefahr erst wieder durch die Emeuerung des Thronstreits in Ungarn im Jahre $1540^{216}$. Zápolya suchte 1538 Anlehnung an die Habsburger, da er das Vertrauen des Sultans verloren hatte. In dem Vertrag von Großwardein vom 24. Februar 1538 schlossen Karl und Ferdinand mit ihm Frieden. Sie billigten Zápolya den Titel eines Königs von Ungarn zu und versprachen ihm Hilfe bei der Rüdkgewinnung der ungarischen Grenzorte einschließlich Griechisch-Weißenburgs. Zápolya verzichtete auf das Bündnis mit den Türken und gab die Zusicherung, daß der von ihm beherrschte Teil Ungarns nach seinem Tod an Ferdinand fallen sollte. Der Großwardeiner Vertrag blieb dem Sultan nicht verborgen. Er beendete keineswegs die Rivalität zwischen den beiden ungarischen Königen und erwies sich vor allem als unwirksam, als Zápolya überraschend am 22. Juli 1540 im Alter von 53 Jahren an den Folgen eines Schlaganfalls starb. Kurz vor seinem Tod riet Zápolya seinen Anhängern, den Großwardeiner Vertrag nicht zu erfüllen und die Königswürde auf seinen damals erst wenige Tage alten Sohn Johann Sigismund zu übertragen. Ein Reichstag in Stuhlweißenburg rief das Kind im September 1540 zum König aus und übertrug die Regentschaft der Königinwitwe Isabella, einer Tochter des Königs Sigismund von Polen, und ihren Räten. Johann Sigismund wurde von Suleiman als König von Ungarn anerkannt. Ferdinand aber, der bereits geglaubt hatte, daß der 14jährige Thronstreit jetzt endlidh zu seinen Gunsten entschieden sei, nahm den Kampf um die Nachfolge Zápolyas auf und ließ Ende 1540 und erneut im Frühjahr 1541 ein Heer gegen Ofen vorgehen, wo sich die Königin mit ihrem Sohn aufhielt. Isabella neigte einem Ausgleich 
mit Ferdinand zu. Ihr wichtigster Ratgeber, der Mönch Martinuzzi, bestand jedoch auf der Verteidigung der Festung ${ }^{217}$.

Während der Belagerung Ofens tagte in Regensburg nach 9jähriger Pause wieder ein Reichstag, an dem auch Karl V. persönlich teilnahm. Ferdinand rief die Reichsstände zur Hilfe auf und erklärte dabei, es gelte, Deutschland in Ungarn zu retten ${ }^{218}$. Sein Appell hatte geringen Erfolg. Die Reichsstände bewilligten nur eine kleine eilende Hilfe zur Rettung Ungarns und der österreichischen Erblande in der Stärke eines halben Romzugs für drei oder vier Monate. Die Hilfe sollte in Geld geleistet und die davon unterhaltenen Truppen zur Verwendung gegen die Türken nach Ungarn geführt werden. Ferdinand verpflichtete sich, das Reichskriegsvolk mit Geschütz auszustatten und das gesamte Führungspersonal zu besolden. Seine Zusagen fanden Aufnahme in den Reichsabschied vom 29. Juli 1541, der damit in dem Abschnitt über die Türkenhilfe den Charakter eines Kooperationsvertrages erhielt ${ }^{210}$.

Im Zusammenhang mit der neuen Türkenhilfe wurde der Nürnberger Religionsfrieden auf alle Reichsstände und Reichsstädte ausgedehnt, die sich inzwischen den augsburgischen Konfessionsverwandten angeschlossen hatten. Die Erweiterung des Nürnberger Friedstandes war von Ferdinand bereits 1539 in dem sogenannten Frankfurter Anstand unter dem Eindruck der damaligen türkischen Rüstungen vereinbart worden. Erst in Regensburg wurde die Erweiterung auch vom Kaiser und von den altgläubigen Ständen genehmigt. In einer besonderen Deklaration räumte der Kaiser sogar allen Ständen die Möglichkeit ein, zu den augsburgischen Konfessionsverwandten überzutreten. Der neue Friedstand wurde auf 18 Monate befristet. In dieser Zeit sollte das Generalkonzil, das Nationalkonzil oder ein Reichstag zur Beilegung des Glaubenszwiespaltes zusammentreten ${ }^{220}$.

Die kleine Reichshilfe, die in Regensburg bewilligt worden war, kam für die Kämpfe des Jahres 1541 zu spät ${ }^{221}$. Am 21. August 1541 mußte die Belagerung Ofens abgebrochen werden, weil der Sultan mit einem großen Heer anrüdkte. Beim Abzug erlitt das Belagerungsheer durch einen Ausfall der Ofener Besatzung eine vernichtende Niederlage. Wenige Tage später traf Suleiman in Ofen ein. Entgegen den Erwartungen der Ungarn machte er das Land um Ofen bis zur Theiß zu einer türkischen Provinz und überließ Johann Sigismund lediglich die Gebiete östlich der Theiß und Siebenbürgen unter türkischer Oberhoheit. Er versprach zwar, das Ofener Gebiet Johann Sigismund zurüdkzugeben, sobald er mündig würde. Tatsächlich ist aber das Land 145 Jahre unter türkischer Herrschaft geblieben. Die Umwandlung der Ofener Hauptkirche in eine Moschee durch den Sultan am 2. September 1541 deutete auf diese Entwicklung bereits hin 222 .

Mit der Festsetzung der Türken in Ofen ergab sich für alle, die seit 1526 davon ausgegangen waren, daß Ungarn unter der Herrschaft Zápolyas ein christliches Land bleiben würde und daß Ferdinands Versuche zur Eroberung Ungarns in keinem Zusammenhang mit der Abwehr der Türkengefahr stünden, eine völlig neue Lage. Ferdinands Anspruch auf Ungarn schien nunmehr die letzte Möglichkeit zu bieten, das Land aus der Hand der türkischen Aggressoren zu befreien.

217 Fessler, S. 472 ff.; 488-513.

218 Bucholtz, Bd V, S. 150.

210 Drudk des Reidhsabschiedes v. 29. 7.1541: NS 2, S. 428-444.

220 Fischer-Galati, pp. 69-83. Frankfurter Anstand v. 19. 4. 1539: J. Ch. Lünig: Des Teutschen Reichs-Archivs Partis generalis Continuatio, Leipzig 1713, Nr.138, S.635-639. Regelung des Friedstandes im Reichsabschied 1541: NS 2, S. 434 f., $\$ \$ 26-30$ sowie $\$ 22$. - Deklaration Karls V. v. 29. 7.1541 : Lünig, a. a. O., Nr. 143, S. 662 f.

221 Bucholtz, Bd V, S. 151.

222 Fessler, S. 513-517. 
Viele Ungarn richteten Hilfegesuche an Ferdinand. Sogar Isabella und ihre Ratgeber waren jetzt bereit, den Großwardeiner Vertrag zu erfüllen und Ferdinand ganz Ungarn zu überlassen, sofern er wirklich das Königreich zu gewinnen und gegen die Türken zu behaupten vermochte ${ }^{223}$.

Um den Stimmungswandel auszunutzen, versuchte Ferdinand, ein großes Heer für den Türkenkrieg aufzubringen. Er schrieb zu diesem Zwedk am 16. Oktober 1541 einen Reichstag nach Speyer aus ${ }^{224}$, der vom 9. Februar bis 11. April 1542 tagte und den Vollzug der in Augsburg 1530 bewilligten beharrlichen Türkenhilfe beschloß. Die seit 20 Jahren erörterte beharrliche Hilfe wurde bereitgestellt, obgleich der Kaiser, der im Juli 1542 in einen neuen Krieg mit Franz I. geriet, dazu keinen eigenen Beitrag leistete und obgleich die Beteiligung anderer christlicher Herrscher nicht im voraus gesichert werden konnte. Der Speyerer Reichsabschied vom 11. April $1542{ }^{225}$ sah zwar vor, die Herrscher Italiens, Frankreichs, Englands, Polens und Schottlands um ihre Mitwirkung an dem Unternehmen zu bitten. Aber in sicherer Aussicht stand nur die Teilnahme der Länder Ferdinands. Die Stände Böhmens, Ungarns und der österreichischen Erblande hatten bereits vor dem Speyerer Reichstag die Einziehung einer Vermögenssteuer gebilligt. Ferdinand hoffte, von dem Steueraufkommen der österreichischen Erblande 10000 leichte Reiter, die Donauflottille, 100 Geschütze und 4000 Schanzknechte unterhalten zu können.

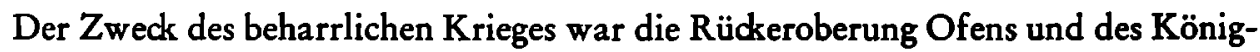
reiches Ungarn. Darüber hinaus sollte versucht werden, die christliche Bevölkerung in den an Ungarn grenzenden türkischen Ländern zum Abfall zu bringen. Nach wie vor galt der Grundsatz, daß die Reichshilfe nur gegen die Türken und ihre Anhänger und Helfer Verwendung finden dürfe. Die Stärke der beharrlichen Hilfe war an sich durch den Augsburger Reichsabschied festgelegt. In Speyer wurde jedoch beschlossen, im ersten Jahr sogleich die Hilfe des zweiten Jahres mit zum Einsatz zu bringen und wenn nötig im zweiten Jahr die Hilfe des dritten Jahres in Anspruch zu nehmen. Hierdurch wurde es möglich, die beharrliche Hilfe, die eigentlich nur die Stärke der Romzugshilfe haben sollte, im Jahre $1542 \mathrm{zu}$ verdoppeln. Offenbar als Ausgleich für den Wegfall der Anschläge des Osterreichischen Kreises, auf die wegen der sonstigen Leistungen Ferdinands verzichtet werden mußte, wurde die beharrliche Hilfe außerdem noch um ein Viertel gesteigert. Das Kriegsvolk sollte von den Ständen und Städten angenommen und nach Wien geschidkt werden. Versammlungstermin für die Truppen aus Franken, Bayern und Schwaben war der 1. Mai, für die übrigen Truppen der 15. Mai 1542.

Die Reichsstände und Reichsstädte waren verpflichtet, ihre Kontingente bis zum 13. Juli 1542 selbst zu besolden. Anschließend mußten die Reichskreise die Besoldung übernehmen. Die Mittel hierzu sollten sie durch die Erhebung des Gemeinen Pfennigs erhalten, das heißt durch eine Steuer, die das Vermögen beziehungsweise das Einkommen aller Klassen mit Ausnahme der Juden gleichmäßig belastete. Anders als bei der Eßlinger Notel wurde demnach jetzt das werbende Gut ebenso hoch besteuert wie das übrige Gut und zwischen den Geistlichen und Nichtgeistlichen bei der Besteuerung kein Unterschied mehr gemacht. Allerdings erhöhte man gleichzeitig mit dem Verzicht auf die abgestufte Besteuerung die Vermögenssteuer von $0,1 \%$ auf $0,5 \%$ und die Einkommensteuer von $2 \%$ auf $10 \%$. Alle

228 Ebd., S. 518 f.

224 Politische Correspondenz der Stadt Straßburg im Zeitalter der Reformation, Bd 3: 15401545, bearb. v. O. Windkelmann, Straßburg 1898, Nr. 208, S. 215 f.

226 Druds: NS 2, S. 444-470. 
Steuerpflichtigen durften sich selbst veranlagen. Fürstentümer und Städte sollten, wie das auch die Eßlinger Notel vorgesehen hatte, den Gemeinen Pfennig einziehen und an die Kreiseinnehmer bis zum 13. Juli 1542 abführen. Wegen der Besorgnisse der Stadtbürger vor einer Offenlegung ihrer Vermögen wurde allen zugestanden, das Geld ungezählt in die Einnahmetruhen der Territorien, Städte und Kreise einzuwerfen. Die Gelder, welche die Stände und Städte für die Aufbringung und Unterhaltung ihres Kriegsvolkes bis zum 13. Juli 1542 benötigten, sollten ihnen aus den Erträgen des Gemeinen Pfennigs ersetzt werden. Außerdem wurde zum 13. Juli 1542 ein neuer Reichstag nach Nürnberg ausgeschrieben, um dort einen Geldausgleich unter den Kreisen und den Ständen vorzunehmen. Zur Besoldung des Obersten Feldhauptmanns und seiner Befehlshaber mußten die Reichsstände und Reichsstädte eine weitere Anlage bezahlen, die für jeden aufzubringenden Fußknecht 1/2 Gulden und für jeden aufzubringenden Reisigen 11/2 Gulden betrug. Die Kosten dieser Anlage sollten ebenfalls von den Kreisen zurückerstattet werden. Die Bereitstellung und Unterhaltung des Belagerungsgeschützes übernahm Ferdinand, das Feldgeschütz sollten die Stände liefern und unterhalten. Der Fehler bei der Neuregelung der Geldaufbringung lag darin, daß keine Übergangszeit für die Umstellung der Besoldung von den Kassen der Stände und Städte auf die Kassen der Kreise nach dem 13. Juli 1542 festgesetzt wurde. $\mathrm{Da}$ sich in mehreren Kreisen der Eingang der Steuergelder verzögerte ${ }^{226}$, entstand bei einem Teil des Feldheeres nach dem Umstellungstermin Soldmangel, der sidh lähmend auf das ganze Kriegsunternehmen auswirkte.

Der Speyerer Reichsabschied vom 11. April 1542 enthielt wieder Zugeständnisse an die augsburgischen Konfessionsverwandten. Und zwar wurde der 1541 in Regensburg neu vereinbarte Friedstand um fünf Jahre verlängert und den Evangelischen die Wahrnehmung von Kammergerichtsämtern gestattet.

Zum Obersten Feldhauptmann für die beharrliche Hilfe des Reiches bestimmte Ferdinand den Kurfürsten Joachim II. von Brandenburg, der sein Amt im Zusammenwirken mit zehn Kriegsräten der Reichskreise versah. Am 6. Juni 1542 übernahm der Kurfürst in Wien den Oberbefehl. Es zeigte sich sofort, daß ein Teil der eingetroffenen Truppen nur noch für begrenzte Zeit über Besoldungsgelder verfügte. Um das Heer in Bewegung zu setzen, mußte Ferdinand bei Augsburger Kaufleuten Geld für die Soldzahlungen leihen. Dank dieser Maßnahme konnte am 10. Juli 1542 endlich der Aufbruch erfolgen. Die Heeresstärke war geringer, als sie nach dem Reichsabschied hätte sein müssen. Die Zahl der Reisigen betrug 6000 statt 8300, die der Fußknechte 27000 statt 45000 . Es fehlte an Geschütz und Munition. 13000 leichte Reiter aus Osterreich, Böhmen und Mähren und 3000 päpstliche Fußknechte stießen während des Vormarsches zu dem Heer. Auf der Donau stand eine Flottille von fast 200 Schiffen zur Verfügung. Krankheiten sowie Geld- und Lebensmittelmangel machten bald die Truppen unzufrieden. Der Vormarsch ging deshalb nur stockend vor sich. Es dauerte zweieinhalb Monate, bis das Heer Ende September 1542 Pest erreichte. Nach mehrtägiger Belagerung der Stadt und nach einem mißglüdkten Sturmversuch wurde bereits am 7. Oktober 1542 wegen des Beginns der kalten Jahreszeit der Feldzug abgebrochen und der Rüdkmarsch angetreten. Hierbei löste sich das Heer in Unordnung auf ${ }^{227}$.

226 Zu den Ergebnissen der Einbringung des Gemeinen Pfennigs durch die Kreise s. Neukirch, S. $172-179$.

227 Traut, S. 32-43, 56-61, 71-87, 95-120. 
Auf dem Nürnberger Reichstag, der vom 24. Juli bis 26. August 1542 abgehalten wurde, war dieser Ausgang des Feldzuges noch nicht vorauszusehen. Die Reichsstände beschlossen, die Einbringung des Gemeinen Pfennigs für das dritte Jahr der beharrlichen Hilfe und vereinbarten verschiedene Maßnahmen, um die Mängel bei der Steuereinziehung abzustellen. Der in Aussicht genommene Geldausgleich unter den Reichsständen konnte nicht vorgenommen werden, da die in Speyer beschlossene Anlage des Gemeinen Pfennigs noch nicht in allen Kreisen eingebracht worden war ${ }^{228}$.

Der Fehlschlag der Offensivexpedition im Jahre 1542 machte offenkundig, daß die Türken von Ferdinand trotz des Aufgebots einer großen Reichshilfe nicht aus Ungarn verdrängt werden konnten, er verminderte die Aussichten für eine Verständigung mit Isabella, und er bedeutete auch einen Wendepunkt in derGeschichte der Reichstürkenhilfe, weil während der Regierungszeit Karls V. kein weiteres Reichsheer zur Verwendung im Türkenkrieg aufgestellt wurde. Im Jahre 1543 kam Suleiman zum sechsten Mal mit einem großen Kriegsheer nach Ungarn und eroberte Gran und Stuhlweißenburg ${ }^{229}$. Auf dem Nürnberger Reichstag, der von Januar bis April 1543 stattfand, bewilligten die Reichsstände eine Türkenhilfe in der Größe der Romzugshilfe für sechs Monate. Aber sie sollte in Geld erlegt und von König Ferdinand verwendet werden, um die Befestigungen an der Donau und in Ungarn mit Kriegsvolk zu besetzen und zu sichern ${ }^{230}$. Man beschränkte sich also auf eine Geldhilfe für defensive Aufgaben, ohne Einfluß auf die Durchführung der Sicherungsmaßnahmen auszuüben. Obgleich damals eine neue Offensivexpedition noch nicht ausgeschlossen wurde, hat der Türkenkrieg auch in der Folgezeit seinen defensiven Charakter behalten, bis Ferdinand 1547 mit dem Sultan einen fünfjährigen Waffenstillstand abschloß ${ }^{231}$. Kurz zuvor fand die Politik der Friedstände, die auf den Reichstagen vom Sommer 1542 bis 1545 durch neue Zusicherungen bekräftigt worden war ${ }^{232}$, in der Niederwerfung des Schmalkaldischen Bundes ihr gewaltsames Ende.

Auf den Reichstagen von 1544 bis 1551 wurden erneut Türkenhilfen bewilligt, und zwar in Speyer 1544 die nochmalige Einziehung des Gemeinen Pfennigs als Vermögenssteuer von $0,5 \%{ }^{29 s}$ und in Augsburg 1548 ein jährliches Baugeld von 100000 Gulden zur Errichtung von Festungen gegen die Türken während der Dauer des fünfjährigen Waffenstillstandes ${ }^{294}$. Die Erträge des Gemeinen Pfennigs von 1544 sollten nicht an die Kreise abgeführt, sondern von den Ständen für eine künftige Offensive gegen die Türken aufbewahrt werden. $\mathrm{Da}$ das Reich das Geld nicht in Anspruch nahm, wurde es von den Ständen für andere Zwecke verbraucht. Der Reichstag in Augsburg 1548 beschloß infolgedessen die nochmalige Erhebung der Steuer ${ }^{235}$. 1551 wollte Ferdinand das Geld bei seiner damaligen

${ }_{228}$ Drudk des Nürnberger Reichsabschiedes v. 26. 8. 1542 : NS 2, S. 470-481.

220 Fessler, S. 525-527; Hammer-Purgstall, S. 248-261.

290 $\iint_{1-31}$ des Nürnberger Reichsabschiedes v. 23. 4. 1543: NS 2, S. 482-489.

291 Hammer-Purgstall, S. 270-277.

202 Zusicherungen im Nürnberger Reichsabschied v. 26. 8. 1542 (NS 2, S. 478, \$ 39), im Nürnberger Reichsabschied v. 23. 4. 1543 (ebd., S. 489-491, \$S 32-37), im Speyerer Reichsabschied $\nabla$. 10. 6. 1544 (ebd., S. 509-513, $\$ \$ 76-98$ ) u. in Wormser Reichsabschied v. 4. 8. 1545 (ebd., S. $519, \$ 11)$.

293 $\iint 26-69$ des Speyerer Reichsabschiedes v. 10. 6. 1544: NS 2, S. 500-508. Auf dem Speyerer Reichstag 1544 bewilligten die Reichsstände eine Türkenhilfe in der Größe einer Romzugshilfe zur Verwendung gegen den König von Frankreich, da dieser mit dem Sultan verbündet war (ebd., S. 496-498, \$5 3-11).

294 IS 96-101 des Augsburger Reichsabschiedes v. 30. 6. 1548: NS 2, S. 544 f. - Die Zahlen bezüglich der Höhe des Baugeldes sind in der Wiedergabe des Reichsabschiedes ausgelassen, können aber dem Aufsatz von Müller, S. 661, entnommen werden.

295 \$ $\$ 103$ des Augsburger Reichsabschiedes v. 30.6.1548: NS 2, S. 545 f. 
Aktion zur Rückgewinnung Siebenbürgens verwenden ${ }^{236}$. Die Ansammlung von Geldvorräten und die Finanzierung des Festungsbaus waren Vorsorgemaßnahmen für künftige kriegerische Verwicklungen. Zu einer aktiven Beteiligung des Reiches am Türkenkrieg wie in der Zeit von 1522 bis 1542 ist es in jenen späteren Jahren nicht mehr gekommen.

Zusammenfassend kann über die Reichstürkenhilfe in der Zeit Karls V. gesagt werden, daß sie keineswegs ein feste Einrichtung war, sondern ständigen Änderungen unterlag, die hauptsächlich wegen der wechselnden politischen Verhältnisse erforderlich schienen. Wer daher die Beschaffenheit der Reichstürkenhilfe beschreiben will, kann nicht typisieren oder systematisieren, sondern er muß die Reichstürkenhilfe in ihrer Entwidklung schildern. Natürlich gab es einige häufig oder ständig wiederkehrende Eigenschaften, die übrigens zum Teil auch bei anderen Hilfen der damaligen Zeit festzustellen sind. Hierzu gehört die Bewilligung der allgemeinen Reichshilfen allein durch die Reichstage, die Finanzierung der Hilfen durch Matrikularbeiträge der Reichsstände und Reichsstädte oder durch eine allgemeine Steuer, der Unterschied zwischen eilender und beharrlicher Türkenhilfe, der Unterschied zwischen Bewilligung und Vollzug der Hilfen, die Leistung der Hilfen in Leuten oder in Geld, die Ausstattung der Hilfen mit Führungspersonal und Geschütz durch ihren Empfänger, die Gewährung der Hilfen als Zusatz oder zur Kooperation mit anderen Streitkräften. Im übrigen besaß aber jede Hilfe ihre besonderen Eigenschaften, mit denen man den jeweiligen Umständen der Hilfeleistung Rechnung tragen wollte. Immer wieder ging man bei der Bereitstellung der Hilfen neue Wege, und es blieb nicht aus, daß bei diesem ständigen Experimentieren auch Fehlentscheidungen getroffen wurden, die sich - wie etwa das doppelte Finanzierungssystem im Jahre 1542 - verhängnisvoll auf den Kriegsverlauf auswirkten.

Sieht man von dem Zeitabschnitt seit 1543 ab, wo die Reichsstände und Reichsstädte nur noch Gelder für den Türkenkrieg und den Festungsbau bereitstellten, ohne auf die Durchführung der finanzierten Maßnahmen Einfluß zu nehmen, so hat es vier von den Reichsständen und Reichsstädten bewilligte und von ihnen aufgestellte Türkenhilfen gegeben, nämlich die aus der Romzugshilfe gewonnene Türkenhilfe von 1522, die eilende Türkenhilfe von 1530, die beharrliche Türkenhilfe von 1530 und die eilende Türkenhilfe von 1541. Wenn man zur Bestimmung der Größe dieser Hilfen dem späteren Brauch folgt und den „Römermonat « beziehungsweise die monatlichen Unterhaltungskosten der Romzugshilfe des Jahres 1521 als Maßeinheit nimmt, so betrug die Türkenhilfe von 15226 Römermonate, die eilende Türkenhilfe von 153012 Römermonate, die beharrliche Türkenhilfe von 153036 Römermonate und die eilende Türkenhilfe von 1541 11/2 Römermonate. Das sind zusammen 55\%/2 Römermonate. Die Türkenhilfen seit 1543 beliefen sich ohne das Baugeld von 500000 Gulden auf 18 Römermonate. Alle Türkenhilfen der Zeit Karls V. betrugen demnach 731/2 Römermonate ${ }^{237}$. Die bis zum Jahre 1542 bewilligten Hilfen sind nur viermal zum Kampfeinsatz gekommen, nämlich 1522 in Kroatien, 1529 bei der Verteidigung Wiens, 1532 bei der Vernichtung der türkischen Renner und Brenner südöstlich von Wien und 1542

286 SS 101-104 des Augsburger Reichsabschiedes v. 14. 2. 1551 : NS 2, S. 626 f. Bucholtz, Bd VII, S. 252.

${ }^{257}$ Müller, S. 660 f., gibt bei der Errechnung der Römermonate in der Zeit Karls V. unrichtige Zahlen an. 
bei der Belagerung von Pest. Die militärische Wirkung der unter so vielen Mühen bereitgestellten Türkenhilfen war also recht gering. Größeren Nutzen hatte eigentlich nur der Einsatz des Reichskriegsvolkes in dem belagerten Wien 1529. Es muß zwar eingeräumt werden, daß auch die bloße Bereitstellung der Truppen ohne größeren Gefechtseinsatz, wie das 1532 der Fall war, zur Sicherung des Reiches gegen die Türken beigetragen hat. Trotzdem muß aber bezweifelt werden, daß die Türkenhilfe des Reiches oder vielmehr der Anteil der Protestierenden an dieser Türkenhilfe in einem angemessenen Verhältnis zu den dafür geleisteten religionspolitischen Konzessionen stand.

Die militärische Leistungsfähigkeit des Reiches war allerdings nur deshalb so gering, weil die Territorien und Städte niemals bereit waren, sich für die Aufgaben des Reiches zu verausgaben, sondern stets zusätzlich für ihre eigene Sicherheit Vorsorge trafen. Wie groß dieses Mißverhältnis zwischen dem Aufwand für die Reichsbelange und dem Aufwand für die eigenen Interessen war, zeigt besonders der braunschweigische Feldzug im Sommer 1542. Damals konnten Kursachsen, Hessen und einige schmalkaldische Bundesstädte mit 20000 bis 30000 Fußknechten und 4000 Reisigen das Territorium des altgläubigen Herzogs Heinrich von Braunschweig-Wolfenbüttel erobern, obgleich sie für die beharrliche Reichstürkenhilfe ihre Zahlungen geleistet hatten ${ }^{239}$. Die Territorien waren eben viel eher zu militärischer Machtentfaltung in der Lage als das Reich. Denn das Reich hatte keine eigenen Finanzquellen und mußte daher für jede militärische Aktion die Mittel der Territorien und Städte in Anspruch nehmen, was wiederum nur möglich war, wenn über den Kriegszweck Übereinstimmung hergestellt werden konnte. 
